Aus dem Universitätsklinikum Münster

Medizinische Klinik und Poliklinik B

- Direktor: Univ.-Prof. Dr. Dr. W. Domschke -

\title{
Genexpressionsprofile humaner intestinaler mikrovaskulärer Endothelzellen (HIMEC)
}

\author{
INAUGURAL - DISSERTATION \\ zur \\ Erlangung des doctor medicinae dentium \\ der Medizinischen Fakultät \\ der Westfälischen Wilhelms-Universität Münster
}

vorgelegt von

Kebschull, Moritz

aus Münster

2004 
Dekan

1. Berichterstatter

2. Berichterstatter

Tag der mündl. Prüfung 16. Dezember 2004
Univ.-Prof. Dr. H. Jürgens

Priv.-Doz. Dr. T. Kucharzik

Priv.-Doz. Dr. Dr. U. Meyer 


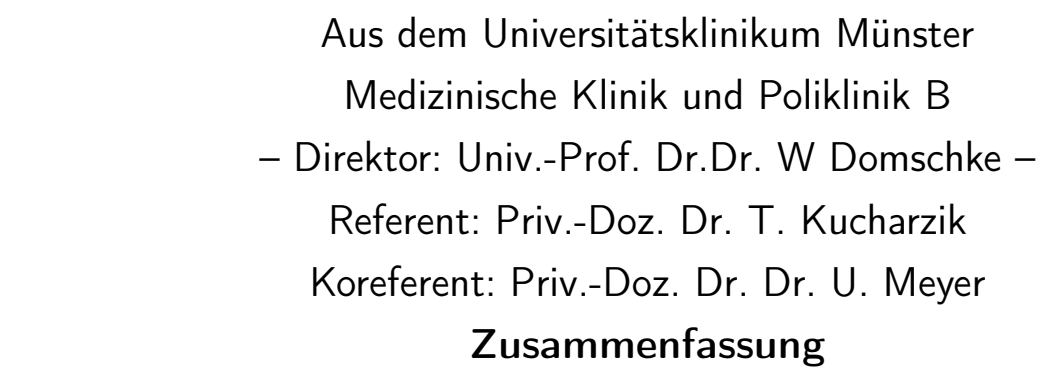

Genexpressionsprofile humaner intestinaler mikrovaskulärer Endothelzellen

Kebschull, Moritz

Bei der Pathogenese chronisch entzündlicher Darmerkrankungen (CED) kommt den Endothelzellen der intestinalen Mikrovaskulatur eine besondere Bedeutung zu. Da Endothelzellen verschiedener Organe und Gefäße sehr heterogen sind, ist ein valides Modell für die Funktion des mikrovaskulären Endothels des Darmes nur durch Isolation und Kultur humaner intestinaler Endothelzellen (HIMEC) untersuchbar. In dieser Arbeit wurde das Genexpressionsprofil von HIMEC sowie seine Modulation durch das proinflammatorische Zytokin Tumor-NekroseFaktor $\alpha($ TNF- $\alpha)$ - einem wesentlichen Zytokin in der Pathogenese der CED - qualitativ und quantitativ charakterisiert.

Aus chirurgischen Darmresektaten isolierte HIMEC-Primärkulturen wurden nach Verifizierung ihrer endothelialen Herkunft für 4 sowie 24 Stunden mit TNF- $\alpha$ stimuliert, als Kontrolle dienten unstimulierte HIMEC. Nach Isolierung der Gesamt-RNA erfolgte die Expressionsanalyse mittels Gene Arrays. Die Bestätigung ausgewählter Ergebnisse erfolgte mittels quantitativer Realtime RT-PCR. Zur Analyse der speziellen Reaktion intestinaler Endothelzellen auf Stimulation mit TNF- $\alpha$ wurden die ermittelten spezifischen Expressionsprofile mit denen der entsprechend stimulierten mikrovaskulären Referenz-Endothelzellinie HMEC-1 verglichen.

Von den nach vier- bzw. 24-stündiger Stimulation hochregulierten bzw. angeschalteten Genen sind nur 93 Gene bei beiden Zellarten gleichermaßen anzutreffen, 148 Gene werden nur in HIMEC, 199 Gene nur in der Referenzzellinie gefunden.

Die meisten der in HIMEC regulierten Gene kodieren für Chemokine/Cytokine, Oberflächenmarker oder Zellproliferationsgene. Es zeigen sich in HIMEC mehrere bisher unbekannte Genexpressionsmuster sowie einige bislang für Endothelzellen bzw. intestinales Gewebe unbeschriebene hochregulierte Gene.

Die in HIMEC durch den proinflammatorischen Mediator TNF- $\alpha$ differenziell regulierten neuen Kandidatengene spielen möglicherweise im Rahmen der mukosalen Entzündung eine bislang unbekannte Rolle.

Tag der mündlichen Prüfung: 16. Dezember 2004 


\section{Inhaltsverzeichnis}

1 Einleitung 1

1.1 Das Endothel . . . . . . . . . . . . . . . . . . . . . . 1

1.2 Endotheliale Strukturheterogenität . . . . . . . . . . . . . 2

1.3 Determination des Phänotyps der Endothelzellen durch ihre Umgebung . . 3

1.4 Endotheliale Heterogenität und Blutgerinnung . . . . . . . . . . . . . 4

1.5 Regulation des Gefäßtonus durch das Endothel . . . . . . . . . . . . . . . . 4

1.6 Embryonale, adulte und alternde Endothelzellen . . . . . . . . . . . . . . 5

1.7 Einfluß des Geschlechts auf endotheliale Funktionen . . . . . . . . . . . . 5

1.8 Die Rolle des Endothels im Rahmen der Entzündung . . . . . . . . . . . . 6

1.9 Rolle des intestinalen mikrovaskulären Endothels bei chronisch entzündlichen Darmerkrankungen . . . . . . . . . . . . . . . . . 7

1.9.1 Mikrovaskuläres Endothel und Gewebsischämie bei chronisch entzündlichen Darmerkrankungen . . . . . . . . . . . . . . . . 7

1.9.2 Vermehrte Leukozytenrekrutierung durch das Endothel bei chronisch entzündlichen Darmerkrankungen . . . . . . . . . . . . . . 9

1.10 Expressionsanalysen von Endothelzellen . . . . . . . . . . . . . . . . 11

1.11 Fragestellung der vorliegenden Arbeit . . . . . . . . . . . . . . . . . . 12

2 Material $\quad 14$

2.1 Chemikalien . . . . . . . . . . . . . . . . . . . . . 14

2.2 Reagenzien für die Zellkultur . . . . . . . . . . . . . . . . . . . . . . . 16

2.2.1 Zellinien . . . . . . . . . . . . . . . . . . . 16

2.2 .2 Seren . . . . . . . . . . . . . . . . . . 16

2.2 .3 Zellkulturmedien . . . . . . . . . . . . . . . 16

2.2.4 Sonstige Reagenzien für die Zellkultur . . . . . . . . . . . . . . . 16

2.3 Enzyme . . . . . . . . . . . . . . . . . . . . . . 17 
2.4 Antikörper . . . . . . . . . . . . . . . . . . 17

2.5 Oligonukleotide . . . . . . . . . . . . . . . . . . 18

2.6 Puffer und Lösungen . . . . . . . . . . . . . . . . . . . . . . . . . 19

3 Methoden 21

3.1 Zellbiologische Methoden . . . . . . . . . . . . . . . . . . 21

3.1.1 Isolation von humanen intestinalen mikrovaskulären Endothelzellen (HIMEC) . . . . . . . . . . . . . . . . . . . 21

3.1.2 Kultivierung der Zellen . . . . . . . . . . . . . . . . . . . . . . . . 24

3.1.3 Stimulation der Zellen . . . . . . . . . . . . . . . . . 24

3.2 Molekularbiologische Methoden . . . . . . . . . . . . . . 25

3.2 .1 Isolierung von Gesamt-RNA . . . . . . . . . . . . . . . 25

3.2.2 Reverse Transkriptase - Polymerase Kettenreaktion (RT-PCR) . . . 26

3.2.3 Quantitative Echtzeit Polymerase Kettenreaktion (Realtime quantitative $R T-P C R)$. . . . . . . . . . . . . . . 30

3.2.4 Expressionsanalyse mittels High-Density Oligonucleotide Arrays . . 31

3.3 Proteinchemische Methoden . . . . . . . . . . . . . . . . 35

3.3.1 Herstellung von Proteinextrakten . . . . . . . . . . . . . . 35

3.3.2 Elektrophoretische Trennung der Proteine durch Natriumdodecylsulfat - Polyacrylamidelektrophorese (SDS-PAGE) . . . . . . . 36

3.4 Immunologische Methoden . . . . . . . . . . . . . . . . . 38

3.4 .1 Immunoblotting . . . . . . . . . . . . . . . . . 38

3.4.2 Indirekte Immunfluoreszenz und durchflusszytometrische Analyse . 41

3.4 .3 Immunhistochemie . . . . . . . . . . . . . . . . . . . . 42

4 Ergebnisse $\quad 47$

4.1 HIMEC sind Endothelzellen . . . . . . . . . . . . . . . . . . 47

4.2 Genexpressionsprofile von HIMEC und der Referenzzellinie HMEC-1 . . . . 49

4.2.1 Oberflächenrezeptoren . . . . . . . . . . . . . . 51

4.2 .2 Zytokine . . . . . . . . . . . . . . . 52

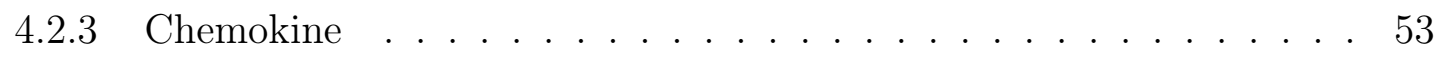

4.2.4 Entzündungsreaktion . . . . . . . . . . . . . . 54

4.2.5 Transkriptionsfaktoren und Signaltransduktion . . . . . . . . . . 55

4.2 .6 Apoptose und Zellproliferation . . . . . . . . . . . . . . . . 56

4.2 .7 Zellmetabolismus . . . . . . . . . . . . . 57 
4.2 .8 Transport und Ionenkanäle . . . . . . . . . . . . . . . . 58

4.2 .9 Modifikatoren der extrazellulären Matrix . . . . . . . . . . . . . . . 59

4.2 .10 Weitere regulierte Gene . . . . . . . . . . . . . . . . 59

4.3 Validierung der Microarray-Ergebnisse durch quantitative Realtime RT-PCR 60

$\begin{array}{lll}5 & \text { Diskussion } & 63\end{array}$

5.1 Validität der Datenbasis . . . . . . . . . . . . . . . . 63

5.2 Literaturanalyse des Genexpressionsprofils von HIMEC . . . . . . . . . . 65

5.2 .1 Oberflächenrezeptoren .................. 66

5.2 .2 Zytokine . . . . . . . . . . . . . . . . 69

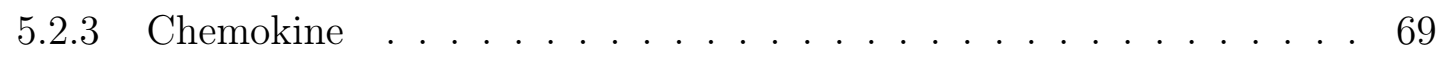

5.2 .4 Entzündungsreaktion . . . . . . . . . . . . . . . . . 70

5.2.5 Transkriptionsfaktoren und Signaltransduktion . . . . . . . . . . 71

5.2.6 Apoptose und Zellproliferation . . . . . . . . . . . . . . . . . . . . . 75

5.2 .7 Zellmetabolismus . . . . . . . . . . . . . 76

5.2 .8 Transport und Ionenkanäle . . . . . . . . . . . . . . . 78

5.2 .9 Modifikatoren der extrazellulären Matrix . . . . . . . . . . . . . . 79

5.2 .10 Weitere regulierte Gene . . . . . . . . . . . . . . . 80

5.3 Fazit und Ausblick . . . . . . . . . . . . . . . . . . . . . . . 81

A Rohdaten der DNA-Microarrayuntersuchung 83

A.1 Hochregulierte bzw. angeschaltete Gene . . . . . . . . . . . . . . . . 83

A.1.1 Nach Stimulation mit TNF- $\alpha$ über vier bzw. 24 Stunden in HIMEC und HMEC-1 hochregulierte Gene . . . . . . . . . . . . . . 83

A.1.2 Nach Stimulation mit TNF- $\alpha$ über vier bzw. 24 Stunden nur in HIMEC hochregulierte Gene . . . . . . . . . . . . . . 85

A.1.3 Nach Stimulation mit TNF- $\alpha$ über vier bzw. 24 Stunden nur in HMEC-1 hochregulierte Gene . . . . . . . . . . . . . . . 88

A.2 Herunterregulierte bzw. ausgeschaltete Gene . . . . . . . . . . . . . . . . 91

A.2.1 Nach Stimulation mit TNF- $\alpha$ über vier bzw. 24 Stunden in HIMEC und HMEC-1 herunterregulierte Gene . . . . . . . . . . . . . . . 91

A.2.2 Nach Stimulation mit TNF- $\alpha$ über vier bzw. 24 Stunden nur in HIMEC herunterregulierte Gene . . . . . . . . . . . . . . . 92

A.2.3 Nach Stimulation mit TNF- $\alpha$ über vier bzw. 24 Stunden nur in HMEC-1 herunterregulierte Gene . . . . . . . . . . . . . . 93 
$\begin{array}{ll}\text { B Lebenslauf } & 95\end{array}$

$\begin{array}{ll}\text { C Danksagung } & 96\end{array}$

$\begin{array}{lr}\text { Literaturverzeichnis } & 97\end{array}$ 


\section{Abbildungsverzeichnis}

3.1 Präparation des Colonresektates zur Isolation von HIMEC . . . . . . . . . 22

3.2 HIMEC - Patch . . . . . . . . . . . . . . . . . . . . . . . . 23

4.1 cobblestone-Morphologie einer HIMEC-Kultur . . . . . . . . . . . . . 47

4.2 HIMEC exprimieren von Willebrand Faktor . . . . . . . . . . . . . . . 48

4.3 VCAM-1 Induktion durch Stimulation mit TNF- $\alpha$ : PCR, Westernblot, FACS 48

4.4 VCAM-1 Induktion durch Stimulation mit TNF- $\alpha$ : Immunfluoreszenz . . . 49

4.5 Ausschluß von Endothelzellen aus high endothelial venules . . . . . . . . . 50

4.6 Venndiagramme der differenziell regulierten Gene . . . . . . . . . . . . . . 50

4.7 Bestätigung der PS-PLA1 Regulation . . . . . . . . . . . . . . . . . . . . . 61

4.8 Bestätigung der EBI3 Regulation . . . . . . . . . . . . . . . . . . 61

4.9 Bestätigung der EBI3 Regulation II . . . . . . . . . . . . . . . . . . 62

4.10 Bestätigung der LST1 Regulation . . . . . . . . . . . . . . . . . 62 


\section{Tabellenverzeichnis}

2.1 Chemikalien und Verbrauchsmaterialien . . . . . . . . . . . . . . 14

2.2 Zellinien . . . . . . . . . . . . . . . . . . . . . . . . 16

2.3 Seren . . . . . . . . . . . . . . . . . . . 16

2.4 Zellkulturmedien . . . . . . . . . . . . . . . . . 16

2.5 sonstige Reagenzien für die Zellkultur . . . . . . . . . . . . . . 16

2.6 Enzyme . . . . . . . . . . . . . . . . . . . . . . 17

2.7 Primärantikörper . . . . . . . . . . . . . . . . . . . 17

2.8 Sekundäre, markierte und enzymgekoppelte Antikörper . . . . . . . . . . . 18

2.9 Oligonukleotide . . . . . . . . . . . . . . . . . . . . . . . 19

2.10 Tris-Puffer $1,5 \mathrm{M} \ldots \ldots \ldots \ldots \ldots$

2.11 Tris-Acetat-EDTA-Puffer . . . . . . . . . . . . . . . . . . . . . . . . . 19

2.12 Phosphate Buffered Saline $(\mathrm{PBS})$. . . . . . . . . . . . . . . 19

$2.134 \%$ ige $(\mathrm{w} / \mathrm{v})$ Paraformaldehydlösung . . . . . . . . . . . . . . . . . . 19

2.14 RNA-Ladepuffer . . . . . . . . . . . . . . . . . . . . . . . . . . . 20

2.15 RIPA-Lysepuffer . . . . . . . . . . . . . . . . . . . . . 20

2.16 DNA-Ladepuffer . . . . . . . . . . . . . . . . . 20

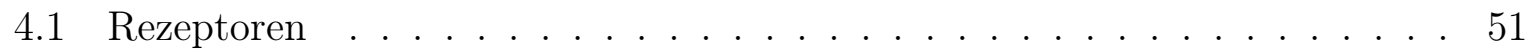

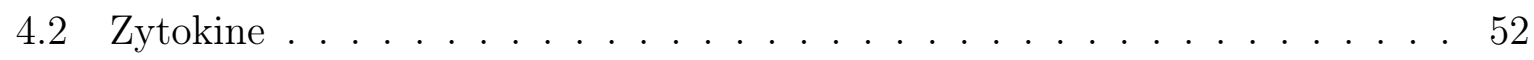

4.3 Chemokine . . . . . . . . . . . . . . . . . . 53

4.4 Entzündungsreaktion . . . . . . . . . . . . . . . . . . . 54

4.5 Transkriptionsfaktoren/Signaltransduktion . . . . . . . . . . . . 55

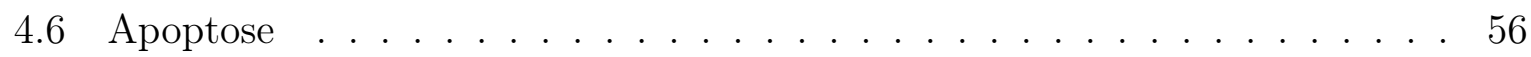

4.7 Zellmetabolismus . . . . . . . . . . . . . . . . . . 57

4.8 Transport und Ionenkanäle . . . . . . . . . . . . . . . . . . . . . . . . 58

4.9 Modifikatoren der EZM . . . . . . . . . . . . . . . . . . . . . . 59 
4.10 Weitere regulierte Gene . . . . . . . . . . . . . . . . . . . 59

4.11 Validierung der Arrayergebnisse . . . . . . . . . . . . . . . 61

A.1 in HIMEC und HMEC-1 hochregulierte Gene . . . . . . . . . . . . . . . . 83

A.2 nur in HIMEC hochregulierte Gene . . . . . . . . . . . . . . . 85

A.3 nur in HMEC-1 hochregulierte Gene . . . . . . . . . . . . . . . . . 88

A.4 in HIMEC und HMEC-1 herunterregulierte Gene . . . . . . . . . . . . . . 91

A.5 nur in HIMEC herunterregulierte Gene . . . . . . . . . . . . . . . 92

A.6 nur in HMEC-1 herunterregulierte Gene . . . . . . . . . . . . . . 93 


\section{Einleitung}

\subsection{Das Endothel}

Das Endothel ist die einschichtige zelluläre innere Auskleidung der Blutgefäße, Lymphgefäße und serösen Höhlen. Es ist die einzige Struktur, die in jedem Abschnitt des kardiovaskulären Systems vorhanden ist [49]. Die Oberfläche dieser Trennschicht zwischen Blut und umgebenden Gewebe besteht bei einem erwachsenen Menschen aus 1-6 x 10 ${ }^{13}$ Endothelzellen und bedeckt eine Fläche von bis zu $350 \mathrm{~m}^{2}$ [129]. Die Masse aller Endothelzellen im menschlichen Körper beträgt etwa $1 \%$ des Körpergewichts [163]. Das Endothel ist nicht nur die anfangs beschreibene passive Membran zwischen Blut und Gewebe [107], sondern zeichnet sich durch eine Vielzahl von biologischen Funktionen wie Transport von Substanzen zwischen Blut und Gewebe, Regulation des Gefäßtonus, Kontrolle der Blutgerinnung, der Gefäß- und Organentwicklung und Extravasation von Leukozyten aus [49]. Manche Autoren bezeichnen das Endothel daher als multifunktionelles Organ [45], welches für die normale Gefäßphysiologie von entscheidender Bedeutung ist [2].

Trotz des gemeinsamen embyronalen Ursprungs der Endothelzellen handelt es sich bei ihnen keineswegs um eine homogene Zellpopulation. Sie zeigen große Unterschiede hinsichtlich Morphologie und biologischer Funktion [49, 136]. Das Endothel lässt sich aufgrund dieser Unterschiede in Gruppen und Untergruppen unterteilen. Sogar innerhalb eines Organs finden sich unterschiedliche Endothelarten (Arterien, Venen, verschiedene Kapillartypen). Diese unterscheiden sich sowohl in anatomisch-morphologischer Hinsicht als auch im Hinblick auf ihre Genexpression [26]. Die verschiedenen Aspekte dieser morphologischen und funktionellen Heterogenität des Endothels sollen im folgenden unter Berücksichtigung der verschiedenen Funktionen dieser Zellpopulation dargestellt werden. 


\subsection{Endotheliale Strukturheterogenität}

Unter morphologischen Gesichtspunkten sind drei Typen von Endothel zu unterscheiden: Das kontinuierliche, das diskontinuierliche und das fenestrierte Endothel. Die beiden letzteren Typen finden sich ausschließlich im Bereich der Kapillaren [49]. Beim kontinuierlichen Endothel finden sich ,dicke“ Endothelzellen (Dicke der Endothelzellen $>2 \mu \mathrm{m}$ ) z.B. in Hoden oder Ovarien, solche mit „dünnem“ Endothel (Dicke $<1 \mu \mathrm{m}$ ) in Haut und Gehirn [136]. In Geweben, in denen eine selektive Permeabilität zur Gewährleistung von Filterung, Sekretion oder Absorption notwendig ist, z.B. Niere oder endokrine Drüsen, finden sich Gefäße mit gefenstertem Endothel [32]. In Leber, Milz, Knochenmark und Darm weisen die Kapillaren ein diskontinuierliches Endothel auf und ermöglichen somit einen Stoffaustausch durch die Interzellularspalten. Der Unterschied zwischen diskontinuierlichem und gefenstertem Endothel besteht in der unterschiedlichen Distanz der Zellen sowie dem Vorhandensein einer Membran über dieser Lücke [136].

Auch innerhalb eines Organs kann man verschiedene Endothelzellarten finden. In den Glomeruli der Niere findet man z.B. diskontinuierliches Endothel, peritubulär fenestriertes Endothel und in allen anderen Regionen dieses Organs kontinuierliches Endothel [137].

Weitere Unterschiede zwischen den Endothelien verschiedener Gefäßarten bestehen in Art und Anordnung von Zell-Zell-Kontaktmolekülen. Arteriolen besitzen zur interzellulären Kommunikation gap junctions, Kapillarendothelzellen nicht. Die Kontaktmolekülmuster von Arteriolen sind strukturierter als die von Arterien, Venen und Venolen [164].

Endothelzellen sind an ihrer inneren Seite von einer etwa $10 \mu \mathrm{m}$ dicken, negativ geladenen Glykosaminoglykanschicht bedeckt [136]. An dieser luminalen Oberfläche finden die meisten Reaktionen der Endothelzellen statt [55]. SimionesCU et al. haben an Pankreasund Leberendothelzellen ein komplexes Netzwerk von Mikrodomänen aus verschiedenen Glykoproteinen und unterschiedlicher negativer Ladung gefunden [165]. AUERBACH et al. konnten mit Hilfe von monoklonalen Antikörpern die Existenz von organspezifischen Antigenen auf der luminalen Gefäßoberfläche nachweisen [7].

RiBATTi et al. unternahmen weitere Versuche zur Aufklärung der Oberflächenstrukturen von Endothelzellen. Sie zeigten, daß isolierte luminale Membranfraktionen von Endothelzellen aus Lunge, Herz und Gehirn ein unterschiedliches Reaktionsmuster mit biotinylierten Lektinen aufweist [136].

Durch ein Bakteriophagen gestütztes in vivo Screening (phage display [147]) der Endothelien eines hirntoten Menschen konnten ARAP et al. eine Kartierung der Oberflächenmolekülmuster verschiedener Endothelzellen erstellen [5]. 
In humanen Lungenpräparaten fand sich in Arterien und Venen eine geringere Expression des Oberflächenmoleküls CD34 (Marker für humane Stammzellen) als in der Mikrovaskulatur [112]. Weiterhin konnten die Autoren einen Anstieg der CD34-Expression in Arterien und Venen im Alter zeigen. Auch in der Expression des Adhäsionsmoleküls VCAM-1 wurden wesentliche Unterschiede zwischen Gefäßen verschiedener Größen und verschiedener Organe gezeigt [153].

\subsection{Determination des Phänotyps der Endothelzellen durch ihre Umgebung}

Werden Endothelzellen isoliert und kultiviert, so verlieren sie nach einer gewissen Zeit ihre spezifischen Charakteristika [20]. Der für das jeweilige Organ oder den Gefäßstyp charakteristische Phänotyp wird in der jeweiligen Umgebung der Endothelzellen durch lösliche Faktoren oder über Zell-Zell-Kontakte induziert [136].

Hinsichtlich der Reaktion von Endothelzellen auf Wachstumsfaktoren existieren Unterschiede zwischen den einzelnen Endothelzellarten. Makrovaskuläre Endothelzellen der Mausaorta zeigen z.B. im Vergleich zu mikrovaskulären Zellen von Herz oder Gehirn eine unterschiedliche Reaktion auf Fibroblasten Wachstumsfaktor-2 (FGF-2) [12].

Werden Endothelzellen durch Wachstumsfaktoren aktiviert, ändert sich ihr Phänotyp. Aufgrund der gesteigerten Proteinproduktion findet man eine Vergrößerung des endoplasmatischen Retikulums sowie des Golgi-Apparates und zur Deckung des erhöhten Energiebedarfs der Endothelzelle eine größere Menge an Mitochondrien [136].

Wachstumsfaktoren wie VEGF (vascular endothelial growth factor) haben nicht auf alle Endothelzellen eine wachstumstimulierende Wirkung. LECOUNTER et al. konnten die Existenz gewebsspezifischer Wachstumsfaktoren nachweisen [88]. Der endocrine-glandderived vascular endothelial growth factor ( $E G$-VEGF) wird lediglich in Organen des endokrinen Systems sowie den Keimdrüsen gefunden, er hat hier mitogene und chemotaktische Wirkung und induziert die Fenestration, welche in diesen Organen benötigt wird.

Nach Stimulation mit Tumor Nekrose Faktor $\alpha$ findet man eine für Entzündungsreaktionen charakteristische Änderung des Endothelzellphänotyps, eine Induktion von bestimmten Oberflächenadhäsionsmolekülen (siehe Abschnitt 1.8, Seite 6) und eine wachstumsfördernde Wirkung. Auch hier zeigt sich die Heterogenität des Endothels von mikround makrovaskulären Zellen [90].

Die Heterogenität von mikro- und makrovaskulären Zellen in ihrer Reaktion auf ih- 
re Umgebung wird besonders deutlich bei in vitro Versuchen zur Angiogenese. Mikrovaskuläre Endothelzellen bilden auf dreidimensionalen Fibringelen eher kapillarähnliche Strukturen als makrovaskuläre Endothelzellen aus [90].

\subsection{Endotheliale Heterogenität und Blutgerinnung}

Der von Willebrand Faktor (vWF) ist ein Glykoprotein, das in Endothelzellen, Megakaryozyten und Thrombozyten vorkommt [56]. Das in den Weibel-Palade-Körperchen in den Endothelzellen gespeicherte Protein [167] vermittelt die Adhäsion der Blutplättchen und ist Träger des Gerinnungsfaktors VIII [145]. Der vWF kann als Marker endothelialer Heterogenität bezeichnet werden [56]. Er wird von Endothelzellen venöser Gefäße im Vergleich zu arteriösen vermehrt exprimiert [124]. Die Unterschiede in der Expression des von Willebrand Faktors bleiben auch nach Isolierung und Kultivierung der Endothelzellen erhalten [167]. Weiterhin hat die Gefäßumgebung eine regulierende Wirkung auf die Expression des vWF [56].

YAмамото et al. konnten in Organextrakten von Mäusen deutliche Unterschiede in der mRNA Expression des endothelialen Gewebsplasminogenaktivatorgens feststellen [197]. Die Expression des tissue factor pathway inhibitor (TFPI) ist nach OsTERUD et al. im mikrovaskulären Endothel höher als im makrovaskulären [122].

Die These einer heterogenen, umgebungsspezifischen Expression von Komponenten des Gerinnungs- und Fibrinolysesystems konnte durch Studien an knock-out-Mäusen untermauert werden. Werden antikoagulatorisch wirkende Gene ausgeschaltet, so entwickeln die Tiere Thrombosen von ortsspezifisch unterschiedlicher Ausprägung [143, 188].

\subsection{Regulation des Gefäßtonus durch das Endothel}

Endothelzellen produzieren vasodilatierende sowie vasokonstringierende Substanzen, um den Gefäßstonus zu regulieren. Dieses ist für eine ausreichende Perfusion der Organe mit Blut wichtig.

Die Vasodilatation wird durch Stickstoffmonoxid (NO, endothelium derived relaxing factor) vermittelt. Guillot et al. zeigten am Mausmodell, daß die relative Expression der endothelialen NO-Synthase (eNOS) in Herz und Lunge am höchsten, in der Leber am niedrigsten ist [57]. Andere Gruppen berichteten, daß die NO-Synthase in den Organen stets auf der arteriellen Seite höher als auf der venösen Seite sei [3]. 
Zur Produktion von NO durch die NO-Sythase wird L-Arginin benötigt. Durch Strömungsstress (shear stress) wird die Argininosuccinatsynthase, die an der Argininsynthese beteiligt ist, hochreguliert [103].

\subsection{Embryonale, adulte und alternde Endothelzellen}

Das Alter von Endothelzellen spielt eine wichtige Rolle in der Funktion der Zellen. Bei embryonalen Endothelzellen findet man eine außergewöhnliche Plastizität und eine ausgeprägte Bereitschaft zur Differenzierung, Angiogenese sowie ein gutes Ansprechen auf Wachstumsfaktoren. Das Altern von Endothelzellen hingegen geht mit einer endothelialen Dysfunktion [189], einer verminderten Fähigkeit zur Angiogenese [138] sowie mit einer verschlechterten Reparaturkapazität [189] einher.

Bei der Alterung der Zellen unterscheidet man die replikative Seneszenz von der vorzeitigen Seneszenz aufgrund von oxidativem Stress [82]. Die replikative Seneszenz gründet auf einen Abbau der Telomere bei der Zellteilung [23]. Die langandauernde oxidative Schädigung von zellulären Makromolekülen durch kontinuierliche Belastung der Zelle durch oxidativen Stress kann die replikative Seneszenz induzieren oder beschleunigen [161]. Endothelzellen sind durch intrazelluläres Glutathion vor Oxidanzien geschützt, sind aber deutlich empfindlicher gegenüber oxidativem Stress als z.B. Fibroblasten [108]. Störungen des Glutathion-Systems der Endothelzellen, welches bereits durch längerdauernden milden oxidativen Stress ausgelöst werden kann, sollen über die Induktion einer vorzeitigen Seneszenz eine wichtige Rolle in der Pathogenese vaskulärer und chronisch entzündlicher Erkrankungen führen [82].

\subsection{Einfluß des Geschlechts auf endotheliale Funktionen}

Die Abhängigkeit bestimmter Eigenschaften des kardiovaskulären Systems vom Geschlecht ist seit langem bekannt. Epidemiologisch unterlegt ist der protektive Einfluß weiblicher Geschlechtshormone auf das Herz-Kreislaufsystem [105]. RECKELHOFF beschrieb geschlechtsspezifische Unterschiede in der Regulation des Blutdrucks [134]. Die Inzidenz für arterielle Hypertension und koronare Herzkrankheit ist bekanntermaßen bei Männern signifikant höher als bei gleichaltrigen prämenopausalen Frauen [93]. Diese Beobachtungen konnten durch KAUSER et al. an der Rattenaorta bestätigt werden, sie fanden einen direkten 
Einfluß von Sexualhormonen auf das Endothel [72]. Mendelsohn et al. zeigten, daß Östrogene eine Vasodilatation von Blutgefäßen herbeiführen können bzw. das Ansprechen dieser Gefäße auf andere vasodilatatorische Stimuli verbessern [105]. Die Blockade des Testosteronrezeptors in Ratten verbessert die Prognose der Tiere nach hämorrhagischem Schock [9]. Es existiert eine Korrelation von Androgenkonzentration im Blut von männlichen Ratten und einer verminderten Endothelfunktion. Der Perfusionsdruck in den Dünndarmgefäßen nach Acetycholingabe war gegenüber der kastrierten Kontrolle signifikant verringert [8].

\subsection{Die Rolle des Endothels im Rahmen der Entzündung}

Die mikrovaskulären Endothelzellen spielen bei der Entzündungsreaktion eine kritische Rolle. Sie produzieren proinflammatorische Zytokine und Chemokine und exprimieren ein für das jeweilige Organ spezifisches Muster von Oberflächenadhäsionsmolekülen.

Die Endothelzellen stellen eine wichtige Barriere für Mikroorganismen und deren Endotoxine dar. Endothelien verschiedener Körperregionen sind diesen gegenüber unterschiedlich empfindlich. Mikrovaskuläre Lungenendothelzellen exprimieren nach Stimulation mit bakteriellem Endotoxin oder den Zytokinen TNF- $\alpha$ bzw. IL-1 $\beta$ das Adhäsionsmolekül VCAM-1 deutlich stärker als makrovaskuläre embryonale Nabelschnurvenenendothelzellen (HUVEC) [153].

In sekundär lymphatischen Organen finden sich zur selektiven und effizienten Rekrutierung von Lymphozyten spezialisierte Venolen (high endothelial venules, HEV). Diese zeichnet eine untypische Morphologie (siehe Abschnitt 1.2, Seite 2) sowie ein spezifisches Arsenal von spezialisierten Adhäsionsmolekülen aus [142]. In peripheren Lymphknoten interagiert das L-Selektin der Lymphozyten mit den peripherial node addressins, PNAd [62], was zur Extravasation von Leukozyten führt. Bei chronisch entzündlichen Darmerkrankungen können HEVs de novo entstehen und mit ihrer spezialisierten Adhäsionsmolekülausstattung an der Rekrutierung von Lymphozyten im Darm teilnehmen [142]. 


\subsection{Rolle des intestinalen mikrovaskulären Endothels bei chronisch entzündlichen Darmerkrankungen}

Bei chronisch entzündlichen Darmerkrankungen (CED) unterscheidet man den Morbus Crohn (MC) [30] von der Colitis ulcerosa (CU). Hauptsymptome von CED sind Diarrhoe, Blutungen des unteren Gastrointestinaltraktes, abdominaler Schmerz, Fieber und Gewichtsverlust.

Die Ätiologie von CED ist weiterhin nicht vollständig aufgeklärt. Aktuell geht man davon aus, daß auf dem Hintergrund genetischer Veränderungen eine gestörte mukosale Immunantwort gegen bakterielle Antigene resultiert.

Pathogenetisch spielt die Überproduktion von proinflammatorischen Zytokinen und Entzündungsmeditoren eine wichtige Rolle. Viele dieser Mediatoren bewirken eine Aktivierung des mikrovaskulären Endothels [86]. Bei CED kommt es zu mikrovaskulären Ischämien, Hyperkoagulabilität und entzündlichen Veränderungen der Darmgefäße. Neuere Untersuchungen zu den molekularen Mechanismen in der Pathogenese der CED zielen daher auf die spezielle Rolle der intestinalen Mikrogefäße und des diese auskleidenden Endothels ab [61]. Eine entscheidende Rolle des mikrovaskulären Endothels im mukosalen Immunsystem sowie bei der chronischen Entzündungsreaktion konnten gezeigt werden.

\subsubsection{Mikrovaskuläres Endothel und Gewebsischämie bei chronisch entzündlichen Darmerkrankungen}

Der gesunde menschliche Darm ist gut durchblutet. Angiographische Studien der Darmdurchblutung zeigten bei früher CED in den betroffenen Darmabschnitten eine bizarre Verteilung dilatierter Gefäße mit Unregelmäßigkeiten des Aufbaus [104]. Bei einer etablierten CED fand man im Gegensatz dazu einen deutlich reduzierten Gefäßquerschnitt, eine geringere Gefäßdichte sowie eine geringere Perfusion des von der CED betroffenen Darmabschnitts [98].

Eine fulminante Kolitis ist im Frühstadium durch eine Mehrperfusion des betroffenen Darmabschnittes gekennzeichnet, in chronisch entzündeten oder fibrotisch umgebauten Abschnitten findet man eine herabgesetzte Durchblutung. WAKEFIELD et al. zeigten eine fibrotische Alteration der die erkrankten Darmabschnitte versorgenden Arterien. Die Schädigung der mukosalen Mikrovaskulatur geht der Ulzeration der Mukosa voraus [186]. Am Tiermodell enstand nach Mikroembolisation der mukosalen und submukosalen Arterien in den unterversorgten Gebieten des Darms ein CED-ähnliches Krankheitsbild [67]. 
Bei der Indometacin-induzierten Ileitis konnten mittels intravitaler Mikroskopie kapilläre Vasokonstriktionen und Mikrothromben zeitlich vor der Entwicklung der Entzündung und Ulzeration gezeigt werden [146]. Ein thrombotischer Verschluss der Mikrogefäße ist ursächlich für die Kolitisentstehung nach Gabe von Trinitrobenzensulfonsäure. Die resultierende Minderdurchblutung führt zu einer Störung der mukosalen Barrierefunktion mit anschließendem Eindringen von Darminhalt in die Mukosa und folgender Entzündung [44]. Heparin verhindert den thrombotischen Verschlusses der Mikrogefäße und kann so die mukosale Entzündung und Zerstörung in vivo deutlich reduzieren [140]. CARR et al. zeigten eine Korrelation der Morbus Crohn-Inzidenz mit einer reduzierten Durchblutung der Darmmukosa [24].

Chronisch entzündliche Darmerkrankungen werden durch eine anhaltende mikrovaskuläre Minderdurchblutung perpetuiert [176]. Die für diese Insuffizienz verantwortlichen Faktoren werden im folgenden diskutiert.

Der potente Vasokonstriktor Endothelin-1 (ET-1) ist im Serum von Crohnpatienten signifikant erhöht [92], die ET-1-Rezeptoren auf den Endothelzellen sind vermehrt. Die Konzentration von ET-1 in der Submukosa des befallenen Darms ist signifikant höher als bei Gesunden [117]. Im Tiermodell kann die Blockade des Endothelin-1-Rezeptors die Infiltration von Entzündungszellen in der Darm und die Darmzerstörung deutlich vermindern [123]. KANAZAWA et al. zeigten, daß durch die Kombination von ET-1 und VEGF (beide Zytokine sind bei CED deutlich erhöht) eine Vasokonstriktion mit anschließender Gewebshypoxie und Angiogenese stattfindet [71]. Haтоum et al. fanden bei Arteriolen aus CED-Darmabschnitten gegenüber Resektaten aus gesundem Darm eine signifikant verringerte vasodilatatorische Potenz, was auf eine verringerte Funktion des Vasodilatators NO zurückgeführt wurde. Zudem postulierten sie einen hohen Bedarf an COX in den Endothelien, um den Gefäßtonus aufrecht erhalten zu können [60].

Ein weiterer Faktor bei der Entstehung der Darmischämie ist die Hyperkoagulabilität des Blutes, welche zu einer Okklusion der Mikrogefäße führt. TALBOT et al. zeigten ein signifikant erhöhtes Thromboserisiko bei CED-Patienten [172]. Die Fibrinogenkonzentration im Serum ist bei Crohnpatienten erhöht, häufig findet sich eine Thrombophilie [27]. Durch die Einnahme von oralen Kontrazeptiva - die auch den Fibrinogenspiegel erhöhen steigt das relative Risiko, an CED zu erkranken um den Faktor vier bis acht [91]. THOMPSON et al. wiesen die geringere Inzidenz von CED bei Patienten mit einer hämorrhagischen Diathese nach [175].

Das Endothel des Gastrointestinaltraktes exprimiert den Blutplättchen-aktivierendenFaktor PAF. In CED-befallenem Gewebe fand sich eine deutlich erhöhte PAF-Expression 
[53]. PAF vermittelt die Aggregation von Thrombozyten, die Bindung von Leukozyten sowie deren Degranulation. RACHMiLEWiTz et al. postulierten eine potentielle Rolle dieses Zytokins bei der Okklusion der Mikrogefäße im Rahmen einer CED [130]. Die ebenfalls von Endothelzellen sezernierte Substanz P verursacht eine Adhärenz von Monozyten und aktiviert via Faktor X die Gerinnungskaskade [39]. Ein weiterer Faktor ist der nach Endothelschädigung in größeren Mengen in Blut abgegebene von-Willebrand-Faktor (vWF). Seine Serumkonzentration ist bei Morbus Crohn signifikant erhöht. Da der vWF ein potenter Mediator der Blutplättchenaggregation ist, wird ein Einfluß auf die Bildung von Mikrothromben in den Darmgefäßen vermutet [170].

\subsubsection{Vermehrte Leukozytenrekrutierung durch das Endothel bei chronisch entzündlichen Darmerkrankungen}

Ein durch Zytokine oder andere Entzündungsmediatoren aktiviertes Endothels ist für die Rekrutierung und Diapedese von Leukozyten notwendig [14]. Bei CED konnten DvOrAK et al. pathologische Veränderungen des Endothels der Mikrogefäße mit Verlust der Integrität des Monolayers, fokalen Endothelnekrosen, einem Ödem des benachbarten Gewebes und einer Hypertrophie der Endothelzellen zeigen [37].

Oberflächenmoleküle der Endothelzellen vermitteln die Leukozytenrekrutierung und Extravasation in die Mukosa. Immunhistochemische Studien zeigten eine deutliche $\mathrm{Zu}$ nahme der Expression von E-Selektin und ICAM-1 (intercellular adhesion molecule 1) bei CED [54]. Da ICAM-1 durch die Zytokine Interleukin-1 $\beta$ und TNF- $\alpha$ sowie bakterielles Lipopolysaccharid in Endothelzellen induzierbar ist, kann dieses vermehrte Auftreten des Moleküls auch sekundär entzündlicher Natur sein [176]. BRISKIN et al. konnten die erhöhte Expression des darmspezifischen Adhäsionsmoleküls mucosal addressin cellular adhesion molecule 1 (MAdCAM-1) bei CED zeigen. Sie postulierten eine wichtige Rolle dieses Moleküls bei der Rekrutierung derjenigen Leukozyten, die das Integrin $\alpha_{4} \beta_{7}$ auf ihrer Oberfläche tragen [19]. Die vermehrte Bindung von Leukozyten dieser Adhäsionsmoleküle ist ein weiterer Faktor bei der Entstehung von Mikrothromben mit nachfolgender Gewebsischämie [176] (siehe Abschnitt 1.9.1, Seite 7).

Mikrovaskuläre Endothelien aus CED-Darmabschnitten rekrutieren primär naive Lymphozyten, während im gesunden Darm vor allem Gedächtniszellen gebunden werden [150]. BURGIO et al. zeigten im Endothel von Crohnpatienten eine bevorzugte Rekrutierung von naiven Monozyten und T-Lymphozyten [21].

Primärkulturen humaner intestinaler mikrovaskulärer Endothelzellen (HIMEC) von 
CED-Patienten zeigen eine gegenüber HIMEC aus gesunden Darmabschnitten nach Zytokinstimulation signifikant gesteigerte Leukozytenadhäsionskapazität. Dieser Effekt ist auf stimulierte Endothelzellen beschränkt und wird auf einen „erworbenen Defekt" der Zellen zurückgeführt [17]. Bei CED-HIMEC geht mit der vermehrten Leukozytenadhäsionsfähigkeit das Gen für die induzierbare NO-Synthase (inducible NO-Syntase (iNOS)) verloren, was eine verringerte vasodilatatorische Potenz der Mikrovaskulatur in CEDDarmabschnitten zur Folge hat. NO wirkt protektiv auf die Integrität der Darmmukosa, reduziert die mikrovaskuläre Permeabilität, relaxiert die glatten Muskelzellen im Darm und den Gefäßwänden und inhibiert die Adhäsion von Neutrophilen und Thrombozyten [125]. SASAKI et al. untersuchten die Rolle des NO in der Pathogenese der CED an endothelialer NO-Synthase (eNOS)-defizienten knock-out-Mäusen. Die Dextransulfatinduzierte Kolitis verlief bei eNO-Synthase negativen Mäusen im Vergleich zum Wildtyp deutlich stärker. Histologisch zeigten die eNOS-defizienten Mäuse eine vermehrte Lymphozyteninfiltration, eine verstärkte Schädigung des Darms sowie eine vermehrte Expression des mukosalen Adhäsionsmoleküls MAdCAM-1 [154].

Im Gegensatz dazu berichten KIMURA et al. beim Morbus Crohn über eine erhöhte Aktivität sowohl der endothelialen als auch der induzierbaren NO-Synthase [74]. LArginin-Mangelzustände oder Ischämie führen zu einer Bildung von freien Radikalen aus den Endprodukten des NO-Metabolismus [109].SCHREIBER et al. fanden eine vermehrte Expression von iNOS und $\mathrm{NF} \kappa \mathrm{B}$ bei CED, beide Faktoren können ebenfalls zu einer Bildung freier Radikale führen [158]. Diese Radikale können im Gewebe zur Peroxidbildung, DNA-Strangbrüchen und dadurch bedingt zu entzündlichen Reaktionen und zelltod führen.

Die vermehrte Expression von Oberflächenadhäsionsmolekülen im mikrovaskulären Endothel der chronisch entzündeten Darmmukosa führten zu einem Therapieansatz, welcher die Hemmung dieser Adhäsionsmoleküle zum Ziel hatte [181]. Die Translation von ICAM-1 wurde durch die Substanz Alicaforsen inhibiert, in klinischen Studien führte diese Therapie bei $40 \%$ der an Morbus Crohn erkrankten Studienteilnehmer zu einer Remission [196]. Eine Blockade des Integrins $\alpha_{4} \beta_{7}$ durch den monoklonalen Antikörper Natalizumab konnte im Primatenmodell eine chronische Kolitis beenden [127].

NIELSEN et al. führten an CED-Darmresektaten eine Untersuchung der in entzündeten Darmresektaten differenziell regulierten Zytokine durch. Sowohl bei aktiver als auch nichtaktiver CED fanden sich signifikante Erhöhungen der mRNA-Konzentration für die Interleukine 3, 7, 11, 14 und 15 sowie TNF- $\alpha$, TGF- $\beta$ (TGF- $\beta$ ) und GMCSF. Diese Erhöhung der Konzentrationen ist unabhängig vom jeweiligen Aktivitätsgrad der Erkrankung, die 
Änderung der Krankheitsaktivität scheint also nicht von der Zytokinkonzentration abzuhängen. Allerdings haben einige Zytokine eine mögliche entzündungsfördernde Wirkung, so das Interleukin-3, das als potenter T-Zell-Aktivator sowie Induktor des endothelialen Leukozytenadhäsionsmoleküls-1 gilt und zusammen mit TNF- $\alpha$ das endothelspezifische E-Selektin induziert [118].

Als sehr bedeutend für den Krankheitsprozess der CED wird die sowohl in aktiver CED als auch in nichtaktiven Phasen gleichermaßen erhöhte endotheliale Expression von TNF$\alpha$ angesehen [118]. Die Konzentration von TNF- $\alpha$ ist bei aktiver und inaktiver Erkrankung in der Mukosa und im Stuhl erhöht [18], eine erhöhte TNF- $\alpha$ gilt als Hinweis auf einen Crohnschub [159].

Die besondere Bedeutung von TNF- $\alpha$ zeigt sich in den Erfolgen einer gegen TNF- $\alpha$ gerichteten immunmodulatorischen Therapie. Ein chimärer monoklonaler Antikörper gegen TNF- $\alpha$ (Infliximab) zeigte in randomisierten Placebo-kontrollierten klinischen Tests eine Remissionsrate von mehr als $60 \%$ nach einmaliger Gabe [173]. Die Ergebnisse von CDP571, einem anderen, gentechnisch hergestellten Antikörper sind ebenfalls erfolgversprechend [169], weitere TNF- $\alpha$ blockierende Substanzen werden erforscht [79]. Die Produktion von TNF- $\alpha$ konnte auch erfolgreich mit Thalidomid inhibiert werden [191].

\subsection{Expressionsanalysen von Endothelzellen}

Verschiedene Aspekte endothelialer Heterogenität wurden in diesem Kapitel dargestellt. Zumeist beschränkte man sich aber auf die Beschreibung der differenziellen Regulation einzelner Gene oder Genfamilien bei unterschiedlichen Endothelzellpopulationen. Die Erstellung von Genexpressionsprofilen von Endothelzellen mittels DNA-Microarraytechnologie (für eine genaue Beschreibung der Technik siehe Abschnitt 3.2.4, Seite 31) erlaubt die sehr umfassende bis genomweite Kartierung der in den Zellen exprimierten Gene und den Vergleich der erstellten Profile mit bioinformatischen Methoden. So kann eine weitergehende Analyse der Heterogenität der Endothelzellen bzgl. der Genexpression und Funktion erfolgen.

Mittels DNA-Microarrays wurde bisher das Genexpressionsprofil von Nabelschnurvenenendothelzellen (HUVEC) [116, 200, 184], des Endothels von Arterien und Venen und der mikrovaskulären Endothelzellen von Lunge, Leber, Hirn und anderer Organe nach Stimulation mit TNF- $\alpha$ [116, 200, 184], IL-1 $\beta$ [200], IFN- $\gamma$ [52], vor und nach Seneszenz [31] und unter diversen anderen Konditionen ermittelt. Bei diesen Arbeiten wurde die Genex- 
pression einer Endothelzellpopulation unter verschiedenen Bedingungen untersucht, aber nicht der Unterschied zwischen verschiedenen Populationen auf Genebene definiert. CHI et al. zeigten mittels DNA-Microarray den Unterschied der basalen Genexpression von 53 unstimulierten Endothelzellkulturen [26]. Aufgrund der Masse der Daten beschränkten die Autoren sich auf ein funktionelles Clustering der regulierten Gene. Sie verwiesen auf eine relative Ähnlichkeit der Genexpressionsprofile von verschiedenen mikrovaskulären Endothelzellen, von Arterien zu Arterien und Venen zu Venen. Ein deutlicher Unterschied der Profile von embryonalen und adulten Endothelzellen wurde gezeigt. In dieser Arbeit wurde die unstimulierte Genexpression von mikrovaskuläre Endothelzellen aus intestinalem Gewebe untersucht, die nach der Methode von HARALDSEN isoliert worden waren [58].

\subsection{Fragestellung der vorliegenden Arbeit}

Das mikrovaskuläre Endothel spielt eine wichtige Rolle bei der Rekrutierung und Extravasation von Leukozyten. Damit hat es Schlüsselpositionen im Rahmen von entzündlichen Reaktionen. Hinweise auf eine Beteiligung des mikrovaskulären Endothels in der Pathogenese der CED wurden oben dargestellt. Die Untersuchung der Funktion des intestinalen mikrovaskulären Endothels bei einer CED kann daher zu neuen Informationen über die bei der CED ablaufenden pathogenetischen Mechanismen führen.

Der größere Teil der Erkenntnisse über Endothelzellen stammt aus Versuchen mit Endothelzellkulturen aus menschlichen Nabelschnurvenen (HUVEC), da sie einfach zu isolieren und kultivieren sind. Die umfangreichen Daten zu HUVECs sind allerdings nur begrenzt auf die Verhältnisse bei chronisch entzündlichen Darmerkrankungen übertragbar. Es existiert eine große Variabilität zwischen den verschiedenen HUVEC-Primärkulturen einzelner Arbeitsgruppen, was die Reproduzierbarkeit der Ergebnisse verschlechtert [187]. Weiterhin besteht eine ausgeprägte Heterogenität von Endothelzellen verschiedener Organe, unterschiedlicher Gefäße und unterschiedlichen Alters (s.o.).

Daher besteht die Notwendigkeit, für ein brauchbares in vitro Modell der Mikrovaskulatur und ihrer Rolle im Rahmen von CED Endothelzellprimärkulturen aus humanem Darm zu isolieren.

Im Rahmen der vorliegenden Arbeit wurde mittels DNA-Microarrays ein Genexpressionsprofil von humanen intestinalen mikrovaskulären Endothelzellen (HIMEC) erstellt und mit den Expressionsprofilen von TNF- $\alpha$-stimulierten HIMEC verglichen. Die gewonnenen Expressionsdaten wurden mit denen der entsprechend stimulierten HMEC-1 Endothelzel- 
linie verglichen.

Die entscheidende Fragestellung war, welche Gene in HIMEC durch Stimulation mit TNF- $\alpha$ differenziell reguliert werden und ob sich das ermittelte Expressionsprofil mit den bisher publizierten Daten zur Pathogenese der CED in Einklang bringen läßt. Weiterhin sollten Unterschiede in dem Expressionsprofil von HIMEC und dem der Referenzzellinie HMEC-1 ermittelt werden, um neue, möglichst darmspezifischen Kandidatengene zu identifizieren. Diese Gene definieren gleichzeitig die Heterogenität zweier mikrovaskulärer Endothelzellpopulationen. Sie sollen dann auf ihre Rolle bei der Initiation und Perpetuation von CED untersucht werden. Kandiatengene, welche als darmspezifisch charakterisiert wurden, ermöglichen eventuell zu einem späteren Zeitpunkt ein gezielteres Eingreifen in den Krankheitsprozess der CED. 


\section{Material}

\subsection{Chemikalien}

Tabelle 2.1: Chemikalien und Verbrauchsmaterialien

\begin{tabular}{|c|c|}
\hline Chemikalien / Verbrauchsmaterial & Hersteller \\
\hline $\begin{array}{l}\text { Marker DNA (Agarosegelelektrophorese, } \\
100 \text { bp Ladder) }\end{array}$ & Invitrogen, Paisley, GB \\
\hline 4’,6’' Diamidino-2-Phenylindol (DAPI) & Sigma, Deisenhofen \\
\hline Aceton & Roth, Karlsruhe \\
\hline Acrylamid $40 \%$ (AA) & Quantum Appligene, Heidelberg \\
\hline Agarose & Sigma, Deisenhofen \\
\hline Ammoniumpersulfat (APS) & Serva, Heidelberg \\
\hline Aqua ad inj. & Braun, Melsungen \\
\hline Bandenmarker (für SDS-PAGE) & Biorad, Hercules, CA, USA \\
\hline Biocoll & Biochrom, Berlin \\
\hline Cleland's Reagenz (Dithiothreitol-DTT) & Sigma, Deisenhofen \\
\hline dNTPs & Qiagen, Hilden \\
\hline $\begin{array}{l}\text { Dulbecco’s PBS (phosphatgepuffer- } \\
\text { te Salzlsg.) mit bzw. ohne Calci- } \\
\text { um/Magnesium }\end{array}$ & PAA, Pasching, Österreich \\
\hline Ethidiumbromid & Sigma, Deisenhofen \\
\hline $\begin{array}{l}\text { Ethylendiamintetraessigsäure } \quad \text { (EDTA), } \\
\text { Mol. biol. grade }\end{array}$ & Sigma, Deisenhofen \\
\hline FACSflow Puffer & Becton Dickinson, Erembodegem, Belgien \\
\hline FACSrinse Puffer & Becton Dickinson, Erembodegem, Belgien \\
\hline Hank's Balanced Salt Solution (HBSS) & Invitrogen, Paisley, GB \\
\hline
\end{tabular}


Tabelle 2.1: Chemikalien und Verbrauchsmaterialien (Forts.)

\begin{tabular}{ll}
\hline Chemikalien / Verbrauchsmaterial & Hersteller \\
$\begin{array}{l}\text { Hank's Balanced Salt Solution (HBSS) } \\
\mathrm{Ca} / \mathrm{Mg}+\text { Phenolrot }\end{array}$ & Bio Whittaker, Beverly, CA, USA \\
$\begin{array}{l}\text { Isopentan (2-Methylbutan) } \\
\text { Kaisers Glyceringelatine }\end{array}$ & Merck, Darmstadt \\
$\begin{array}{l}\text { Lipopolysaccharid Typ 0111:B4 (aus } \\
\text { coli) }\end{array}$ & $\begin{array}{l}\text { Merck, Darmstadt } \\
\text { Sigma, Deisenhofen }\end{array}$ \\
\hline Magermilchpulver & ICN, Eschwege \\
\hline Mowiol 4-88 & Calbiochem, Bad Soden \\
\hline Natriumlaurylsulfat 10\% & Serva, Heidelberg \\
\hline n-Butanol & Sigma, Deisenhofen \\
\hline Normales Serum (Esel) & Sigma, Deisenhofen \\
\hline OCT Tissue Tek compound & Sakura, Japan \\
\hline Paraformaldehyd & Merck, Darmstadt \\
PCR-Puffer 10x & Invitrogen, Paisley, GB \\
\hline Permount Eindeckmedium & Fisher, Fair Lawn, NJ, USA \\
\hline Rinderserumalbumin (BSA) & Sigma, Deisenhofen \\
\hline B-Mercaptoethanol & Sigma, Deisenhofen \\
\hline Saccharose & Sigma, Deisenhofen \\
\hline TEMED & Sigma, Deisenhofen \\
\hline $\begin{array}{l}\text { Tumor Nekrose Faktor - alpha, rekombi- } \\
\text { nant, human }\end{array}$ & R D Systems, Minneapolis, MN, USA \\
\hline Triton X-100 & Sigma, Deisenhofen \\
Tween 20 & Sigma, Deisenhofen \\
\hline
\end{tabular}

Soweit nicht anders angegeben, wurden alle Chemikalien in p.A. Qualität eingesetzt. Alle nicht aufgeführten Chemikalien wurden in p.A. Qualität bei der Firma Sigma (Deisenhofen) erworben. 


\subsection{Reagenzien für die Zellkultur}

\subsubsection{Zellinien}

Tabelle 2.2: Zellinien

\begin{tabular}{ll}
\hline Zellinie & Quelle \\
\hline HMEC-1 & Centers for Disease Control, Atlanta, GA, \\
& USA [195] \\
\hline
\end{tabular}

\subsubsection{Seren}

Tabelle 2.3: Seren

\begin{tabular}{ll}
\hline Serum & Hersteller \\
\hline Fetales Kälberserum (FCS) & Invitrogen, Paisley, GB \\
\hline
\end{tabular}

\subsubsection{Zellkulturmedien}

Tabelle 2.4: Zellkulturmedien

\begin{tabular}{ll}
\hline Medium & Hersteller \\
\hline Endothelial cell growth medium & Promo Cell, Heidelberg \\
\hline
\end{tabular}

\subsubsection{Sonstige Reagenzien für die Zellkultur}

Tabelle 2.5: sonstige Reagenzien für die Zellkultur

\begin{tabular}{ll}
\hline Chemikalie & Hersteller \\
\hline Penicillin/Streptomycin & Invitrogen, Paisley, GB \\
Kollagen Typ I (Rattenschwanz) & Upstate Biotech, Hamburg \\
Trypsin/EDTA & Invitrogen, Paisley, GB \\
Trypanblau 0,5\% (w/v) in phys. Salzlsg. & Biochrom, Berlin \\
\hline
\end{tabular}




\subsection{Enzyme}

Tabelle 2.6: Enzyme

\begin{tabular}{|c|c|}
\hline Enzym & Hersteller \\
\hline $\begin{array}{l}\text { Moloney Murine Leukemia Virus Reverse } \\
\text { Transkriptase (MMLV-RT) }\end{array}$ & Invitrogen, Paisley, GB \\
\hline $\begin{array}{l}\text { Thermus aquaticus Polymerase (Super } \\
\text { Taq Polymerase) }\end{array}$ & Invitrogen, Paisley, GB \\
\hline Collagenase Typ II & Worthington, Lakewood, NY, USA \\
\hline
\end{tabular}

\subsection{Antikörper}

Tabelle 2.7: Primärantikörper

\begin{tabular}{|c|c|}
\hline Antikörper & Hersteller \\
\hline $\begin{array}{l}\text { anti-human VCAM-1 (aus Maus) mAb } \\
\text { (Klon BBA5) }\end{array}$ & R \& D Systems, Minneapolis, MN, USA \\
\hline $\begin{array}{l}\text { anti-human VCAM-1 (aus Ziege) pAb } \\
\text { (Klon C19) }\end{array}$ & $\begin{array}{l}\text { Santa Cruz Biotechnology, Santa Cruz, } \\
\text { CA, USA }\end{array}$ \\
\hline $\begin{array}{l}\text { anti-human MeCa-79 (aus Maus) mAb } \\
\text { [171] }\end{array}$ & $\begin{array}{l}\text { freundliche Gabe von Prof. Vestweber, } \\
\text { Inst. für Zellbiologie, Münster }\end{array}$ \\
\hline $\begin{array}{l}\text { anti-human vWF (von-Willebrand- } \\
\text { Faktor) (aus Kaninchen) pAb }\end{array}$ & Sigma, Deisenhofen \\
\hline
\end{tabular}


Tabelle 2.8: Sekundäre, markierte und enzymgekoppelte Antikörper

\begin{tabular}{|c|c|}
\hline Antikörper & Hersteller \\
\hline $\begin{array}{l}\text { anti-Kaninchen FITC-konjugiert (aus } \\
\text { Esel) }\end{array}$ & $\begin{array}{l}\text { Jackson Immunoresearch, San Diego, CA, } \\
\text { USA }\end{array}$ \\
\hline $\begin{array}{l}\text { anti-Kaninchen IgG (aus Ziege), Biotin } \\
\text { konjugiert }\end{array}$ & Pharmingen, Palo Alto, CA,USA \\
\hline $\begin{array}{l}\text { anti-Maus IgG (aus Ziege), Biotin konju- } \\
\text { giert }\end{array}$ & Pharmingen, Palo Alto, CA, USA \\
\hline anti-Ziege Cy3-konjugiert (aus Esel) & $\begin{array}{l}\text { Jackson Immunoresearch, San Diego, CA, } \\
\text { USA }\end{array}$ \\
\hline $\begin{array}{l}\text { anti-Ziege IgG (aus Esel), Biotin konju- } \\
\text { giert }\end{array}$ & Pharmingen, Palo Alto, CA, USA \\
\hline Streptavidin, $\mathrm{Cy} 3^{\mathrm{TM}}$ konjugiert & $\begin{array}{l}\text { Jackson Immunoresearch, San Diego, CA, } \\
\text { USA }\end{array}$ \\
\hline $\begin{array}{l}\text { Streptavidin, horseradish peroxidase, } \\
\text { HRP konjugiert }\end{array}$ & $\begin{array}{l}\text { Jackson Immunoresearch, San Diego, CA, } \\
\text { USA }\end{array}$ \\
\hline $\begin{array}{l}\text { Streptavidin, Fluoresceinisothiocyanat } \\
\text { (FITC) konjugiert }\end{array}$ & $\begin{array}{l}\text { Jackson Immunoresearch, San Diego, CA, } \\
\text { USA }\end{array}$ \\
\hline
\end{tabular}

\subsection{Oligonukleotide}

Alle Oligonukleotidprimer für die Polymerasekettenreaktion wurden mit dem Programm PrimerExpress 2.0 (Fa. Applied Biosystems, Foster City, CA, USA) entworfen, als Rohdaten wurden die kodierenden Sequenzen für die einzelnen Gene aus der Gene Bank des National Institute of Health, Bethesda, ML, USA (http://ncbi.nlm.nih.gov) entnommen. Besondere Beachtung fanden beim Primerdesign die Anforderungen des Realtime-PCRSystems an die Oligonukleotidprimer (Fragmentlänge zwischen 150 - 200 bp, Schmelzpunkt $\left.58-62^{\circ} \mathrm{C}\right)$. 
Tabelle 2.9: Oligonukleotide

\begin{tabular}{cc}
\hline Primer & Sequenz $\mathbf{5}^{\bullet}-\mathbf{3}^{\bullet}$ \\
\hline VCAM-1 sense & CTA TAC CAT CCG AAA GGC CCA \\
VCAM-1 antisense & GAG CAC GAG AAG CTC AGG AGA A \\
$\beta$-Aktin sense & CAA AGA CCT GTA CGC CAA CAC \\
$\beta$-Aktin antisense & CAT ACT CCT GCT TGC TGA TCC \\
PS-PLA1 sense & TGT GTC GGA ATC CTC AAT CCA \\
PS-PLA1 antisense & ATC CAA GCG CTC TTC CAC ACT \\
S100A11 sense & AGT CCC TGA TTG CTG TCT TCC A \\
S100A11 antisense & TCC AGT TTC TTC ATC ATG CGG \\
EBI3 sense & ATG TCG TAC AAT TGG ATT GGT ATC CG \\
EBI3 antisense & GTA CTG ATT GTC GTC AGC CAC CAG \\
LST1 sense & ATG AGG AAC TTG AGG CAA GTC \\
LST1 antisense & TCT CAG CAA TGC AGG CAT AGT \\
\hline
\end{tabular}

\subsection{Puffer und Lösungen}

Tabelle 2.10: Tris-Puffer 1,5 M

\begin{tabular}{cc}
\hline Chemikalie & Menge \\
\hline Tris-Base & $181,65 \mathrm{~g}$ \\
aqua dest. ad & $1000 \mathrm{ml}$ \\
pH einstellen auf & 6,8 bzw. 8,8 \\
\hline
\end{tabular}

Tabelle 2.12: Phosphate Buffered Saline (PBS)

\begin{tabular}{cc}
\hline Chemikalie & Menge \\
\hline $\mathrm{NaCl}$ & $8 \mathrm{~g}$ \\
$\mathrm{KCl}$ & $0,2 \mathrm{~g}$ \\
$\mathrm{Na}_{2} \mathrm{HPO}_{4} * 2 \mathrm{H}_{2} \mathrm{O}$ & $1,44 \mathrm{~g}$ \\
$\mathrm{KH}_{2} \mathrm{PO}_{4}$ & $0,24 \mathrm{~g}$ \\
aqua dest. ad & $1000 \mathrm{ml}$ \\
\hline
\end{tabular}

Tabelle 2.11: Tris-Acetat-EDTAPuffer

\begin{tabular}{cc}
\hline Chemikalie & Menge \\
\hline Tris-Base & $242 \mathrm{~g}$ \\
Essigsäure & $57,1 \mathrm{ml}$ \\
0,5 M EDTA pH 8,0 & $100 \mathrm{ml}$ \\
aqua dest. ad & $1000 \mathrm{ml}$ \\
\hline
\end{tabular}

Tabelle 2.13: 4 \%ige (w/v) Paraformaldehydlösung

\begin{tabular}{cc}
\hline Chemikalie & Menge \\
\hline Paraformaldehyd & $4 \mathrm{~g}$ \\
$\mathrm{PBS}-\mathrm{Ca} / \mathrm{Mg}$ & ad $100 \mathrm{ml}$ \\
\hline
\end{tabular}


Tabelle 2.14: RNA-Ladepuffer

\begin{tabular}{cc}
\hline Chemikalie & Menge \\
\hline Formamid & $0,72 \mathrm{ml}$ \\
$50 x T A E$ & $60 \mu \mathrm{l}$ \\
Formaldehyd $37 \%(\mathrm{v} / \mathrm{v})$ & $260 \mu \mathrm{l}$ \\
Glycerin & $100 \mu \mathrm{l}$ \\
Bromphenolblau & $100 \mu \mathrm{g}$ \\
aqua dest. & $360 \mu \mathrm{l}$ \\
\hline
\end{tabular}

Tabelle 2.16: DNA-Ladepuffer

\begin{tabular}{cc}
\hline Chemikalie & Menge \\
\hline Glycerin & $50 \%(\mathrm{v} / \mathrm{v})$ \\
SDS & $0,2 \%(\mathrm{w} / \mathrm{v})$ \\
Bromphenolblau & $0,05 \%(\mathrm{w} / \mathrm{v})$ \\
Xylencyanol & $0,05 \%(\mathrm{w} / \mathrm{v})$ \\
1x TAE - Puffer & ad $100 \%$ \\
\hline
\end{tabular}

Tabelle 2.15: RIPA-Lysepuffer

\begin{tabular}{cc}
\hline Chemikalie & Konz. \\
\hline Tris HCl $(\mathrm{pH} 7,6)$ & $50 \mathrm{mM}$ \\
EDTA $(\mathrm{pH} 8,0)$ & $1 \mathrm{mM}$ \\
$\mathrm{NaCl}$ & $150 \mathrm{mM}$ \\
SDS & $0,1 \%(\mathrm{w} / \mathrm{v})$ \\
Natrium Deoxycholat & $0,25 \%(\mathrm{w} / \mathrm{v})$ \\
NP-40 & $1 \%(\mathrm{w} / \mathrm{v})$ \\
\hline
\end{tabular}




\section{Methoden}

\subsection{Zellbiologische Methoden}

\subsubsection{Isolation von humanen intestinalen mikrovaskulären Endothelzellen (HIMEC)}

Prinzip Zur organspezifischen Untersuchung des Darmendothels in vitro werden Endothelzellen aus Operationsresektaten isoliert und als sog. Primärkultur kultiviert. Bedingt durch den Alterungsprozeß haben Primärkulturen im Gegensatz zu immortalisierten Zellinien eine begrenzte Lebensdauer von ca. sechs bis zehn Passagen.

Bei der Isolation von HIMEC werden in mehreren Waschschritten die hohen Keimzahlen der Darmflora reduziert, das Epithel abgelöst und anschließend ein Kollagenaseverdau durchgeführt. Durch mechanische Kompression der Darmstücke wird versucht, kleine Verbände von Endothelzellen (sog. cluster) aus dem Gewebe zu lösen. Nach Abfilterung sowohl der groben Darmzellreste als auch einzelner Zellen und Zelltrümmer werden kleine Mengen an Endothelzellen auf Zellkulturplatten ausgesäht. Nach sieben bis zehn Tagen können auf den Zellkulturplatten Primärkulturen mechanisch isoliert und kultiviert werden.

\section{benötigtes Material}

- Mukosaresektat aus Kolon (ca. 2x2 cm)

- Hanks Balanced Salt Solution (HBSS)

- Cleland's Reagenz (DTT)

- 10 mM EDTA (w/v) Lösung (pH 7,4) in HBSS 
- Collagenase Typ 2

- Endothelzellmedium für HIMEC

- Mikrofilter $20 \mu \mathrm{m}$ (Fa. Sefar, Neuenburg am Rhein) und $70 \mu \mathrm{m}$ Porengrösse ( $70 \mu \mathrm{m}$ cell strainer, Fa. Becton Dickinson Labware, Franklin Lakes, NJ, USA)

- 100 mm Zellkulturschalen (Fa. Nalge Nunc, Naperville, IL, USA) mit Kollagenbeschichtung (siehe hierfür Abschnitt 3.1.2, Seite 24)

- sterile Klonierringe aus Glas (7 mm) mit Silikonfett (Fa. Sigma, Deisenhofen)

- Zellkulturschaber

\section{Protokoll}

1. Colonresektat trockentupfen, mit der Präparationsschere drei bis vier keilförmige Streifen aus Mukosa und Submukosa, aber ohne Muskulaturanteile herausschneiden. An der Unterseite der Streifen sollten feine Gefäße zu erkennen sein (siehe Abbildung $3.1)$
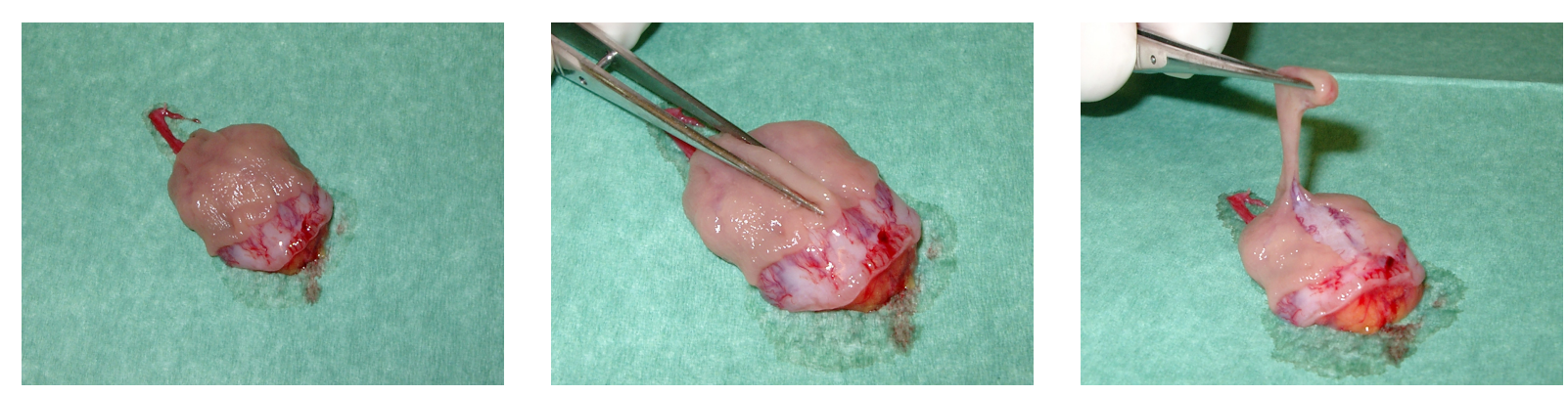

Abbildung 3.1: Präparation eines frischen Colonresektates zur Isolation von HIMEC: Ein keilförmiger Streifen Mukosa / Submukosa ohne Muscularis wird ausgeschnitten, auf der Unterseite des Streifens sind Mikrogefäße zu erkennen

2. Mukosastreifen in 0,15 \% iger (w/v) DTT-Lösung (Herstellung: 75 mg Clelands Reagenz in $50 \mathrm{ml}$ HBSS) 30 Min. bei $60 \mathrm{rpm}$ waschen

3. dreimaliges Waschen (jeweils $30 \mathrm{Min}$ ) in $80 \mathrm{ml} 1 \mathrm{mM}$ EDTA-Lösung (Herstellung:100 ml 10 mM EDTA Lösung in $900 \mathrm{ml}$ HBSS) in jeweils neuem Becherglas bei $60 \mathrm{rpm}$ 
4. Von jetzt an Arbeit unter Sterilbank. Zerteilen der Mukosastreifen (MS) mit Skalpell in ca. 3 x $3 \mathrm{~mm}$ große Quadrate, Verdau für 15 Min. bei $37^{\circ} \mathrm{C}$ (Verdaulösung: 0,2 \%ige (w/v) Collagenaselösung; Herstellung: $40 \mathrm{mg}$ Collagenase II in $20 \mathrm{ml}$ PBS ohne $\mathrm{Ca} / \mathrm{Mg}$, Konzentration $150 \mathrm{U} / \mathrm{ml}$ )

5. Überführen der MS in ca. $5 \mathrm{ml}$ Zellkulturmedium in eine Zellkulturschale (100 mm), Kompression der Präparate mit der flachen Seite eines Fig. 22 Skalpells (Fa. Feather, Tokyo, Japan)

6. Filtration durch $70 \mu \mathrm{m}$ cell strainer, Filtrat zentrifugieren (5 Min., $370 \mathrm{~g}$ )

7. Überstand absaugen, Zellpellet in $10 \mathrm{ml}$ Medium resuspendieren, Filtration durch $20 \mu \mathrm{M}$ Filter, Filtrat verwerfen, Überstand in $10 \mathrm{ml}$ neuem Medium aufnehmen, Zentrifugation (5 Min., $370 \mathrm{~g}$ )

8. Überstand verwerfen, Pellet in $30 \mathrm{ml}$ Endothelzellmedium aufnehmen und auf drei $100 \mathrm{~mm}$ kollagenbeschichtete (siehe hierzu Abschnitt 3.1.2, Seite 24) Zellkulturschalen aussähen

9. Nach etwa drei bis sieben Tagen können unter dem Lichtmikroskop Primärkulturen von Endothelzellen beobachtet werden. Mit einem Zellkulturschaber wird die Umgebung einer Kultur von anderen Zellarten freizuhalten, um eine Kontamination der jungen Kultur zu vermeiden (siehe hierzu Abbildung 3.2)

Abbildung 3.2: HIMEC-Primärkultur. Aufnahme mittels PhasenkontrastMikroskopie, Vergrößerung: 100fach

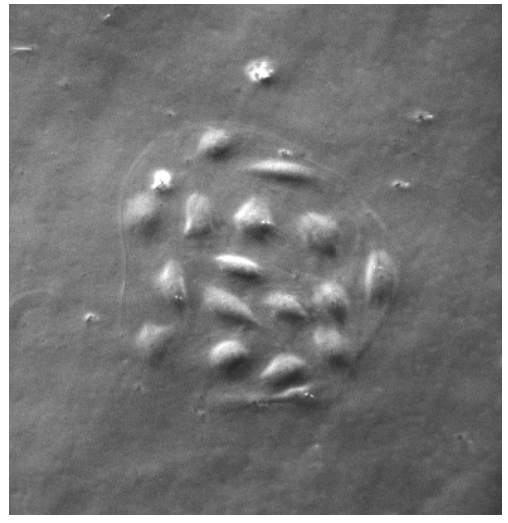

10. Nach Erreichen einer Größe von 6 - $8 \mathrm{~mm}$ im Durchmesser wird die Kultur mittels Klonierring selektiv trypsinisiert und ausgedehnt (wie in Abschnitt 3.1.2, Seite 24 beschrieben). 


\subsubsection{Kultivierung der Zellen}

HIMEC-Primärkulturen wachsen für maximal acht Passagen in Endothelzellmedium mit Zusätzen gemäß Herstellerangaben und $10 \%$ Rinderserum, sie werden bei $37^{\circ} \mathrm{C}, 5 \% \mathrm{CO}_{2}$ im Brutschrank auf kollagenbeschichteten Kunststoffkulturflaschen kultiviert. Die Kollagenbeschichtung der Kunststoffoberflächen erfolgt durch Beschichten mit einer 0,75 \%igen Lösung Kollagen Typ II in PBS + Ca/Mg für mindestens 15 Minuten bei RT. Für Versuche wurden Endothelzellen zwischen Passage vier und acht verwendet.

Bei Konfluenz der kultivierten HIMEC müssen diese passagiert, also auf eine größere Wachstumsfläche ausgedehnt werden. Nach Absaugen des Mediums wird der Zellmonolayer einmal mit $\mathrm{Ca} / \mathrm{Mg}$-freien PBS gewaschen und mit Trypsin/EDTA Lösung überschichtet. Das Ablösen der Zellen kann unter dem Lichtmikroskop beobachtet und durch leichtes Klopfen auf die Zellkulturflasche beschleunigt werden. Bei erfolgter vollständiger Ablösung der HIMEC von der Kunststoffoberfläche wird die Trypsinreaktion durch Zugabe von Endothelzellmedium gestoppt und die Zellsuspension für 5 Min. bei $370 \mathrm{~g}$ und RT zentrifugiert. Nach Absaugen des Überstandes erfolgt die Resuspendierung des Zellpelletts in frischem Endothelzellmedium, je nach Dichte der Primärkultur erfolgt eine Ausdehnung der HIMEC um den Faktor zwei bis drei. Das Zellkulturmedium muß alle zwei bis drei Tage durch frisches Medium ersetzt werden.

Die immortalisierte humane mikrovaskuläre Endothelzellinie HMEC-1 (Fr. Dr. Viemann, Inst. für experimentelle Dermatologie) wurde bei identischen Zellkulturbedingungen kultiviert (s.o.).

\subsubsection{Stimulation der Zellen}

Zur Stimulation der HIMEC wurde im Rahmen dieser Arbeit rekombinanter Tumor Nekrose Faktor- $\alpha$ (TNF- $\alpha$, Fa. Calbiochem, La Jolla, CA, USA) verwendet. Zur Stimulierung vor RNA-Isolierung wurden die Primärkulturen mit $20 \mathrm{ng} / \mathrm{ml}$ TNF- $\alpha$ für 4 sowie 24 Stunden inkubiert, für proteomische Experimente 4 oder 12 sowie 24 Stunden.

Vor der Stimulation wurde den Zellen für 16 Stunden das serum- und wachstumsfaktorreiche Endothelzellmedium entzogen. Es wurden lediglich $1 \%$ Rinderserum und 2,5\% Antibiotika-Fungizid-Lösung (PSF, Fa. Sigma, Deisenhofen) zugegeben. Dieses Vorgehen stellt sicher, daß alle Endothelzellen nur basale Proliferationsraten ausweisen [48].

Bei den PCR-Validierungsuntersuchungen wurden die HIMEC neben dem Zytokin TNF$\alpha(20 \mathrm{ng} / \mathrm{ml})$ auch mit den proinflammatorischen Agenzien Interleukin-1 $\beta$ (40 ng/ml, Fa. Promega, Mannheim), Interferon- $\gamma$ (20 ng/ml,Fa. Promega), bakteriellem Lipopolysac- 
charid (LPS, $1 \mu \mathrm{g} / \mathrm{ml}$, Fa. Sigma, Deisenhofen) sowie der Kombination TNF- $\alpha+$ LPS stimuliert.

\subsection{Molekularbiologische Methoden}

\subsubsection{Isolierung von Gesamt-RNA}

Die Isolation von Gesamt-RNA aus HIMEC-Primärkulturen und der Kontrollzellinie HMEC erfolgte für die anschließende Analyse mit DNA-Microarrays mittels des RNeasy Kits (Fa. Qiagen, Hilden), für die Polymerase Kettenreaktion mit der TRIzol-Methode (Fa. Invitrogen) jeweils entsprechend den Anweisungen der Hersteller.

\section{Photometrische Quantifizierung der RNA}

Zur Quantifizierung der RNA wurde $1 \mu \mathrm{l}$ der RNA-Lösung mit $49 \mu \mathrm{l}$ DEPC-Wasser verdünnt, diese Probe wurde im Photometer (Fa. Eppendorf) bei 260 und $280 \mathrm{~nm}$ gegen einen Leerwert (nur DEPC-Wasser) gemessen. Bei 260 nm (Absorptionsmaximum der Nukleotide) ermittelt man die Konzentration von Nukleinsäuren, bei $280 \mathrm{~nm}$ die Konzentration von Proteinen (d.h. Kontaminationen). Eine reine RNA-Lösung hat einen Quotienten von $\mathrm{OD}_{260} / \mathrm{OD}_{280}=2,0$ [151]. Die Konzentration an RNA wurde nach der folgenden Formel ermittelt:

$$
\mathrm{c}[\mathrm{mg} / \mathrm{ml}]=\mathrm{OD}_{260} \times \text { Verdünnung } \mathrm{x} \text { Multiplikationsfaktor (für RNA: 40) }
$$

Für die Analyse der RNA auf Microarrays ist eine Mindestmenge von $10 \mu \mathrm{g}$ RNA / Probe sowie eine Probenkonzentration von mind. $1 \mu \mathrm{g}$ RNA / $\mu$ l Probe erforderlich, bei der Polymerase Kettenreaktion genügt eine Menge von ca. $2 \mu \mathrm{g}$ RNA für eine cDNA-Analyse.

\section{Qualitätskontrolle der RNA-Präparation für DNA-Microarrays}

Zur Qualitätskontrolle der RNA-Präparation wurden $5 \mu \mathrm{g}$ der gewonnenen RNA mit $5 \mu \mathrm{l}$ RNA-Ladepuffer auf ein konventionelles 0,8\%iges Agarosegel aufgetragen (zur allgemeinen Durchführung der Agarosegelelektrophorese siehe dort: Abschnitt 3.2.2, Seite 29).

Nach Elektrophorese bei $70 \mathrm{~V}$ und Färbung mit dem interkalierenden Farbstoff Ethidiumbromid konnten die RNA-Banden unter UV-Licht visualisiert und photographiert werden. Zwei komplett separierte Banden ohne Schlieren für die 18S und die 28S RNA zeigten eine intakte Präparation an. 


\subsubsection{Reverse Transkriptase - Polymerase Kettenreaktion (RT-PCR)}

\section{cDNA Erststrangsynthese aus RNA mit der reversen Transkriptase}

Prinzip Vor der Polymerase Kettenreaktion wird aus der Gesamt-RNA der HIMECPrimärkultur mittels reverser Transkriptase cDNA (complementary DNA) hergestellt. Bei den dieser Arbeit zugrunde liegenden Versuchen wurde eine modifizierte Version der reversen Transkriptase des Moloney murine leukemia virus (MMLV-RT) der Firma Invitrogen verwendet, die im Unterschied zur nativen MMLV-RT keine intrinsische RNase H Aktivität mehr besitzt und dadurch deutlich längere Transkripte ermöglicht [47]. Zur cDNA-Synthese werden durch kurzes Erhitzen der RNA mit einem Primer (hier: Oligo dT Primer aus 16 - 20 Thymidinen, die an den Poly-A ${ }^{+}$-Schwanz der mRNAs binden) auf $70^{\circ} \mathrm{C}$ die Sekundärstrukturen der RNA aufgeschmolzen und ein Hybridisieren der Primer während der darauf folgenden Abkühlphase ermöglicht, darauf gibt man die RT, den Reaktionspuffer sowie Nukleotide im Überschuss hinzu und inkubiert bei $42^{\circ} \mathrm{C}$, dem Arbeitsoptimum der MMLV-RT. Vor der Reaktion kann optional, wie bei unseren Versuchen, eine Hydrolyse eventuell vorhandener DNA-Reste erfolgen.

\section{benötigtes Material}

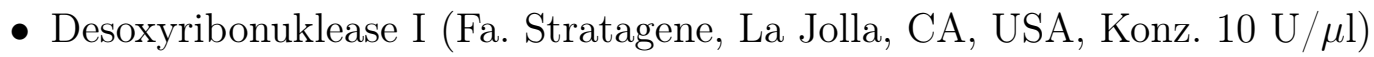

- 10x PCR-Puffer (Fa. Invitogen)

- $25 \mathrm{mM}$ EDTA-Lsg.

- Oligo dT-Primer

- $10 \mathrm{mM}$ dNTPs (Konz. 0,5 $\mu \mathrm{g} / \mu \mathrm{l}$ )

- $50 \mathrm{mM} \mathrm{MgCl}_{2}$-Lsg.

- 0,1 mM DTT-Lsg.

- Aqua ad. inj.

- Superscript II MMLV Reverse Transkriptase (Fa. Invitrogen, Konz. $200 \mathrm{U} / \mu \mathrm{l}$ )

Die Reagenzien wurden als Teil des Superscript First-Strand Synthesis System for RT$P C R$ von der Firma Invitrogen erworben. 


\section{Protokoll}

1. $2 \mu \mathrm{g}$ RNA $+8 \mu \mathrm{l}$ DEPC Wasser

2. je $1 \mu \mathrm{l}$ 10x PCR-Puffer und DNAse hinzupipettieren, für 15 Min. bei RT inkubieren

3. $1 \mu \mathrm{l} 25 \mu \mathrm{M}$ EDTA hinzugeben, $10 \mathrm{Min}$. bei $65^{\circ} \mathrm{C}$ inkubieren

4. $1 \mu \mathrm{l}$ Oligo dT Primer hinzupipettieren, Inkubation 5 Min. bei $65^{\circ} \mathrm{C}$, dann $1 \mathrm{Min}$. auf Eis abkühlen

5. Zum Reaktionsansatz folgende Komponenten hinzufügen:

- $2 \mu \mathrm{l}$ 10x PCR-Puffer

- $1 \mu \mathrm{l} 10 \mathrm{mM}$ dNTPs

- $1 \mu \mathrm{l} 50 \mathrm{mM} \mathrm{MgCl} 2$

- $2 \mu \mathrm{l} 0,1 \mathrm{mM}$ DTT

- $1 \mu \mathrm{l}$ DEPC Wasser

6. Inkubation des Reaktionsgemisches bei $42^{\circ} \mathrm{C}$ für $2 \mathrm{Min}$.

7. $1 \mu \mathrm{l}$ (200 units) der Superscript Reversen Transkriptase hinzufügen, Inkubation bei $42^{\circ} \mathrm{C}$ für 50 Min., danach bei $70^{\circ} \mathrm{C}$ für 15 Min., danach Abkühlen auf Eis

\section{Polymerase Kettenreaktion}

Prinzip Die Polymerase Kettenreaktion (polymerase chain reaction, $P C R$ ) wurde erstmals von SAIKI et al. beschrieben, ein Verfahren, um mittels einer thermostabilen DNAPolymerase und zweier spezifischer Oligonukleotidprimer bestimmte Zielsequenzen exponentiell zu amplifizieren und somit einen qualitativen Nachweis dieses speziellen Produktes zu ermöglichen [148].

Die PCR-Reaktion erfolgt temperaturgesteuert in einem thermocycler in Zyklen von drei verschiedenen Reaktionszuständen:

1. Denaturierung der doppelsträngigen DNA bei $94^{\circ} \mathrm{C}$

2. Senkung der Temperatur auf $55^{\circ} \mathrm{C}$, Anlagern der spezifischen Oligonukleotidprimer (Annealing) 
3. DNA-Strangsynthese durch Anlagern komplementärer Basen (Elongation) bei $72^{\circ} \mathrm{C}$.

Durch Festlegung verschiedener Zyklenzahlen für verschiedene zu untersuchende Gene kann die Menge der entstehenden DNA innerhalb der für die Analyse geeigneten Grenzen gehalten werden.

Durch Vergleich eines aus derselben DNA-Probe herausamplifizierten housekeeping ge$n e$, also eines konstitutiv in Zellen produzierten Gens wie GAPDH oder $\beta$-Aktin mit dem $\mathrm{zu}$ untersuchenden amplifizierten Fragment in der Agarosegelelektrophorese (Abschnitt 3.2.2, Seite 29) kann bei mehreren verschiedenen DNA-Proben eine semiquantitative Aussage zur Expression des jeweiligen untersuchten Gens gemacht werden. Diese Methode wird als die semiquantitative (RT)-PCR bezeichnet.

\section{Benötigtes Material}

- cDNA-Probe

- Thermocycler TRIO Thermoblock (Fa. Biometra, Göttingen)

- Oligonukleotidprimer (für die Sequenz siehe Abschnitt 2.5, Seite 18)

- $50 \mathrm{mM}$ dNTP-Lsg.

- $10 \mathrm{mM} \mathrm{MgCl}{ }_{2}$-Lsg.

- Taq Polymerase (Fa. Invitrogen, $5 \mathrm{U} / \mu \mathrm{l}$ )

- 10x PCR Puffer (Fa. Invitrogen)

- DEPC Wasser

\section{Protokoll}

1. In ein $0,2 \mathrm{ml}$ Reaktionsgefäß pipettieren:

- $1 \mu \mathrm{l}$ cDNA

- je $1 \mu \mathrm{l}$ sense und antisense Primer (25 pmol/Ansatz)

- $1 \mu \mathrm{l}$ dNTPs

- $1 \mu \mathrm{l} \mathrm{MgCl}_{2}$

- $0,5 \mu \mathrm{l}$ Taq-Polymerase (2,5 units/Ansatz) 
- $2,5 \mu \mathrm{l} 10$ x PCR Puffer

- $17 \mu \mathrm{l}$ DEPC Wasser

2. Initialer Denaturierungsschritt bei $95^{\circ} \mathrm{C}$ für drei Minuten

3. für VCAM-1 30 Zyklen, für $\beta$-Aktin (als „housekeeping gene“) 25 Zyklen:

- Denaturierung $1 \mathrm{Min}$. bei $95^{\circ} \mathrm{C}$

- Annealing $1 \mathrm{Min}$. bei $65^{\circ} \mathrm{C}$

- Elongation $1 \mathrm{Min}$. bei $72^{\circ} \mathrm{C}$

4. Zum Sicherstellen einer komplett verlaufenden Elongation ein zusätzlich einmalig auf 10 Minuten verlängerter Elongationsschritt bei $72^{\circ} \mathrm{C}$

Die bei der PCR entstandenen Amplifikate können bei $4^{\circ} \mathrm{C}$ gelagert werden. Zur Analyse werden sie auf ein Agarosegel aufgetragen (siehe Abschnitt 3.2.2,Seite 29).

\section{Agarosegelelektrophorese}

Prinzip Zur elektrophoretischen Auftrennung von DNA wurden Gele mit einer Agarosekonzentration von $2 \%$ verwendet. Unter Elektrophoresebedingungen liegen die Nucleotide der Nukleinsäure als Polyanion vor. Die DNA bewegt sich entsprechend ihrer Größe im elektrischen Feld von der Kathode zur Anode.

Nach Abschluss der Elektrophorese kann die DNA im Gel durch den mit der Doppelhelix interkalierenden Farbstoff Ethidiumbromid angefärbt und so im UV-Licht visualisiert und dokumentiert werden.

\section{benötigtes Material}

- Agarose

- 1x TAE Puffer (hergestellt durch Verdünnung mit aqua dest. aus 50x TAE Puffer, siehe Abschnitt 2.11, Seite 19)

- DNA - Längenstandard „100 bp Ladder“ (Fa. Invitrogen, Paisley, GB)

- Probenauftragspuffer (siehe Abschnitt 2.16, Seite 20)

- horizontale Gelelektrophoreseapparatur und Transformator 


\section{Protokoll}

1. $1 \mathrm{~g}$ Agarose in $50 \mathrm{ml} 1 \mathrm{x}$ TAE - Puffer suspendieren, das Gemisch in einem Mikrowellengerät aufkochen, daraufhin auf $60^{\circ} \mathrm{C}$ abkühlen lassen

2. Gelkamm an der Kathodenseite einsetzen (ca. $10 \mathrm{~mm}$ vom Gelrand entfernt)

3. Agarose - Lösung blasenfrei in die Gelkammer gießen, bei RT abkühlen lassen

4. Nach 30 - 60 Min. Gelkamm vorsichtig aus dem festen Gel ziehen

5. Gel in die Elektrophoreseapparatur einsetzen, mit 1x TAE - Puffer überschichten

6. Auf einer Mikrotiterplatte jeweils $10 \mu \mathrm{l}$ DNA - Probe mit $2 \mu \mathrm{l}$ DNA - Probenpuffer mischen, das Gemisch in die Geltaschen pipettieren

7. Elektrophorese starten (z.B. 60 Min. bei 90 V)

8. Nach beendigtem Lauf Färben des Gels durch 15 minutiges Inkubieren in Ethidiumbromid - Färbelösung (Konz. $50 \mu \mathrm{g} / \mathrm{ml}$ )

9. Gel in einem Transilluminator (Fa. -ltf- Labortechnik, Wasserburg/Bodensee) in UV - Licht (366 nm Wellenlänge) zur Dokumentation photographieren

\subsubsection{Quantitative Echtzeit Polymerase Kettenreaktion (Realtime quantitative $R T-P C R$ )}

Prinzip Zur quantitativen Bestimmung der DNA wird ein mit der DNA-Doppelhelix interkalierender Farbstoff verwendet (zuerst Ethidiumbromid [63], heute SYBR Green I ${ }^{\mathrm{TM}}$ (Fa. Molecular Probes, Eugene, OR, USA)). Aus der Fluoreszenz unter UV-Licht kann während der Reaktion die Menge doppelsträngiger DNA bestimmt werden. Da die Amplifikation der template-DNA nur während der ersten Reaktionszyklen exponentiell verläuft - später wird die Reaktion durch Produktanhäufung und Verknappung von Primern und Nukleotiden gehemmt - erfolgt eine Bestimmung des $\mathrm{C}_{\mathrm{T}^{-}}$Wertes einer Reaktion durch Auftragen der Fluoreszenzkurve mit logarithmischem Maßstab. Der $\mathrm{C}_{\mathrm{T}}$-Wert liegt im Bereich der exponentiellen Amplifikation (im geraden Bereich der Kurve). Dieser Wert wird gegen den Logarithmus der anfänglich eingesetzen DNA-Menge aufgetragen. Hieraus folgt eine Standardkurve, die es ermöglicht, aus den $\mathrm{C}_{\mathrm{T}}$-Werten der Versuchsansätze die jeweils 
ursprünglich vorhandene Menge an zu amplifizierender DNA zu bestimmen. Durch Mitamplifikation eines housekeeping genes wie $\beta$-Aktin und anschließender Verrechnung der bestimmten DNA-Mengen mit denen aus den Versuchsansätzen ist eine Normalisierung der verschiedenen Ansätze möglich. Bei den der vorliegenden Arbeit wurde die Realtime PCR zur Kontrolle der Ergebnisse der RNA Analyse mittels der DNA-Microarrays (siehe Abschnitt 3.2.4, Seite 31) verwendet.

\section{Benötigtes Material}

- Realtime-PCR Maschine ABI Prism 7000 Sequence Detection System (Fa. Applied Biosystems, Foster City, CA, USA) und 96-Well Platten (Fa. Applied Biosystems)

- Oligonukleotidprimer (Konz. 25 pmol)

- SYBR Green Mastermix (Fa. Applied Biosystems, mit DNA-Polymerase, Puffer, Fluoreszenzfarbstoff, Magnesium)

- Aqua ad inj.

- Template DNA

Protokoll Pro Ansatz (96-well Platte):

- $1 \mu \mathrm{l}$ Template

- $30 \mu \mathrm{l}$ Mastermix

- 26,6 $\mu \mathrm{l}$ DEPC - Wasser

- jeweils 1,2 $\mu$ l sense und antisense Primer (entspricht $30 \mathrm{pmol} /$ Ansatz)

Die Reaktion und Auswertung erfolgt nach Anweisung des Herstellers Applied Biosystems.

\subsubsection{Expressionsanalyse mittels High-Density Oligonucleotide Arrays}

Um eine Genexpressionsanalyse der HIMEC im genomischen Maßstab durchzuführen, wurden bei den der vorliegenden Arbeit High-Density Oligonucleotide Arrays [95] (im folgenden auch synonym Microarray genannt) der Firma Affymetrix (Santa Clara, CA, USA) verwendet. 
Die Genexpressionsanalyse auf Microarrays beruht auf dem Prinzip eines umgekehrten Northern Blots [43]. Auf einer festen Matrix werden für das einzelne Gen spezifische Sequenzen (Sonde, engl. probe) immobilisiert. Markierte und in kleine Oligonukleotide fragmentierte RNA des Versuchsansatzes (Probe, engl. sample) hybridisiert mit diesen Sonden. Bei der Analyse geht man von einem linearen Zusammenhang von Genexpression in den zu untersuchenden Zellen, der Menge der im Versuchsansatz vorhandenen markierten RNA, der an die Sonde hybridisierten Probe und des zu detektierenden Signals aus. Allerdings gilt es bei dieser effizienten Technik zu beachten, daß so nur relative Transkriptionsniveaus bestimmt werden können, nicht aber die absoluten Mengen an RNA eines Gens.

Bei den hier verwendeten Microarrays des Typs Affymetrix HG-U133A wurden mittels Photolithographie 22.308 Sonden für die Detektion von 13.220 bekannten Genen vom Hersteller in situ auf dem Chip synthetisiert. Schrittweise werden die Oligonukleotidsonden, deren Sequenzen der UniGene Database (Build 133, 20.04.2001) sowie der Washington University EST Trace Repository und University of California, Santa Cruz - Path Human Genome Database entstammen, an der jeweils definierten Position auf dem Chip aufgebaut. Dabei werden auf einer Fläche von $20 \times 20 \mu \mathrm{m}$ jeweils etwa $1 \mathrm{x} 10^{6}$ bis $1 \mathrm{x}$ $10^{7}$ Kopien eines entsprechenden Oligonukleotids aufgebracht [157]. Die Länge der Oligonukleotide beim Affymetrix-System ist aus produktionstechnischen Gründen auf 25 Basenpaare begrenzt. Diese Sondenlänge hat gegenüber Microarrays anderer Hersteller, die z.T. mit 1 bis $2 \mathrm{kB}$ langen Sonden arbeiten, den Vorteil, daß sich Kreuzhybridisierungen vermeiden lassen [51]. Dieses verfahren hat allerdings den Nachteil, daß mit einer Sonde dieser Länge keine hochspezifische Hybridisierung möglich ist. Dieser Nachteil wird dadurch ausgeglichen, daß für jedes zu detektierende Gen mehrere verschiedene Sonden auf dem Chip verwendet werden, die sich nach Möglichkeit nicht überlappen sollten. Zu jeder Sonde (perfect match probe, PM) existiert eine Kontrollsonde (mismatch probe, $M M$ ), bei der die 13. Base des Oligonukleotids ausgetauscht ist. So kann der unspezifische Hintergrund (Fehlhybridisierungen oder Hintergrundrauschen) ermittelt und vom spezifischen Signal einer Probe abgezogen werden.

Zur Durchführung der Experimente mit den Affymetrix DNA-Microarrays wird das Gene Chip Instrument System verwendet [1]. Dieses wurde für diese Arbeit in der Servicestelle Integrierte Funktionelle Genomik, IFG des Interdisziplinären Zentrums für Klinische Forschung der medizinischen Fakultät der WWU Münster zur Verfügung gestellt. Dort erfolgte die standardisierte Aufbereitung und Hybridisierung unserer Versuchsansätze nach Anweisung des Herstellers [1]. Nach Quantifizierung der isolierten Gesamt-RNA wird mit 
einer Reversen Transkriptase ein komplementärer DNA-Strang erstellt (hierzu siehe auch Abschnitt 3.2.2, Seite 26). Dieser cDNA-Strang wird in der darauf folgenden Zweit-StrangSynthesereaktion zu einem DNA-Doppelstrang umgebaut, wobei der vorhandene RNAStrang abgebaut wird. Diese DNA wird bei der folgenden in vitro-Transkription (IVT, [43]) umgeschrieben. Um die entstehende RNA zu markieren, verwendet man bei dieser Synthese biotinylierte Nukleotide. Bei den vorangegangenen Reaktionen erfolgte die Umschreibung der Stränge immer im Verhältnis 1:1, bei der IVT erfolgt eine lineare Amplifikation um den Faktor 30 bis 100. Die Linearität ist Voraussetzung für die Aussagefähigkeit des Verfahrens über die Expressionslevel der einzelnen Gene [95].

Nach Aufreinigung der synthetisierten RNA wird diese in Fragmente der Größe 35 200 Basenpaare zerlegt. So kann eine exakte Hybridisierung an die Sonden gewährleistet werden. Darauf erfolgt die 16-stündige Hybridisierung der biotinylierten RNA-Fragmente an die Microarrays. Nach Waschschritten können die an die Sonden hybridisierten Proben mit Streptavidin-Phycoerythrin (SAPE) detektiert werden. Gegebenenfalls kann eine zweite Färbung mit Antikörperverstärkung (mit biotinyliertem anti-Streptavidin-AK und nochmaligem Färben mit SAPE) zur Intensivierung der Signale durchgeführt werden. Die Detektion der hybridisierten Fragmente erfolgt mittels eines konfokalen Laserscanners (Gene Array Scanner, Fa. Hewlett Packard, Palo Alto, CA, USA). Die an die markierten und hybridisierten Oligonukleotide gebundenen Chromophore werden bei einer Wellenlänge von $488 \mathrm{~nm}$ angeregt und die Emission bei $570 \mathrm{~nm}$ gemessen. Die Auflösung des Scanners beträgt $3 \mu \mathrm{m}$, die Messung wird doppelt durchgeführt und die Lichtintensität aus beiden Messungen gemittelt. Darauf erfolgt die Speicherung eines gescannten Bildes des Microarrays mit einer Farbtiefe von 16 Bit.

Die Software der Firma Affymetrix (MicroArray Suite 5.0 (MAS)) erstellt aus den Rohdaten eine Liste aller auf dem Microarray vorhandenen Gene sowie der entsprechenden Signale. Es wird außerdem eine Aussage darüber getroffen, ob das entsprechende Gen exprimiert wird (anwesend, engl. present - $p$ ), abwesend ist (engl. absent - a) oder grenzwertig (engl. marginal - m) erkannt wird. Um Fehler durch unspezifische Bindungen oder die systembedingten Ungenauigkeiten bei niedrigen Signalstärken für ein einzelnes Gen zu vermeiden, werden Meßwerte, bei denen kein signifikanter Unterschied zwischen den perfect match probes und der mismatch probe besteht, durch das Programm entfernt.

Bei den der vorliegenden Arbeit zugrunde liegenden Versuchen wurde die Genexpression von HIMEC nach Stimulation mit TNF- $\alpha$ über 4 und 24 Stunden mit dem Expressionsprofil von nicht stimulierten HIMEC verglichen (siehe auch Abschnitt 3.1.3, Seite 24). Diese Versuche wurden dreimal mit verschiedenen Primärzellkulturen durchgeführt. 
Die Auswertung der aufgearbeiteten Rohdaten erfolgt mit dem Programmpaket Expressionist Suite der Firma Gene Data (Martinsried). Dieses Paket erlaubt im Gegensatz zur MAS eine weitgehende statistische Analyse der Meßdaten. Mit Programm Expressionist Refiner (Version 3.0.4) erfolgte eine Qualitätskontrolle des gesamten Arrays mit Korrektur des Fluoreszenzgradienten, Entfernung von offensichtlichen Fehlern z.B. durch Kratzer auf dem Chip sowie eine Regulation der Varianzen [184]. Die weitere Analyse wurde mit Hilfe des Programms Expressionist Analyst (Version 4.0.5) durchgeführt.

Zunächst erfolgt zum Ausgleich nichtbiologischer Einfluffaktoren auf die Rohdaten (Unterschiede bei der Probenverarbeitung, bei den Hybridisierungsbedingungen, zwischen verschiedenen Produktionschargen desselben Microarraytyps) eine Normalisierung der Meßwerte verschiedener zu vergleichender Experimente. Die Normalisierung ermöglicht den direkten Vergleich verschiedene Experimente auf demselben Chiptyp. Nach Entfernung extremer Ausreißer in der Fluoreszenzaktivität bildet die Software von jedem Microarray einen bereinigten Mittelwert der Leuchtintensität. Dieser wird durch Multiplikation mit einem individuellen Skalierungsfaktor auf eine vom Benutzer einzustellenden Wunschmittelwert aller zu vergleichender Experimente korrigiert. Hier wird angenommen, daß die mittlere Intensität aller Signale des Experiments relativ ähnlich ist. Ein Skalierungsfaktor größer als 5 ist beim direkten Vergleich zweier Microarraydatensätze zu vermeiden. Hier fände eine zu starke Verzerrung der einzelnen Meßwerte statt, womit das Ergebnis verfälscht würde. Bei der vorliegenden Arbeit wurden alle Experimente auf einen Mittelwert von 220 normalisiert.

Um den Unterschied zwischen den jeweils drei Datensätzen für die unstimulierte Kontrolle und der TNF- $\alpha$-Stimulation über 4 bzw. 24 Stunden zu ermitteln, wurden aus diesen Datensätzen Analysegruppen gebildet. Die Analysegruppen wurden nach Meßwerten durchsucht, die eine Expression oberhalb des Hintergrundrauschens anzeigten. Zwischen der Analysegruppe der unstimulierten Kontrollzellen und den beiden stimulierten Gruppen konnte darauf ein Vergleich der Expressionswerte durchgeführt werden. Änderungen des Expressionslevels wurden von der Programmfunktion $n$-fold-change grafisch dargestellt. Bei den der vorliegenden Arbeit zugrunde liegenden Versuchen wurden nur Gene, die mehr als dreifach positiv oder negativ reguliert wurden, beachtet. Zur Untersuchung der statistischen Signifikanz der Expressionsunterschiede wurde ein t-Test nach STUDENT durchgeführt. Nur Gene mit einem p-Wert $<0,05$ wurden als signifikant reguliert in der Analyse belassen.

Weiterhin kam zur Betrachtung der sog. On/Off-Phänomene - also einer durch die Stimulation bedingten An- bzw. Ausschaltung der Expression eines Gens- ein durch VIE- 
MANN et al. publiziertes Auswertungsverfahren für Microarray-Experimente zur Anwendung [184]. Aus den aus drei Einzelexperimenten bestehenden Analysegruppen für die zwei Stimulationszeitpunkte und die unstimulierte Kontrolle wurden Gene mit einem Verhältnis von an- zu abgeschalteten Zellen von 3:0, 0:3, 3:1, 1:3, 2:0 sowie 0:2 und einem p-Wert $<0,05$ als signifikant an- bzw. abgeschaltet betrachtet und in die Analyse mit einbezogen. Das Programm Expressionist Analyst kann für diese an- bzw. abgeschalteten Gene Regulationsfaktoren errechnen. Hierbei wird als Bezugsebene gegenüber dem exprimierten Gen der durchschnittliche Hintergrund gewählt. Das Programm nimmt für das nicht nachweisbare Gen einen Expressionslevel ähnlich der Intensität des Hintergrundrauschens oder darunter an. Aufgrund dieser Tatsache empfiehlt ViEMANn, nur an- bzw. abgeschaltete Gene mit einem errechneten Regulationsfaktor $>5$ in die Analyse aufzunehmen. Weiterhin hält sie die Angabe von Zahlenwerten, die durch den Vergleich einer Signalintensität mit dem Hintergrund errechnet wurden, neben den sehr genauen Werten für die ohne On/Off-Phänomen regulierten Gene nicht für zulässig. Daher werden hier - analog dem publizierten Vorgehen - angeschaltete Gene mit einer errechneten Regulation gegenüber dem Hintergrund von 5-10 mit einem + bezeichnet, bei Faktor $10-25$ mit ++ , bei

Faktor $25-50$ mit +++ sowie bei einem Faktor $>50$ mit ++++ . Bei Ausschaltungen erfolgte die Bezeichnung analog mit - bis - - - -

Zum orientierenden Vergleich mit den ermittelten Expressionsdaten der HIMEC wurden die Experimente mit der mikrovaskulären Referenzzellinie HMEC-1 wiederholt. Aufgrund nur einmaliger Durchführung konnten für die hier gewonnenen Expressionsdaten keine Signifikanzniveaus errechnet werden. Die Auswertung erfolgte analog den HIMECExperimenten.

\subsection{Proteinchemische Methoden}

\subsubsection{Herstellung von Proteinextrakten}

Zur Herstellung von Proteinextrakten erfolgte nach Waschen der kultivierten Zellen mit kaltem $\mathrm{PBS}+\mathrm{Ca} / \mathrm{Mg}$ das Abschaben der Zellen mit einem Zellkulturschaber in einem Überstand aus PBS. Es folgt eine Zentrifugation (5 Min., $\left.4^{\circ} \mathrm{C}, 370 \mathrm{~g}\right)$, das entstandene Zellpellet wurde mit $50 \mu \mathrm{l}$ eiskaltem, modifizierten RIPA-Puffer (siehe Abschnitt 2.15, Seite 20) lysiert. Das Zellysat kann optional durch mehrmaliges Aufziehen durch eine 25 G Kanüle homogenisiert werden.

Die Zellysate können bei $-80^{\circ} \mathrm{C}$ für mehrere Monate gelagert werden. 


\section{Quantifizierung von Proteinen}

Um die extrahierten Proteine zu quantifizieren wurde bei unseren Versuchen die BRADFORDMethode angewandt. Die Absorption der Proben wurde in einem Spektralphotometer (Dynatech MR 5000, Fa. Dynatech, Chantilly, VA, USA) bei einer Wellenlänge von 600nm bestimmt, die Referenzwellenlänge betrug $405 \mathrm{~nm}$. Die jeweilige Proteinkonzentration wurde anhand des eingesetzten BSA-Standards mit Hilfe des Programms BioLinx 2.20 (Fa. Dynatech) berechnet.

\subsubsection{Elektrophoretische Trennung der Proteine durch Natriumdodecylsulfat - Polyacrylamidelektrophorese (SDS-PAGE)}

Prinzip Bei den dieser Arbeit zugrundeliegenden Versuchen wurde die vertikale SDSPAGE im diskontinuierlichen Puffersystem nach LAEMmLi et al. durchgeführt [84].

Bei der SDS-PAGE werden Proteine auf einem Gel aus Polyacrylamid elektrophoretisch entsprechend ihres Molekulargewichtes aufgetrennt. Durch das negativ geladene Detergens Natriumlaurylsulfat (sodium dodecyl sulfate - SDS), das im Gel enthalten ist, werden die Proteine in einem konstanten Ladungs-zu-Masse-Verhältnis separiert. Je nach Vernetzungsgrad des Gels und des Anteils an Polyacrylamid existiert je ein spezifischer Molekulargewichtsbereich, in dem die elektrophoretische Auftrennung der Proteine linear ist. Daher wählt man entsprechend der Größe des zu untersuchenden Proteins diejenige Acrylamid-Konzentration, bei der die lineare Auftrennung im zu untersuchenden Bereich liegt (z.B. für eine Proteingröße von 10 - 60 kDa ein 12 \%iges Gel).

\section{benötigtes Material}

- 30 \%ige Lösung Acrylamid (AA)/ N,N-Methylenbisacrylamidlösung (BAA) (AA/BAA Verhältnis: 19:1)

- Tris - Puffer pH 8,8 (Trenngel); Tris - Puffer pH 6,8 (Sammelgel) Herstellung: Siehe Abschnitt 2.10, Seite 19

- Natriumlaurylsulfat $2 \%$ ige Lösung

- Aqua dest.

- $10 \%$ ige (w/v) Lösung Ammoniumpersulfat (APS): 0,2 g APS ad 2 ml $\mathrm{H}_{2} \mathrm{O}$ 
- $\mathrm{N}, \mathrm{N}, \mathrm{N}^{\natural}, \mathrm{N}^{\natural}$-Tetramethylethylendiamin (TEMED)

- n-Butanol, gesättigte Lösung mit $\mathrm{H}_{2} \mathrm{O}$

- 10x Elektrodenpuffer ( $\mathrm{pH} 8,9)$ :

- 144 g Glycin

- 30 g Tris - Base

$-10 \mathrm{~g}$ SDS

- Aqua dest. ad $1000 \mathrm{ml}$

- 4x Probenpuffer [84]:

- 1,75 ml Tris pH 6,8 (Sammelgelpuffer)

- 1,5 ml Glycerin

$-5 \mathrm{ml} 10 \%(\mathrm{w} / \mathrm{v}) \mathrm{SDS}$

- 0,5 ml $\beta$-Mercaptoethanol

- 1,25 ml Bromphenolblau (gesättigt, in 0,1 \% Ethanol)

- Gelelektrophoreseapparatur vertikal (OWL Systems, Portsmouth, NH, USA) u. Elektrophoresekamm

\section{Protokoll}

1. Trenngelherstellung (12\%):

- 6,0 $\mathrm{ml} \mathrm{AA/BAA}$

- 5,0 ml Tris $\mathrm{pH} 8,8$

- 1,0 ml SDS (10\% (w/v), Herstellung: 10 g SDS ad 100 ml $\mathrm{H}_{2} \mathrm{O}$ )

- $7,7 \mathrm{ml}$ Aqua dest.

2. $100 \mu \mathrm{l} 10 \%$ ige Lsg. APS und $10 \mu \mathrm{l}$ TEMED geben, das flüssige Trenngel mischen und blasenfrei in die Elektrophoresekammer gießen

3. Mit $500 \mu \mathrm{l}$ n-Butanol überschichten, 3 Stunden härten lassen, n-Butanol entfernen

4. Sammelgelherstellung (4\%) analog der Herstellung des Trenngels: 
- $1,0 \mathrm{ml} \mathrm{AA} / \mathrm{BAA}$

- $2,5 \mathrm{ml}$ Tris $\mathrm{pH} 6,8$

- $0,5 \mathrm{ml} \mathrm{SDS}$

- 5,94 ml Aqua dest.

- $50 \mu$ l APS-Lsg. $10 \%$

- $10 \mu \mathrm{l}$ TEMED

5. Sammelgel vorsichtig über das Trenngel schichten, Elektrophoresekamm in Sammelgel einsetzen, 30 - 60 Minuten polymerisieren lassen

6. Zur Vorbereitung der Proteinproben Proteinlysat mit 4x Auftragspuffer im Verhältnis 1:4 mischen, bei $60^{\circ} \mathrm{C}$ für 20 Minuten denaturieren lassen, danach 5 Min. auf Eis abkühlen

7. Zentrifugation der denaturierten Proben (5 Min., $\left.4^{\circ} \mathrm{C}, 1000 \mathrm{~g}\right)$, um unlösliche Bestandteile abzutrennen

8. Elektrophoresekamm entfernen, Taschen mit 1x Elektrodenpuffer spülen, beide Elektrodenkammern der Elektrophoreseapparatur mit Puffer auffüllen

9. Alternativ wurden auch industriell gefertigte Fertiggele gleicher Konzentration (Fa. Biorad, München) verwendet. Diese wurden nach Herstellerangeben verwendet.

10. Proben (Proteinlysate sowie Protein-Längenstandard und evtl. Positivkontrolle) in die entstandenen Geltaschen pipettieren

11. Elektrophoreseprogramm am Spannungsgeber (PowerPac 200, Fa. Biorad) starten (40 mA), Dauer der Elektrophorese bei den hier verwendeten Minigelen ca. 60 Min.

12. Gel aus der Apparatur entnehmen, Immunoblot

\subsection{Immunologische Methoden}

\subsubsection{Immunoblotting}

Prinzip Beim Immunoblotting nach [177] (auch Western Blotting genannt [22]) wird ein Proteingemisch elektrophoretisch getrennt und auf eine Membran übertragen. Die Pro- 
teine werden mittels Antigen-Antikörper-Reaktion spezifisch nachgewiesen und anhand ihrer Laufeigenschaften im Vergleich zu einem Proteinstandard charakterisiert.

Die proteinbeladene Membran wird in Blockierungspuffer zur Absättigung überschüssiger Proteinbindungsstellen und zur Verhinderung einer unspezifischen Bindung der Nachweisreaktion inkubiert. Die „geblockte“ Membran wird anschließend mit einem gegen das nachzuweisende Protein gerichteten Antikörper inkubiert. Der entstandene Protein-Antikörperkomplex wird mittels eines zweiten, gegen die konstanten Bereiche des ersten Antikörpers gerichteten Antikörpers, der an das Enzym Meerrettichperoxidase (engl. horseradish peroxidase; HRP) gekoppelt ist, detektiert. Die Aktivität dieses Enzyms wird bei der folgenden Nachweisreaktion (enhanced chemoluminescence reaction; ECL) nachgewiesen. Hierbei wird nach Umsatz eines Substrates Licht emittiert, was zur Schwärzung eines Röntgenfilms führt [36].

\section{Benötigtes Material}

- Polyacrylamidgel mit elektrophoretisch getrennten Proteinproben

- Nitrocellulosemembran (Hybond ECL, Fa. Amersham, Braunschweig)

- Cellulosefilterpapier (Gel Blottingpapier 460 x 570 mm, Fa. Schleicher \& Schuell, Dassel)

- Stromgeber Power-Pac 200 (Fa. Biorad, Hercules, CA, USA)

- flache Inkubationsschalen, Schüttler (GFL 3015, Fa. GFL, Burgwedel)

- Semi-Dry-Blottingapparatur (Trans-Blot SD, Fa. Biorad, Hercules, CA, USA)

- Transferpuffer (pH 8,3):

- 3,03 g Tris - Base (25 mM Tris)

- 14,4 g Glycin (192 mM Glycin)

- $100 \mathrm{ml}$ Methanol (10\% (v/v) Methanol)

- Aqua bidest. ad $1000 \mathrm{ml}$

- $1 \%$ Tween-20 in PBS -Ca/Mg (1 ml Tween-20 ad 1000 ml mit PBS auffüllen)

- Block-Puffer $(5 \%(\mathrm{w} / \mathrm{v}))$ : 
- 2 g Trockenmilchpulver entfettet (Fa. Sigma, Deisenhofen)

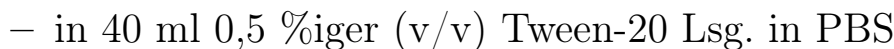

- Primärantikörper in 0,5 \% Tween-20 Lsg. (beim Nachweis von VCAM-1: pAb Konz. $1: 200)$

- Konjugat aus einem Sekundärantikörper gegen den Primärantikörper (bei VCAM-1: anti - Ziege IgG, Fa. Sigma, Verd. 1:10000) und Meerrettichperoxidase (HRP)

- Detektionsreagenz enhanced chemoluminescence reaction (ECL) western blotting detection reagents (Fa. Amersham)

- Röntgenfilm (Hyperfilm MP, Fa. Amersham)

- Filmkassette 35,6 x 43,2 cm (Fa. Biotech Trade and Services, St. Leon-Rot)

\section{Protokoll}

1. Auf die Größe des Polyacrylamidgels zugeschnittene Membran und sechs etwas grössere Stücke Whatman-Papier in Transferpuffer einweichen, das Gel in Transferpuffer äquilibrieren (5 Min. unter leichtem Schwenken)

2. Blottingapparatur nach Anweisungen des Herstellers zusammensetzen, zwischen den Elektroden das Blotting-Sandwich aufbauen:

a) drei in Puffer getränkte Filterpapiere blasenfrei aufeinanderlegen

b) darauf die Membran legen

c) das Gel mittig auf die Membran legen

d) mit drei feuchten Filterpapieren bedecken

3. Den Deckel der Blottingapparatur gleichmäßig mit Transferpuffer anfeuchten und über dem Blotting-Sandwich schließen

4. 45 Min. bei konstant 400 mAmp blotten

5. Nach Ende des Blottingvorgangs die Membran entnehmen und die Banden des Protein-Größenstandards sowie die Laufrichtung des Gels mit Kugelschreiber vorsichtig auf der Membran markieren 
6. Blockieren der Membran mit Block-Puffer für 1 Std. bei RT

7. Waschen der Membran mit $1 \%$ PBST Lsg. (2 x 1 Min.)

8. Inkubation der Membran mit Primärantikörperlösung (Menge s.o., bei leichtem Schwenken und $4^{\circ} \mathrm{C}$ über Nacht)

9. Waschen der Membran mit $1 \%$ PBST Lsg. (3 x 5 Min.)

10. Inkubation mit Sekundärantikörperlösung (RT, 1 Std.)

11. Waschen der Membran mit $1 \%$ PBST Lsg. (3 x 5 Min.)

12. Visualisierungsreaktion mit dem ECL-Reagenz in Dunkelkammer nach Anweisung des Herstellers, Entwicklung des Röntgenfilms

\subsubsection{Indirekte Immunfluoreszenz und durchflusszytometrische Analyse}

Prinzip Bei der durchflusszytometrischen Analyse werden einzelne Zellen, die den Fokus eines Laserstrahls passieren, detektiert, gezählt und nach Größe und Granularität (dem Scatterverhalten) analysiert. Oberflächenantigene (hier VCAM-1) der zu untersuchenden Zellen werden vor der Analyse mittels Antikörpern markiert, welche mit Fluoreszenzfarbstoffen gekoppelt sind. Die Analyse erfolgte mit dem FACScalibur (FACS für fluorescence activated cell sorting, Fa. Becton Dickinson, Erembodegem, Belgien).

\section{benötigtes Material}

- zu untersuchende Zellpopulation z.B. HIMEC in Medium

- FACS-Röhrchen aus Glas oder Kunststoff

- $\mathrm{PBS}$ - $\mathrm{Ca} / \mathrm{Mg}$ (eisgekühlt)

- Trypsin-EDTA (kalt)

- Zentrifuge Megafuge 1,0 R (Fa. Heraeus, Osterode)

- Monoklonaler Antikörper gegen ein Oberflächenantigen der zu identifizierenden Zellpopulation, hier: anti-humanes VCAM (mAB aus Maus) sowie biotinylierter Sekundärantikörper und Streptavidin-Fluorochrom-Konjugat (hier Streptavidin-PE) 
- FACScalibur-Gerät

\section{Protokoll}

1. Trypsinisierung adhärenter Zellen auf Eis

2. Überführung der jeweiligen Zellpopulation (in Medium, PBS o.̈̈.) in spezielle FACSRöhrchen

3. Zentrifugation (2 Min., 370g)

4. Vorsichtiges Dekantieren des Überstandes

5. $5 \mu$ l Antikörperlsg. auf das Zellpellett pipettieren, vorsichtig vortexen

6. 30 Min. Inkubation bei $4^{\circ} \mathrm{C}$ unter Lichtschutz

7. Resuspendieren in 1ml eisgekühltem PBS (zum Abwaschen des ungebundenen Antikörpers)

8. Zentrifugation der Röhrchen (2 Min., 370g)

9. Vorsichtiges Verwerfen des Überstandes, Wiederholung der Inkubation mit $5 \mu$ l des Sekundärantikörpers sowie des Streptavidin-Fluorochrom-Konjugates, Resuspendieren des Zellpelletts in $300 \mu$ l eiskaltem PBS

10. Durchführung der durchflusszytometrischen Analyse

11. Auswertung der gewonnenen Daten mit dem Programm WinMDI 2.7 (Autor: James Trotter, Scipps Research Institute, La Jolla, CA, USA)

\subsubsection{Immunhistochemie}

\section{Anfertigung von Gefrierschnitten zur immunhistochemischen Aufarbeitung}

Aus Operationsresektaten oder Bioptaten gewonnene Gewebeproben von menschlichem Colon werden zur immunhistochemischen Untersuchung mit Hilfe der Gefrierschnittmethode untersucht:

Ein mittels Einmalskalpell auf eine Größe von ca. 2 × 2 × $2 \mathrm{~mm}$ zugeschnittenes Gewebestück, das sowohl Epithel als auch Anteile der Darmsubmukosa, aber nicht der Tunica 
muscularis enthalten soll, wird in einem mit OCT Tissue Tek gefüllten speziellem Cryomold (Cryomold Intermediate (15 x 15 x 5 mm), Fa. Miles, Elkhart, IN, USA) in durch flüssigen Stickstoff gekühltem Isopentan eingefroren. Die so gewonnenen Proben lassen sich bei $-80^{\circ} \mathrm{C}$ für mehrere Monate lagern.

Die Proben werden mit einem Kryostaten (hier: Kryostat HM 500 OM, Fa. Microm, Walldorf) bei $-25^{\circ} \mathrm{C}$ bei einer Schichtdicke von $5 \mu \mathrm{m}$ geschnitten. Auf speziell beschichteten Objektträger (hier: Superfrost Plus, Fa. Microm, Walldorf) werden die Schnitte 30 Min. bei RT getrocknet und anschließend fixiert.

\section{Fixierung der Gewebeschnitte}

Die Fixierung der Schnitte erfolgt in kaltem Aceton für 10 Min. bei $-20^{\circ} \mathrm{C}$. Nach Trocknen können die Schnitte bei $-80^{\circ} \mathrm{C}$ gelagert werden. Vor der immunhistochemischen Färbung erfolgt nach dem Auftauen der Schnitte unter einem kontinuierlichen Luftzug ein weiterer Fixierungsschnitt in Aceton (s.o.), durch diesen weiteren Schritt scheint die Morphologie der Gewebsschnitte besser erhalten zu werden (eigene Beobachtung).

\section{Immunhistochemische Färbungen}

Zur Untersuchung der Expression von VCAM-1, von-Willebrand-Faktor sowie des für HEV (high endothelial venules) typischen peripherial Node Adressins (PNAd) [171] wurden Gefrierschnitte von Gesunden und CED-Patienten nach Acetonfixierung mit immunhistochemischen Methoden gefärbt.

Nach Inkubation der Schnitte mit dem Primär-Antikörper wird ein zweiter, gegen den Fc-Anteil des primären Antikörpers gerichteter biotinkonjugierter Antikörper zugegeben. Es erfolgt eine Inkubation mit HRP-konjugiertem Streptavidin bzw. einem Fluoreszenzfarbstoff wie Cy3 oder FITC. Die Fluoreszenzfarbstoffe können mit einem Fluoreszenzmikroskop (Leica DMLB, Fa. Leica, Solms) bei einer charakteristischen Wellenlänge des Lichts nachgewiesen werden (Cy3: $457 \mathrm{~nm}$, FITC: $495 \mathrm{~nm}$ ). HRP setzt ein zugegebenes Substrat (Diaminobenzidin-DAB) zu einem im Lichtmikroskop braun erscheinenen Komplex um. Diese Gewebsschnittfärbungen können nach einer Gegenfärbung mit Hämatoxylin nach Harris (5 Min. im Hämatoxylinbad färben, 1 Min. Spülen mit Leitungswasser) lichtmikroskopisch ausgewertet werden.

Bei den Versuchsreihen für die vorliegende Arbeit erfolgte der Nachweis sowohl über die Peroxidasereaktion als auch über die Immunfluoreszenz. 


\section{Immunfluoreszenz}

\section{benötigtes Material}

- DaKo-Pen

- 10\% Serum (aus der Tierart, in der der Sekundärantikörper hergestellt wurde, Fa. Sigma, Deisenhofen) in PBS zum Blockieren (100 $\mu$ l pro Schnitt)

- Biotin/Avidin - Blockingkit (Fa. Vector Labs, Burlingame, CA, USA)

- Primär/Sekundärantikörper und Streptavidin-Farbstoff-Konjugat in der individuell ermittelten Arbeitskonzentration in 10\%iger Serumlösung (s.o.)

- $\mathrm{PBS}-\mathrm{Ca} / \mathrm{Mg}$

- Färbetröge nach HELlENDAHL

- feuchte, dunkle Kammer zur Inkubation

- Deckgläser (Fa. Menzel, Braunschweig)

- Eindeckmedium Vectashield (Fa. Vector Labs), Klarlack

\section{Protokoll}

1. Fixierte und luftgetrocknete Gefierschnitte auf dem Objektträger mit dem Dako-Pen umfahren und für 5 Min. bei RT trocknen lassen

2. Schnitte 5 Min. in PBS rehydrieren

3. 0,1 ml 10\%ige Serumlösung überschichten, Inkubation 1h bei RT (zum Blockieren der unspezifischen Proteinbindung)

4. Waschen: 3 x 5 Min. in PBS

5. Avidin/Biotin-Blockierung mittels Kit gemäß Anweisungen des Herstellers

6. Waschschritt (siehe 4.)

7. Zugeben von 0,1 ml Primärantikörper, Inkubation $1 \mathrm{~h}$ bei RT; Konzentration:

- anti-VCAM-1 pAb: 1:100 
- anti-vWF: 1:200

- anti-MeCa-79: unverdünnt (in Medium) einsetzen

8. Waschschritt (siehe 4.)

9. Zugeben von 0,1 ml Sekundärantikörper, Inkubation 1h bei RT; Konzentration:

- bei VCAM-1: anti-Ziege: 1:1000

- bei vWF: anti-Kaninchen: 1:500

- bei MeCa-79: anti-Maus: 1:1000

10. Waschschritt (siehe 4.)

11. Mit 0,1 ml Streptavidin-Farbstoff-Konjugat überschichten, Inkubation 15 Min. bei RT unter Lichtschutz; Konzentration:

- bei VCAM-1: Streptavidin-Cy3: 1:1000

- bei vWF: Streptavidin-FITC: 1:500

- bei MeCa-79: Streptavidin-FITC: 1:1000

12. Waschschritt (siehe 4.) unter Lichtschutz

13. Eindeckeln mit Vectashield, Fixierung des Deckglases mit Klarlack

\section{Immunhistochemie mit Peroxidasetechnik}

\section{benötigtes Material}

- 3\%ige Wasserstoffperoxidlösung (zum Blockieren der endogenen Peroxidase im Schnitt)

- Streptavidin-HRP-Konjugat (Meerrettichperoxidase)

- HRP-Substratlösung mit Diaminobenzidin (DAB)

- Hämatoxylin nach HARRIS (Fertiglösung), Färbebad

- Eindeckmedium KAISERS Glyceringelatine 
Protokoll Das Protokoll gleicht dem der Immunfluoreszenzfärbung mit folgenden Ergänzungen:

- Vor dem Blockieren mit Serumlösung erfolgt das Blockieren der endogenen Peroxidasen mit Wasserstoffperoxidlösung für 5 Min. bei RT

- Nach Inkubation des Tertiärantikörpers (Streptavidin-HRP-Konjugat,1:500 in Serumlösung) erfolgt nach einem Waschschritt die Umsetzung des DAB-Substrats durch die HRP unter lichtmikroskopischer Kontrolle

- Gegenfärbung mit Hämatoxylin nach Harris (Schnitte 5 Min. im Hämatoxylinbad färben, darauf eine Min. Waschen in Leitungswasser)

- Eindeckeln mit im Wasserbad auf $37^{\circ} \mathrm{C}$ erwärmter Kaisers Glyceringelatine

Die Konzentrationen der verschiedenen Antikörper entsprechen denen bei der Immunfluoreszenz, das Streptavidin-HRP-Konjugat sowie das Substrat wurde nach Anweisung des Herstellers des DaKo-Kits angewendet.

Färbung von Zellmonolayern auf chamber slides Um in Kultur gehaltene adhärente Zellen immunhistochemisch färben zu können, werden diese auf kollagenbeschichtete Objektträger mit aufgesetzten Zellkulturkammern (chamber slides „Labtek“, Fa. Nalge Nunc, Naperville, IL, USA) ausgedehnt. Nach Erreichen der Konfluenz wird das Medium abgesaugt. Die Zellen in den Kammern werden mit jeweils 0,5 $\mathrm{ml} 4$ \% Paraformaldehyd in PBS für 10 Min. bei RT fixiert. Dann folgt eine Permeabilisierung der Zellen mit je 0,5

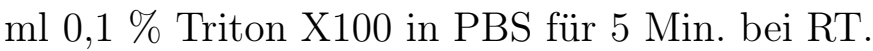

Die anschließende Immunfluoreszenzfärbung der chamber slides erfolgt entsprechend dem Protokoll für Gewebeschnitte (siehe Abschnitt 3.4.3, Seite 44), pro Zellkulturkammer sind $300 \mu \mathrm{l}$ der entsprechenden Lösungen einzusetzen.

Mit Hilfe einer vom Hersteller gelieferten Abschervorrichtung können die aufgeklebten Zellkulturkammern nach Beendigung der Färbung vom Objektträger gelöst werden. Anschließend erfolgt die Eindeckelung mit Vectashield entsprechend des Protokolls für Gewebeschnitte . 


\title{
4 Ergebnisse
}

\subsection{HIMEC sind Endothelzellen}

Bei allen Versuchen mit Endothelzellprimärkulturen muß die endotheliale Herkunft der Zellen gesichert werden. SCOTT et al. empfehlen, die Kulturen auf mehrere (mindestens drei) verschiedene endotheliale Eigenschaften zu überprüfen [160]. Bei der vorliegenden Arbeit erfolgte standardmäßig eine Überprüfung der Kulturen auf:

- die pflastersteinartige Morphologie einer konfluenten Kultur (Abbildung 4.1, Seite 47)

\begin{abstract}
Abbildung 4.1: Aufsicht auf eine konfluente HIMEC-Kultur: Charakteristische Pflasterstein (engl. cobblestone) Morphologie. Phasenkontrast-Mikroskopie, Vergrößerung: 100fach
\end{abstract}

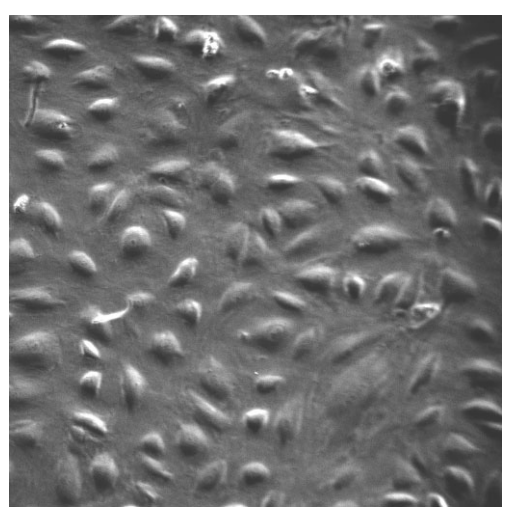

- die starke Expression des von Willebrand Faktors (im Vergleich zu Endothelzellen von Lymphgefäßen, die den vWF nur schwach exprimieren): Abbildung 4.2, Seite 48

- die Hochregulation des Adhäsionsmoleküls VCAM-1 durch Stimulation mit TNF- $\alpha$ [153] (auf RNA und/oder Proteinebene, siehe Abbildung 4.3, Seite 48 sowie Abbildung 4.4, Seite 49) 

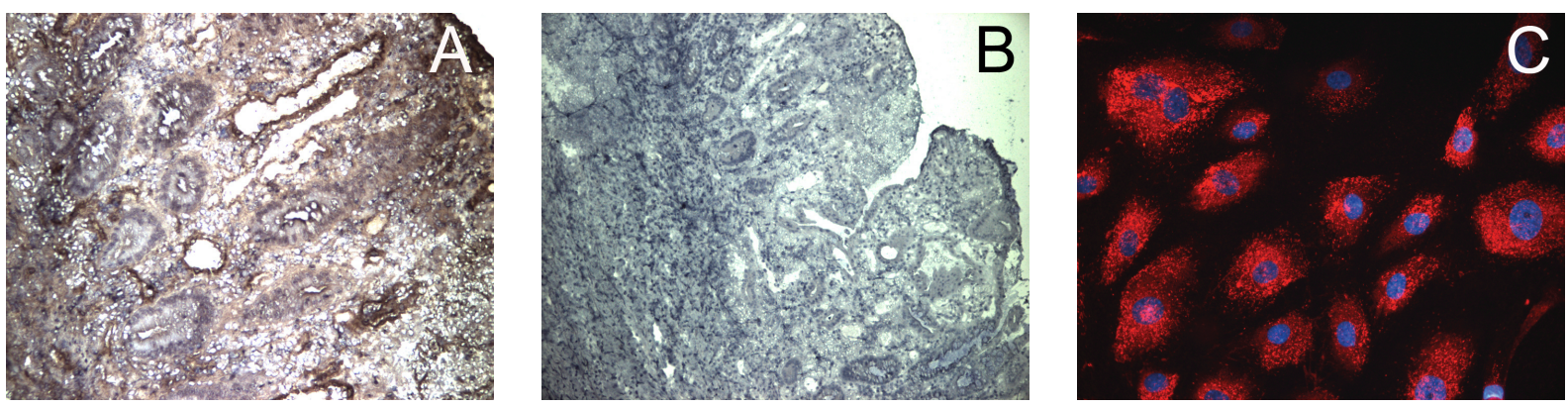

Abbildung 4.2: Endothelzellen exprimieren den von Willebrand Faktor: Abbildung A: Immunhistochemische Darstellung des vWF (braun), Colonmukosa eines gesunden Probanden, Vergrößerung 200fach. Abbildung B: no primary-Kontrolle zu Abb. A. Abbildung C: vWF-Darstellung (Immunfluoreszenzmikroskopie: vWF: FITC (grün), Zellkernfärbung mit DAPI (blau), Vergrößerung 400fach).
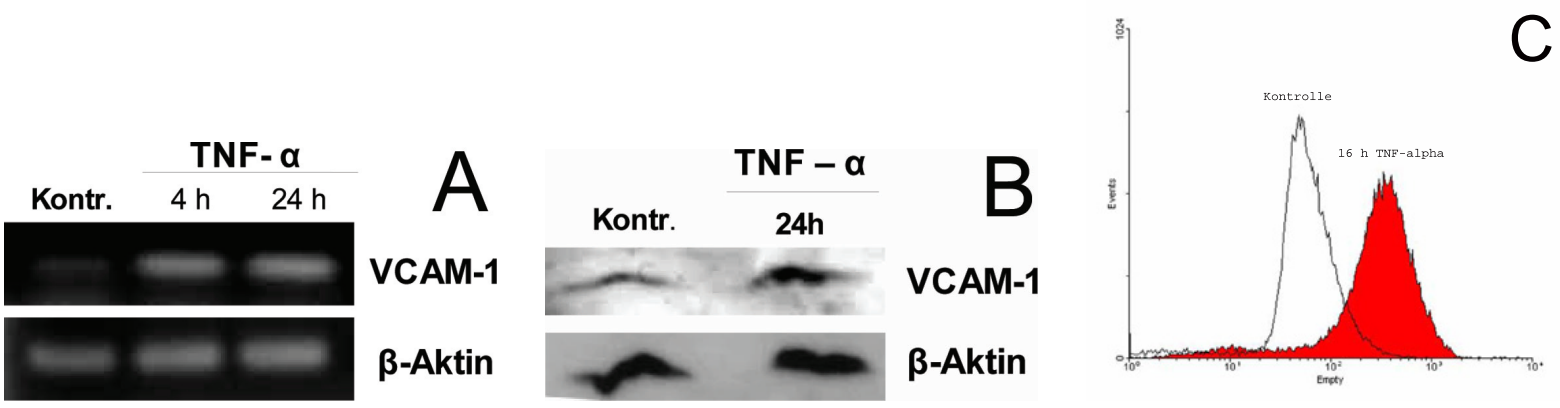

Abbildung 4.3: In HIMEC kann durch Stimulation mit TNF- $\alpha$ das Adhäsionsmolekül VCAM-1 induziert werden. Abbildung A: Nachweis des induzierten VCAM-1 mittels RT-PCR. Abbildung B: Westernblot. Abbildung C: Flowzytometrie.

- die Abwesenheit des für Endothelzellen spezialisierter Venolen (high endothelial venules) spezifischen Oberflächenmarkers PNAd (peripherial node addressin) [171] (Abbildung 4.5, Seite 50). Die HEVs werden in sekundären lymphatischen Organen, also auch der Darmmukosa, angetroffen. Eine versehentliche Isolation von HEVEndothelzellen kann nach der beschriebenen Methode nicht ausgeschlossen werden. In der vorliegenden Arbeit wurden PNAd-positive Primärkulturen verworfen.

Da in der Colonmukosa, aus der HIMEC isoliert werden, keine makrovaskulären Gefäße vorhanden sind, muß es sich um mikrovaskuläre Endothelzellen handeln (siehe Abbildung 3.1, Seite 22). 

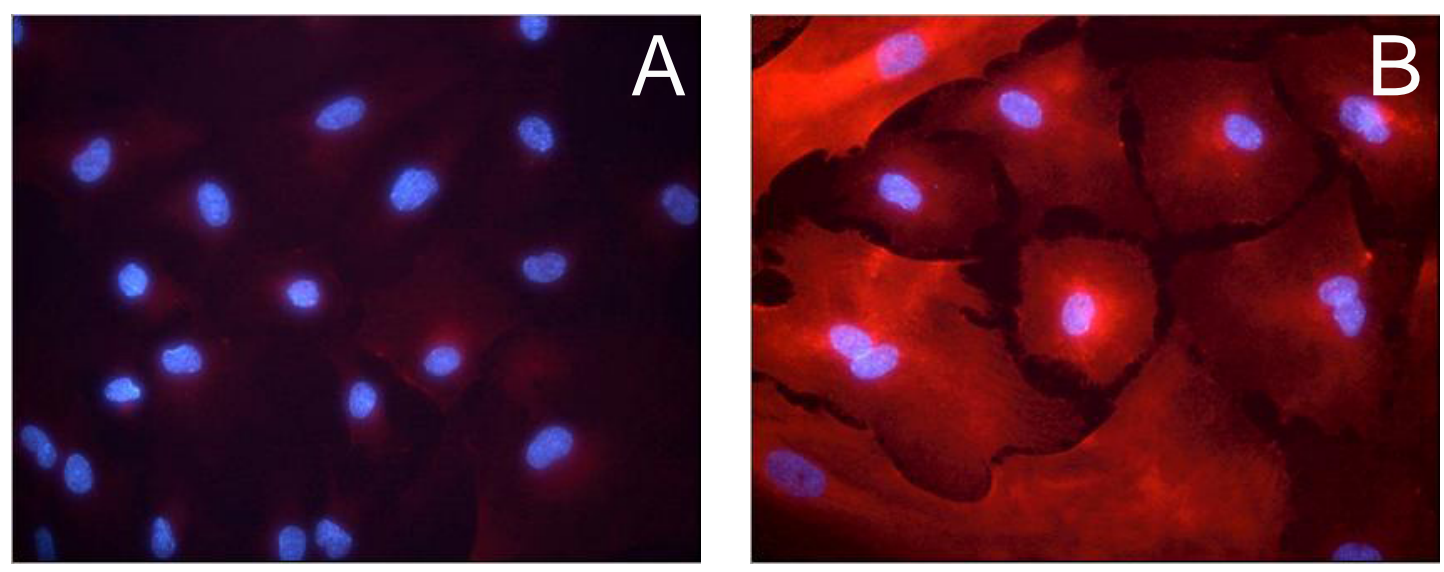

Abbildung 4.4: Immunfluoreszenzmikroskopischer Nachweis der Induktion von VCAM-1 in HIMEC: Abbildung A: unstimulierte HIMEC; Abbildung B: HIMEC nach Stimulation mit TNF$\alpha$ über 16 Std. (VCAM-1: Cy3 (rot), Kernfärbung mit DAPI (blau))

\subsection{Genexpressionsprofile von HIMEC und der Referenzzellinie HMEC-1}

Zur Ermittlung des Genexpressionsprofils humaner intestinaler mikrovaskulärer Endothelzellen wurden diese für 4 und 24 Stunden mit $20 \mathrm{ng} / \mu \mathrm{l}$ TNF- $\alpha$ stimuliert oder unstimuliert als Kontrolle verwendet. Der frühe Zeitpunkt wurde gewählt, um autokrine oder parakrine Beeinflussung der Zellen zu minimieren. Die 24-stündige Stimulation der Zellen diente zur Identifikation der para- oder autokrin aktivierten Gene. Für die Analyse mittels DNA-Microarrays wurden drei aus chirurgischen Darmresektaten verschiedener Patienten (meist Tumor-OP, keine CED) isolierte HIMEC-Primärkulturen verwendet.

Die Aktivierung der Endothelzellen durch TNF- $\alpha$ wurde durch Hochregulation des Oberflächenadhäsionsmoleküls VCAM-1 (siehe hierzu die Abbildungen 4.3 und 4.4, Seite 48) sowie durch Veränderung der Zellmorphologie bewiesen. Nach BINION et al. zeigen TNF- $\alpha$-stimulierte HIMEC eine spindelförmige, längliche Morphologie. Sie ist lichtmikroskopisch einfach von der bei den unstimulierten HIMEC anzutreffenden rundlichen, „Cobblestone“-Zellform der Endothelzellen zu differenzieren [16].

Bei der Auswertung wurden nur Gene, die signifikant um einen Faktor $>3$ reguliert oder um einen Faktor $>5$ an-/ausgeschaltet wurden, berücksichtigt. In HIMEC wurden nach vierstündiger TNF- $\alpha$-Stimulation 62 Gene signifikant hochreguliert und die Expression von 68 Genen signifikant angeschaltet. Herunterreguliert wurden 13 Gene, die Expression von drei Genen wurde ausgeschaltet. Nach 24 Stunden wurden 115 Gene signifikant 

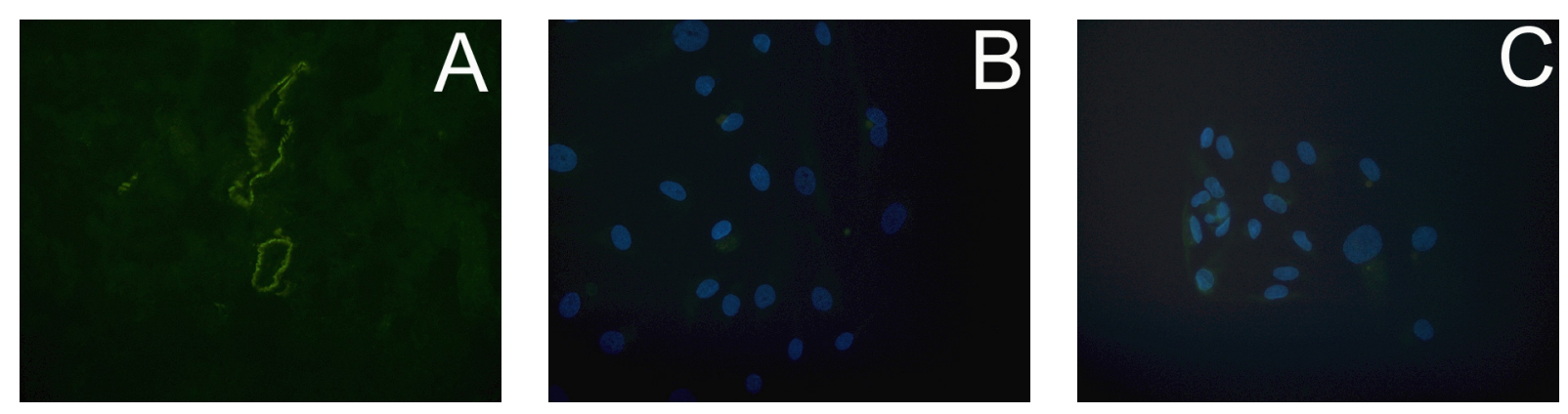

Abbildung 4.5: Um eine Kontamination der Primärkultur mit Endothelzellen aus den spezialisierten Venolen (HEVs) auszuschließen, erfolgte eine fluoreszenzmikroskopische Kontrolle auf die für HEVs typischen PNAds. Abbildung A: immunfluoreszenzmikroskopischer HEV-Nachweis (PNAd: FITC (grün), Vergrößerung 400fach) in der Colonmukosa eines Patienten mit Colitis ulcerosa. Abbildung B: kein PNAd-Immunfluoreszenznachweis in einer HIMEC-Kultur (PNAd: FITC (grün), Kerne: DAPI (blau), Vergrößerung 400fach). Abbildung C: no primary-Kontrolle zu Abbildung B

heraufreguliert und 52 Gene angeschaltet. Herunterreguliert wurden 44 Gene, 16 wurden ausgeschaltet. Bei der Kontrollzellinie HMEC-1 wurden 137 Gene hochreguliert und 76 angeschaltet (4 Std. TNF- $\alpha$ ) bzw. 117 Gene hochreguliert und 61 angeschaltet (24 Std. TNF- $\alpha$ ). Herunterreguliert wurden 24 bzw. 18 Gene, ausgeschaltet 22 bzw. 18 Gene.

Die Schnittmenge dieser Expressionsprofile ist relativ gering. Von den nach vier- und 24-stündiger Stimulation hochregulierten bzw. angeschalteten Genen sind nur 93 Gene bei beiden Zellarten gleichermaßen anzutreffen, 148 Gene werden nur in HIMEC, 199 Gene nur in der Referenzzellinie gefunden. Von den herunterregulierten bzw. abgeschalteten Genen wurden nur 4 in beiden Endothelzellpopulationen reguliert, 65 nur in HIMEC und 74 in der Referenzzellinie HMEC-1 (siehe hierzu die sog. Venn-Diagramme, Abbildung 4.6, Seite 50).
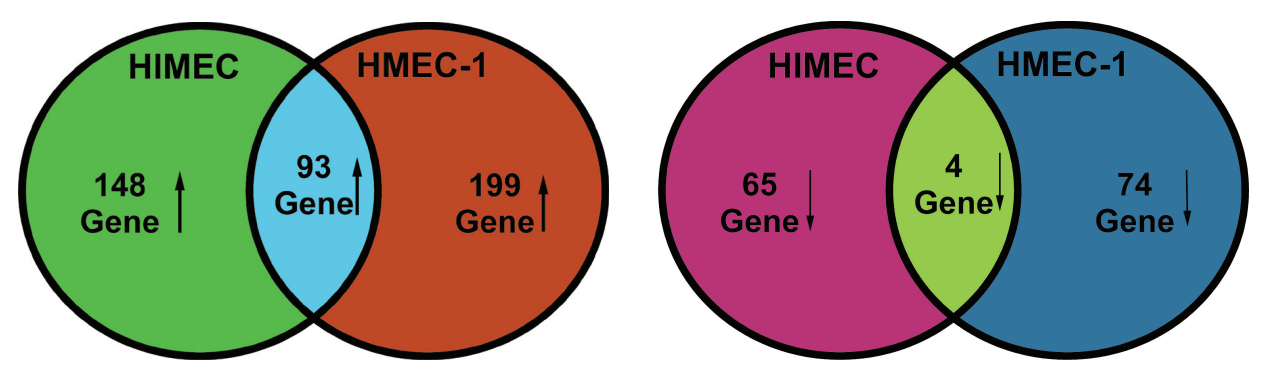

Abbildung 4.6: Schnittmengendiagramme (Venndiagramme) der in HIMEC und HMEC-1 durch vier- und/oder 24-stündige Stimulation mit TNF- $\alpha$ hochregulierten bzw. angeschalteten und herunterregulierten bzw. abgeschalteten Gene: Nur einer kleiner Teil der differenziell regulierten Gene ist beiden Zellarten gemeinsam 
Die differenziell regulierten Gene werden gemäß der Einteilung nach biologischer Funktion des Gene Ontology Consortium(www.geneontology.org, [6]) in Gruppen sortiert. Die durch TNF- $\alpha$-Stimulation regulierten Gene können den Gruppen der Zelloberflächenrezeptoren, Chemo- und Zytokine, Transkriptionsfaktoren, Entzündungsmediatoren, Apoptose, Zellmetabolismus, Transportmoleküle und der Modifikatoren der extrazellulären Matrix zugeordnet werden.

\subsubsection{Oberflächenrezeptoren}

Tabelle 4.1: Durch TNF- $\alpha$-Stimulation differenziell regulierte Oberflächenrezeptoren (Auswahl)

\begin{tabular}{|c|c|c|c|c|c|c|}
\hline Gen & HIMEC 4h & p-Wert & HIMEC 24h & p-Wert & HMEC 4h & HMEC $24 \mathrm{~h}$ \\
\hline VCAM-1 & 24,41 & $<0,01$ & 22,54 & $<0,01$ & 69,22 & 50,88 \\
\hline E-Selektin & 82,52 & $<0,00001$ & 23,36 & $<0,005$ & $+^{a}$ & \\
\hline ICAM-1 & 12,55 & $<0,005$ & 13,17 & $<0,005$ & 22,13 & 13,44 \\
\hline $\mathrm{CD} 44^{b}$ & & & 4,16 & $<0,005$ & & \\
\hline CD47 & & & & & 3,62 & 4,34 \\
\hline $\mathrm{CD} 58^{c}$ & 3,7 & $<0,00001$ & & & & \\
\hline CD74 & & & 7,75 & $<0,005$ & & ++ \\
\hline CD83 & 3,25 & $<0,01$ & & & & \\
\hline $\mathrm{CSF}^{2 \mathrm{RB}}{ }^{d}$ & & & 6,03 & $<0,05$ & & \\
\hline $\operatorname{GPR} 56^{e}$ & 5,8 & $<0,005$ & 4,87 & $<0,05$ & 3,33 & \\
\hline GPR & 12,24 & $<0,005$ & 8,33 & $<0,005$ & & \\
\hline IL3R & ++ & $<0,005$ & ++ & $<0,005$ & & \\
\hline $\mathrm{MMD}^{f}$ & 4,52 & $<0,005$ & & & & \\
\hline TNFR3 & & & + & $<0,01$ & & 3,2 \\
\hline TNFR11b $^{g}$ & ++ & $<0,05$ & + & 0,059 & ++++ & ++++ \\
\hline $\mathrm{CAR}^{h}$ & $-3,34$ & $<0,005$ & $-5,46$ & $<0,001$ & & 5,01 \\
\hline
\end{tabular}

${ }^{a}$ Anschaltungen der Genexpression von Faktor 5 - 10 werden mit einem + gekennzeichnet, bei Faktor $10-25$ mit ++ , bei Faktor $25-50$ mit +++ sowie bei einem Faktor $>50$ mit ++++

${ }^{b} \mathrm{CD} 44$ antigen (homing function and Indian blood group system)

${ }^{c}$ CD58 antigen (lymphocyte function-associated antigen 3)

${ }^{d}$ colony stimulating factor 2 receptor, beta, low-affinity (granulocyte-macrophage)

${ }^{e} \mathrm{G}$ protein-coupled receptor 56

$f_{\text {monocyte to macrophage differentiation associated }}$

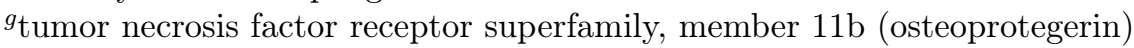

${ }^{h}$ coxsackie virus and adenovirus receptor

Durch Stimulation mit dem Zytokin TNF- $\alpha$ wurden in HIMEC und HMEC-1 Gene, die für Oberflächenadhäsionsmoleküle und Rezeptoren kodieren, hochreguliert. Neben den klassischen Adhäsionsmolekülen E-Selektin, ICAM-1 und VCAM-1 wurden in bei- 
den Zellarten nur der G protein-coupled receptor 56 (GPR56), CD74, der TNF Rezeptor 3 (TNFR3) und der TNF Rezeptor 11b (TNFR11b, Osteoprotegerin) hochreguliert. Ausschließlich in HIMEC reguliert oder angeschaltet wurden die Gene CD44, CD58, CD83, der colony stimulating factor 2 receptor $\beta$ (CSF2RB), ein G-Protein gekoppelter Rezeptor (chemokine orphan receptor, der Interleukin-3 Rezeptor (IL3R) und das Gen monocyte to macrophage differentiation associated (MMD).

\subsubsection{Zytokine}

Tabelle 4.2: Durch TNF- $\alpha$-Stimulation differenziell regulierte Zytokine

\begin{tabular}{lcccccc}
\hline Gen & HIMEC $4 \mathbf{h}$ & $\mathbf{p}$-Wert & HIMEC 24h & p-Wert & HMEC $4 \mathbf{4 h}$ & HMEC 24h \\
\hline IL1- $\beta$ & & & & & $+^{a}$ & + \\
Inhibin, $\beta$ a & & & & & + \\
EBI3 & ++ & $<0,01$ & +++ & $<0,005$ & & \\
IL6 & & & & 4,07 & 3,81 \\
IL7 & & & & & ++ \\
IL8 & 15,32 & $<0,05$ & 11,22 & $<0,05$ & ++++ & ++++ \\
IL15 & 6,42 & $<0,05$ & 6,45 & $<0,01$ & 3,54 & 3,19 \\
LT- $\beta$ & 14,42 & $<0,01$ & 9,53 & $<0,05$ & + & \\
\hline
\end{tabular}

${ }^{a}$ Anschaltungen der Genexpression von Faktor 5 - 10 werden mit einem + gekennzeichnet, bei Faktor $10-25$ mit ++ , bei Faktor $25-50$ mit +++ sowie bei einem Faktor $>50$ mit ++++

Die durch TNF- $\alpha$-Stimulation in beiden Zellarten hochregulierten Zytokine sind die Interleukine 8 und 15 sowie Lymphotoxin $\beta$. Das Epstein-Barr virus induced gene 3 (EBI3) wurde nur in HIMEC signifikant angeschaltet. Interleukin $1 \beta$, Inhibin $\beta$ a und Interleukin 6 und 7 wurden nur in HMEC-1 hochreguliert bzw. angeschaltet. 


\subsubsection{Chemokine}

Tabelle 4.3: Durch TNF- $\alpha$-Stimulation differenziell regulierte Chemokine

\begin{tabular}{|c|c|c|c|c|c|c|}
\hline Gen & HIMEC 4h & p-Wert & HIMEC 24h & p-Wert & HMEC 4h & HMEC 24h \\
\hline CCL2 (MCP-1) & & & & & 18,64 & 18,97 \\
\hline CCL5 (RANTES) & + & $<0,01$ & $+++^{a}$ & $<0,00001$ & & +++ \\
\hline CCL8 (MCP-2) & & & + & $<0,05$ & +++ & +++ \\
\hline CCL20 (MIP-3 $\alpha)$ & 75,4 & $<0,05$ & +++ & $<0,05$ & ++++ & +++ \\
\hline CXCL1 (GRO- $\alpha$ ) & 7,92 & $<0,05$ & 7,75 & $<0,05$ & ++ & ++ \\
\hline CXCL2 (GRO- $\beta)$ & + & $<0,005$ & ++ & $<0,005$ & ++ & ++ \\
\hline CXCL3 (GRO- $\gamma)$ & ++ & $<0,00001$ & ++ & $<0,00001$ & ++ & \\
\hline CXCL5 (ENA-78) & & & 21,55 & $<0,05$ & 11,01 & 14,52 \\
\hline CXCL6 (GCP-2) & 4,75 & 0,081 & 10,21 & 0,079 & & \\
\hline CXCL8 (IL8) & 15,32 & $<0,05$ & 11,22 & $<0,05$ & ++++ & ++++ \\
\hline CXCL10 (IP10) & & & + & $<0,05$ & +++ & ++++ \\
\hline CXCL11 (I-TAC) & + & 0,079 & ++++ & $<0,05$ & + & +++ \\
\hline CX3CL1 (Fractalkine) & ++ & $<0,05$ & ++ & $<0,005$ & & \\
\hline
\end{tabular}

${ }^{a}$ Anschaltungen der Genexpression von Faktor 5 - 10 werden mit einem + gekennzeichnet, bei Faktor $10-25$ mit ++ , bei Faktor $25-50$ mit +++ sowie bei einem Faktor $>50$ mit ++++

Durch TNF- $\alpha$-Stimulation wurden in HIMEC und HMEC-1 zahlreiche Chemokine hochreguliert oder angeschaltet. Die Chemokine CXCL6 (GCP-2) und CX3CL1 (Fractalkine) wurden nur in HIMEC reguliert, CCL2 (MCP-1) nur bei der Referenzzellinie HMEC-1. Große Unterschiede zwischen den Regulationsfaktoren der einzelnen Gene in den beiden Zellarten bestehen bei den Chemokinen CCL8 (MCP2, bei HMEC-1 stärker und früher angeschaltet), CXCL8 (Interleukin 8, in HMEC-1 stärker angeschaltet) und CXCL10 (IP10, bei HMEC-1 deutlich stärker und früher angeschaltet). 


\subsubsection{Entzündungsreaktion}

Tabelle 4.4: Durch TNF- $\alpha$ differenziell regulierte, mit Entzündungsreaktionen assoziierte Gene (Auswahl)

\begin{tabular}{|c|c|c|c|c|c|c|}
\hline Gen & HIMEC $4 \mathrm{~h}$ & p-Wert & HIMEC $24 \mathrm{~h}$ & p-Wert & HMEC 4h & HMEC 24h \\
\hline PS-PLA1 & & & $++^{a}$ & $<0,005$ & & ++ \\
\hline Cyclooxygenase 2 & 8,96 & 0,069 & 7,5 & 0,053 & & \\
\hline Komplementkomponente $1 \mathrm{r}$ & & & ++ & $<0,00001$ & & 3,71 \\
\hline Komplementkomponente 1s & & & ++ & $<0,005$ & & ++ \\
\hline PLA2, IV A & 3,82 & $<0,05$ & 5,16 & $<0,05$ & & \\
\hline Cathepsin S & & & 5,01 & $<0,00001$ & 3,08 & 10,46 \\
\hline TNFAIP2 & 15,73 & $<0,00001$ & 7,7 & $<0,00001$ & 19,37 & 5,52 \\
\hline $\mathrm{LST} 1^{b}$ & & & +++ & $<0,005$ & & \\
\hline
\end{tabular}

${ }^{a}$ Anschaltungen der Genexpression von Faktor 5 - 10 werden mit einem + gekennzeichnet, bei Faktor $10-25$ mit ++ , bei Faktor $25-50$ mit +++ sowie bei einem Faktor $>50$ mit ++++

${ }^{b}$ leukocyte specific transcript 1

Die durch TNF- $\alpha$-Stimulation in HIMEC und HMEC-1 hochregulierten Gene der Gruppe der Entzündungsgene sind die phosphatidylserinspezifische Phospholipase A1 (PSPLA1), die Komponenten des Komplementsystems 1r und 1s, Cathepsin S und das TNF alpha induced protein 2 (TNFAIP2). Die Cyclooxygenase 2, die Phospholipase A2 (PLA2 Typ IV A) und das leukocyte specific transcript 1 wurden nur in HIMEC hochreguliert. 


\subsubsection{Transkriptionsfaktoren und Signaltransduktion}

Tabelle 4.5: Ausgewählte, durch TNF- $\alpha$-Stimulation differenziell regulierte Transkriptionsfaktoren oder Signaltransduktionsgene

\begin{tabular}{|c|c|c|c|c|c|c|}
\hline Gen & HIMEC $4 \mathrm{~h}$ & p-Wert & HIMEC 24h & p-Wert & HMEC $4 \mathrm{~h}$ & HMEC $24 \mathrm{~h}$ \\
\hline TNFAIP & 30,31 & $<0,00001$ & 8,03 & $<0,00001$ & 4,96 & \\
\hline S100A11 (Calgizzarin) & & & 5,86 & $<0,05$ & & \\
\hline $\mathrm{TSSC}^{a}$ & & & 5,38 & $<0,05$ & & \\
\hline $\operatorname{IRF} 1^{b}$ & 6,3 & $<0,00001$ & 4,9 & $<0,00001$ & 5,29 & \\
\hline $\mathrm{I} \kappa \mathrm{B} \alpha$ & 5,89 & $<0,01$ & 4,77 & $<0,01$ & 9,63 & 8,17 \\
\hline NKX3-1 ${ }^{c}$ & 3,42 & $<0,00001$ & 4,75 & $<0,00001$ & & \\
\hline $\mathrm{RIPK}^{d}$ & 8,38 & $<0,005$ & 4,31 & $<0,05$ & $+^{e}$ & \\
\hline Nibrin & 3,22 & $<0,005$ & 4,24 & $<0,00001$ & & \\
\hline $\mathrm{NF}-\kappa \mathrm{B} 2(\mathrm{p} 49 / \mathrm{p} 100)$ & 5,1 & $<0,005$ & 3,83 & $<0,01$ & 7,95 & 6,58 \\
\hline $\mathrm{I} \kappa \mathrm{B} \epsilon$ & & & 3,15 & $<0,00001$ & 3,78 & 3,03 \\
\hline $\begin{array}{l}\text { activating } \quad \text { transcription } \\
\text { factor } 3\end{array}$ & 8,93 & $<0,00001$ & 3,08 & $<0,01$ & 3,17 & \\
\hline TNFSF18 & + & & & & & \\
\hline FSTL3 $^{f}$ & 9,24 & $<0,00001$ & & & & \\
\hline MAPKKK5 & 4,15 & $<0,01$ & & & 3,7 & 3,26 \\
\hline MAPKK3 & 3,67 & $<0,005$ & & & & \\
\hline NFAT $1^{g}$ & 3,62 & $<0,05$ & & & & \\
\hline Jagged 1 & 3,23 & $<0,05$ & & & & \\
\hline jun B proto-oncogen & 3,08 & $<0,05$ & & & 3,09 & 3,15 \\
\hline Ephrin-A1 & & & & & 6,8 & 3,16 \\
\hline VEGF C & & & & & 6,64 & 6,99 \\
\hline $\mathrm{NF}-\kappa \mathrm{B} 1(\mathrm{p} 105)$ & & & & & 3,04 & \\
\hline $\begin{array}{l}\text { bone marrow stromal cell } \\
\text { antigen } 2\end{array}$ & & & +++ & $<0,05$ & & +++ \\
\hline $\begin{array}{l}\text { LPS-induced TNF-alpha } \\
\text { factor }\end{array}$ & ++ & $<0,05$ & ++ & $<0,05$ & & \\
\hline $\begin{array}{l}\text { basic helix-loop-helix do- } \\
\text { main containing, class } \mathrm{B}, 2\end{array}$ & ++ & $<0,00001$ & + & $<0,00001$ & & \\
\hline tumor protein p63 & & & + & $<0,05$ & & \\
\hline follistatin & & & $-8,77$ & $<0,05$ & & \\
\hline T-box 1 & $-9,01$ & $<0,01$ & $-4,99$ & $<0,01$ & $-3,65$ & \\
\hline $\begin{array}{l}\text { inhibitor of DNA binding } \\
1 \text {, dominant negative helix- } \\
\text { loop-helix protein }\end{array}$ & & & $-4,38$ & $<0,05$ & & 7,70 \\
\hline
\end{tabular}

${ }^{a}$ tumor suppressing subtransferable candidate 3

$b$ interferon regulatory factor 1

${ }^{c}$ NK3 transcription factor related, locus 1 (Drosophila)

${ }^{d}$ receptor-interacting serine-threonine kinase 2

${ }^{e}$ Anschaltungen der Genexpression von Faktor 5 - 10 werden mit einem + gekennzeichnet, bei Faktor $10-25$ mit ++ , bei Faktor $25-50$ mit +++ sowie bei einem Faktor $>50$ mit ++++

${ }_{\text {follistatin-like } 3 \text { (secreted glycoprotein) }}$

${ }^{g}$ nuclear factor of activated T-cells, cytoplasmic, calcineurin-dependent 1

Durch TNF- $\alpha$-Stimulation wurden in HIMEC und HMEC-1 Transkriptionsfaktoren dif- 
ferentiell reguliert. Von den Bestandteilen der Nuclear factor $\kappa B(N F-\kappa B)$-Signalkaskade wurden $\mathrm{NF}-\kappa \mathrm{B} 2, \mathrm{I} \kappa \mathrm{B} \alpha$ und $\mathrm{I} \kappa \mathrm{B} \epsilon$ in beiden Zellinien reguliert, NF- $\kappa \mathrm{B} 1$ nur bei HMEC-1. Weiterhin wurden die Gene TNF alpha induced protein (TNFAIP), interferon regulatory factor 1 (IRF1), receptor-interacting serine-threonine kinase 2 (RIPK2), activating transcription factor 3 (ATF3), jun B proto-oncogen und bone marrow stromal cell antigen 2 in HIMEC und HMEC-1 hochreguliert bzw. angeschaltet.

Nur in HIMEC reguliert wurden S100A11 (Calgizzarin), tumor suppressing subtransferable candidate 3 (TSSC3), NK3 transcription factor related (Drosophila, NK3X3), Nibrin (Nijmegen breakage syndrome 1 (nibrin), follistatin-like 3 (secreted glycoprotein, FSTL3), Jagged 1, nuclear factor of activated T-cells, cytoplasmic, calcineurin-dependent 1 (NFAT1), LPS-induced TNF-alpha factor, basic helix-loop-helix domain containing, class B, 2 (BCL2) und das tumor protein p63. Von der Familie der Mitogen-aktivierten Kinasen wurde die MAPKKK5 in HIMEC und HMEC, die MAPKK3 nur bei HIMEC hochreguliert.

Das Gen für Follistatin wurde nur in HIMEC herunterreguliert, T-box 1 und inhibitor of DNA binding 1, dominant negative helix-loop-helix protein in beiden Endothelzellpopulationen.

\subsubsection{Apoptose und Zellproliferation}

Tabelle 4.6: Durch TNF- $\alpha$-Stimulation differenziell regulierte Apoptosegene (Auswahl)

\begin{tabular}{lcccccc}
\hline Gen & HIMEC $\mathbf{4 h}$ & p-Wert & HIMEC 24h & p-Wert & HMEC 4h & HMEC 24h \\
\hline baculovirales IAP 3 & $++^{a}$ & $<0,05$ & ++ & $<0,05$ & ++ & + \\
TRAF1 & ++ & $<0,00001$ & ++ & $<0,00001$ & ++ & ++ \\
TNFAIP & 30,31 & $<0,00001$ & 8,03 & $<0,00001$ & 4,96 & \\
TNFAIP3IP1 & 4,63 & $<0,005$ & 5,64 & $<0,005$ & 8,67 & 5,65 \\
CASP1 & & & 5,6 & $<0,00001$ & & \\
TNFAIP1 & 6,93 & $<0,005$ & 4,7 & $<0,005$ & ++ & + \\
CASP8 & 3,59 & $<0,005$ & & & 7,52 & 5,15 \\
TRAF4 & & & & & + \\
TRAIL $^{b}$ & & & & & & 3,88 \\
\hline
\end{tabular}

${ }^{a}$ Anschaltungen der Genexpression von Faktor 5 - 10 werden mit einem + gekennzeichnet, bei Faktor $10-25$ mit ++ , bei Faktor $25-50$ mit +++ sowie bei einem Faktor $>50$ mit ++++

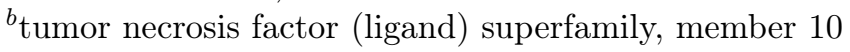

Durch TNF- $\alpha$-Stimulation wurden in HIMEC und HMEC-1 Apoptose-relevante Gene hochreguliert. In beiden Zellinien reguliert wurden Mitglieder der TNF-Familie (TNF alpha induced protein (TNFAIP), TNFAIP1, TNFAIP3 interacting protein 1 (TNFAIP3IP1), 
TNF receptor activating factor 1 (TRAF1) und Caspase 8 (CASP8). Die CASP8 wurde in HMEC-1 stärker und zu einem späteren Zeitpunkt als in HIMEC hochreguliert. Die Caspase 1 (CASP1) wurde nur in HIMEC hochreguliert. Der TNF receptor activating factor 4 (TRAF4) und TRAIL wurden nur in HMEC-1 reguliert.

\subsubsection{Zellmetabolismus}

Tabelle 4.7: Durch TNF- $\alpha$ differenziell regulierte Zellmetabolismus-Gene (Auswahl)

\begin{tabular}{|c|c|c|c|c|c|c|}
\hline Gen & HIMEC $4 \mathrm{~h}$ & p-Wert & HIMEC 24h & p-Wert & HMEC $4 \mathrm{~h}$ & HMEC $24 \mathrm{~h}$ \\
\hline Acetylcholinesterase & & & $+^{a}$ & $<0,005$ & & \\
\hline GTP binding protein 1 & ++ & $<0,00001$ & + & $<0,005$ & & \\
\hline $\begin{array}{l}\text { Superoxid-Dismutase (mit- } \\
\text { ochondriell) }\end{array}$ & 5,87 & $<0,005$ & 8,51 & $<0,00001$ & 18,68 & 22,48 \\
\hline GTP Cyclohydrolase & 14,43 & $<0,00001$ & 8,24 & $<0,00001$ & 7,65 & 4,51 \\
\hline $\begin{array}{l}\text { Proteasom Untereinheit } \beta \\
9^{b}\end{array}$ & & & 7,97 & $<0,00001$ & & \\
\hline $\begin{array}{l}\text { Guanylat-bindendes Prote- } \\
\text { in } 1\end{array}$ & 12,62 & $<0,005$ & 6,15 & $<0,01$ & 10,79 & 6,01 \\
\hline $\mathrm{GGH}^{c}$ & & & 5,08 & $<0,05$ & & \\
\hline PA $28 \beta^{d}$ & & & 4,94 & $<0,00001$ & & \\
\hline $\begin{array}{l}\text { Hydroxymethylglutaryl- } \\
\text { Coenzym A Synthase } 1 \\
\text { (gelöst) }\end{array}$ & & & 3,82 & $<0,00001$ & & 4,19 \\
\hline Cathepsin H & & & 3,68 & $<0,01$ & & \\
\hline Lanosterolsynthase & & & 3,42 & $<0,005$ & & \\
\hline $\begin{array}{l}\text { hydroxysteroid } \text { (17-beta) } \\
\text { dehydrogenase } 2\end{array}$ & & & $-10,46$ & $<0,005$ & & \\
\hline $\operatorname{eNOS}^{e}$ & & & - & $<0,0005$ & & \\
\hline cytochrome $\mathrm{b}$ reductase 1 & & & - & $<0,005$ & & \\
\hline
\end{tabular}

${ }^{a}$ Anschaltungen der Genexpression von Faktor 5 - 10 werden mit einem + gekennzeichnet, bei Faktor 10 -25 mit ++ , bei Faktor $25-50$ mit +++ sowie bei einem Faktor $>50$ mit ++++ . Die Darstellung der Ausschaltung von Genen erfolgte entsprechend mit - bis - - - -

${ }^{b}$ proteasome (prosome, macropain) subunit, beta type, 9 (large multifunctional protease 2)

${ }^{c}$ gamma-glutamyl hydrolase (conjugase, folylpolygammaglutamyl hydrolase)

${ }^{d}$ proteasome (prosome, macropain) activator subunit 2 (PA28 beta)

${ }^{e}$ nitric oxide synthase 3 (endothelial cell)

Durch TNF- $\alpha$-Stimulation wurden in den untersuchten Endothelzellpopulationen einige Zellmetabolismusgene positiv oder negativ reguliert. Nur bei HIMEC wurden das GTP binding protein 1, die Proteasombestandteile proteasome (prosome, macropain) subunit, beta type, 9 (large multifunctional protease 2) und proteasome (prosome, macropain) activator subunit 2 (PA28 beta) und die Enzyme Acetycholinesterase, gamma-glutamyl hydrolase (conjugase, folylpolygammaglutamyl hydrolase), Cathepsin $\mathrm{H}$ und Lanosterolsynthase reguliert. 
Das Enzym hydroxysteroid (17-beta) dehydrogenase 2 (17 $\beta$ HSD) wurde nur in HIMEC herunterreguliert, die Gene für nitric oxide synthase 3 (endothelial cell) (eNOS) und cytochrome $b$ reductase 1 nur in HIMEC nach 24-stündiger Stimulation ausgeschaltet.

\subsubsection{Transport und Ionenkanäle}

Tabelle 4.8: Durch TNF- $\alpha$ differenziell regulierte Gene für Transporter und Ionenkanäle (Auswahl)

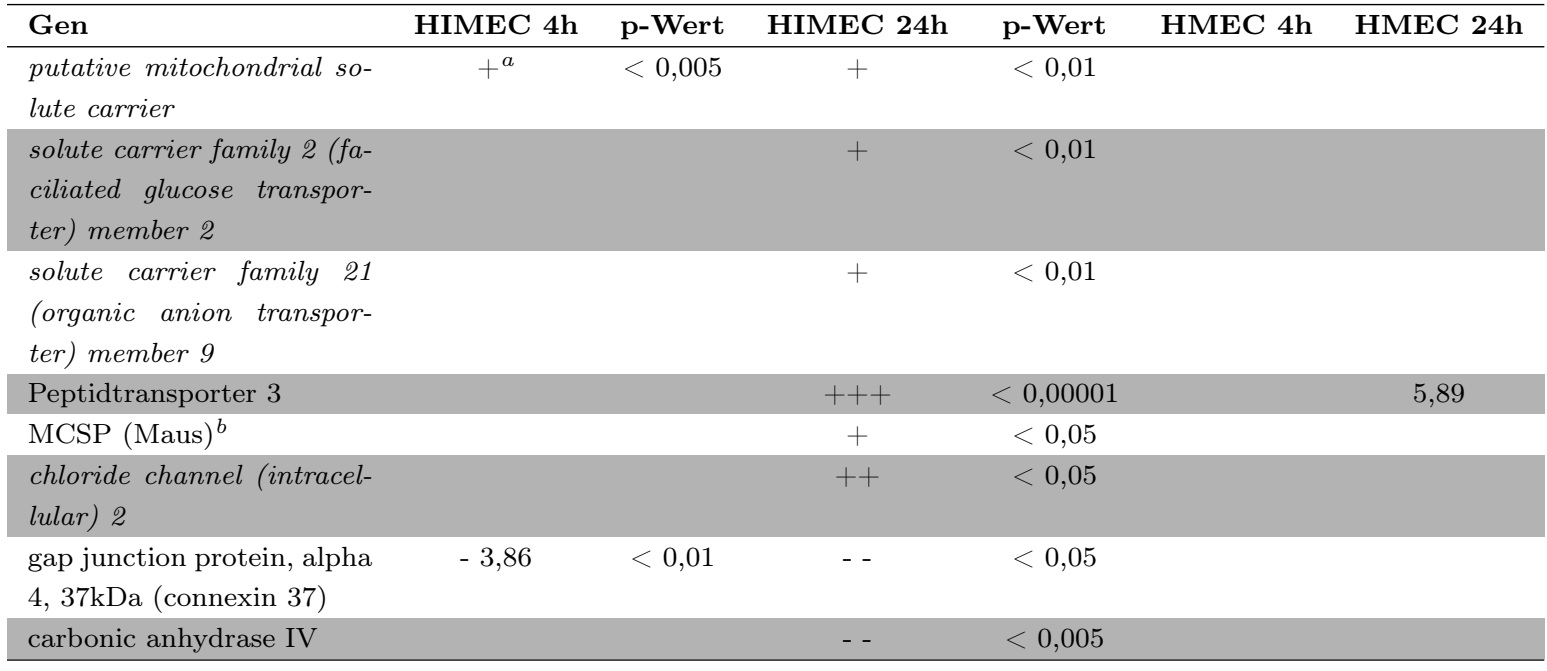

${ }^{a}$ Anschaltungen der Genexpression von Faktor 5-10 werden mit einem + gekennzeichnet, bei Faktor 10 -25 mit ++ , bei Faktor $25-50$ mit +++ sowie bei einem Faktor $>50$ mit ++++ . Die Darstellung der Ausschaltung von Genen erfolgte entsprechend mit - bis - - - -

${ }^{b}$ likely ortholog of mouse mitochondrial solute carrier protein

Durch die Stimulation mit TNF- $\alpha$ wurde in HIMEC und HMEC-1 der Peptidtransporter 3 angeschaltet. Folgende Gene wurden nur in HIMEC hochreguliert: putative mitochondrial solute carrier, solute carrier family 2 (faciliated glucose transporter) member 2, solute carrier family 21 (organic anion transporter) member 9, chloride channel (intracellular) 2 und likely ortholog of mouse mitochondrial solute carrier protein (MCSP).

Das Connexin 37 wurde nur in HIMEC nach 4-stündiger Stimulation herunterreguliert und nach 24 Stunden ausgeschaltet. Die Expression des Gens für carbonic anhydrase IV wurde nur in HIMEC nach 24-stündiger Stimulation ausgeschaltet. 


\subsubsection{Modifikatoren der extrazellulären Matrix}

Tabelle 4.9: Durch TNF- $\alpha$ differenziell regulierte, die extrazelluläre Matrix modifizierende Gene

\begin{tabular}{lcccccc}
\hline Gen & HIMEC $4 \mathbf{h}$ & p-Wert & HIMEC 24h & p-Wert & HMEC 4h & HMEC 24h \\
\hline BMP2 & 5,57 & $<0,05$ & & & & \\
MMP1 & & & $++++^{a}$ & $<0,01$ & ++ & ++ \\
MMP10 & 4,33 & 0,092 & 11,56 & $<0,05$ & ++ & ++ \\
\hline
\end{tabular}

${ }^{a}$ Anschaltungen der Genexpression von Faktor 5 - 10 werden mit einem + gekennzeichnet, bei Faktor $10-25$ mit ++ , bei Faktor $25-50$ mit +++ sowie bei einem Faktor $>50$ mit ++++

Nach TNF- $\alpha$-Stimulation wurden in den untersuchten Endothelzellen die Matrixmetalloproteinasen (MMP) 1 und 10 hochreguliert. Die Anschaltung von MMP1 erfolgte in HIMEC deutlich später und stärker als bei HMEC-1. Das Bone morphogenetic protein 2 (BMP2) wurde nur HIMEC nach 4 Stunden hochreguliert.

\subsubsection{Weitere regulierte Gene}

Tabelle 4.10: Weitere durch TNF- $\alpha$ regulierte Gene (Auswahl)

\begin{tabular}{|c|c|c|c|c|c|c|}
\hline Gen & HIMEC 4h & p-Wert & HIMEC 24h & p-Wert & HMEC 4h & HMEC 24h \\
\hline PSTPIP2 $^{a}$ & 4,59 & $<0,005$ & 7,86 & $<0,005$ & & \\
\hline WTAP $1^{b}$ & 4,96 & $<0,00001$ & 5,76 & $<0,00001$ & 4,33 & \\
\hline $\begin{array}{l}\text { natural killer cell trans- } \\
\text { cript } 4 \text { (NK4) }\end{array}$ & & & 4,81 & $<0,005$ & $+++^{c}$ & ++++ \\
\hline EH-domain containing 1 & 5,44 & $<0,01$ & 4,12 & $<0,005$ & 5,78 & \\
\hline $\begin{array}{l}\text { pleckstrin homology do- } \\
\text { main containing, family } \\
\text { C (with FERM domain) } \\
\text { member } 1\end{array}$ & 4,24 & $<0,00001$ & & & & \\
\hline $\begin{array}{l}\text { myxovirus } \quad \text { (influenza } \\
\text { virus) resistance 1, } \\
\text { interferon-inducible prote- } \\
\text { in p78 (mouse) }\end{array}$ & & & ++ & $<0,005$ & 7,3 & 21,3 \\
\hline LOXL2 & & & ++ & $<0,01$ & & \\
\hline TFPI $^{d}$ & & & $-3,56$ & $<0,05$ & & \\
\hline
\end{tabular}

${ }^{a}$ proline-serine-threonine phosphatase interacting protein 2

${ }^{b}$ Wilms' tumour 1-associating protein

${ }^{c}$ Anschaltungen der Genexpression von Faktor 5-10 werden mit einem + gekennzeichnet, bei Faktor $10-25$ mit ++ , bei Faktor $25-50$ mit +++ sowie bei einem Faktor $>50$ mit ++++

$d_{\text {tissue factor pathway inhibitor (lipoprotein-associated coagulation inhibitor) }}$

Durch Stimulation mit TNF- $\alpha$ wurden in HIMEC und HMEC-1 Gene hochreguliert, angeschaltet oder herunterreguliert, die keiner der aufgeführten funktionellen Gruppe 
eindeutig zuzuordnen sind. Bei beiden Endothelzellen wurden das Wilms' tumour 1associating protein (WTAP1), EH-domain containing 1, myxovirus (influenza virus) resistance 1, interferon-inducible protein p78 (mouse) hochreguliert. Das Gen natural killer cell transcript 4 (NK4) wurde in HMEC-1 zu beiden Zeitpunkten stark angeschaltet, in HIMEC nur schwach nach 24 Stunden. Nur in HIMEC wurden hochreguliert prolineserine-threonine phosphatase interacting protein 2, pleckstrin homology domain containing, family C (with FERM domain) member 1 und lysyl oxidase-like 2 (LOXL2). tissue factor pathway inhibitor (lipoprotein-associated coagulation inhibitor) (TFPI) wurde nur in HIMEC herunterregeguliert.

\subsection{Validierung der Microarray-Ergebnisse durch quantitative Realtime RT-PCR}

Die mittels DNA-Microarray-Technologie gewonnenen Expressionsprofile von HIMEC wurden im Rahmen der vorliegenden Arbeit in Stichproben durch quantitative Realtime RTPCR kontrolliert. Zur Überprüfung wurden drei bisher noch nicht für Endothelzellen beschriebenen Gene ausgewählt: Das Enzym Phospholipase A1 (PS-PLA1), der Zytokinbestandteil Epstein-Barr virus induced gene 3 (EBI3) und der Entzündungsmediator leukocyte specific transcript 1 (LST1). Eine Übersicht der Ergebnisse ist in Tabelle 4.11 dargestellt.

Bei den PCR-Validierungsuntersuchungen wurden die HIMEC neben dem Zytokin TNF$\alpha(20 \mathrm{ng} / \mathrm{ml})$ auch mit den proinflammatorischen Agenzien Interleukin-1 $\beta$ (40 ng/ml), Interferon- $\gamma(20 \mathrm{ng} / \mathrm{ml})$, bakteriellem Lipopolysaccharid (LPS, $1 \mu \mathrm{g} / \mathrm{ml}$ ) sowie der Kombination TNF- $\alpha+$ LPS stimuliert. Die Stimulation erfolgte bei allen PCR-Versuchen und beim Nachweis des EBI3-Proteins mittels Westernblot über einen Zeitraum von 24 Stunden (bei LST1 zusätzlich auch 4-stündige Stimulation). 
Tabelle 4.11: Überprüfung der Microarraydaten mittels Realtime RT-PCR

\begin{tabular}{lcc}
\hline Gen & Bestätigung durch PCR & Bestätigung auf Proteinebene \\
\hline $\begin{array}{l}\text { leukocyte specific tran- } \\
\text { script 1 (LST1) }\end{array}$ & ja (siehe Abb. 4.10) & \\
Phospholipase A1 (PS- & ja (siehe Abb. 4.7) & ja (Enzymaktivitätsassay) \\
PLA1) & ja (siehe Abb. 4.8) & ja (siehe Abb. 4.9) \\
$\begin{array}{l}\text { Epstein-Barr virus in- } \\
\text { duced gene 3 (EBI3) }\end{array}$ & & \\
\hline
\end{tabular}
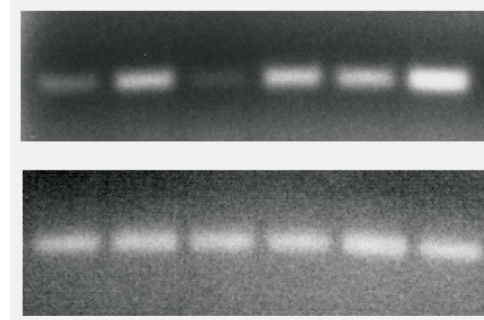

PS-PLA1

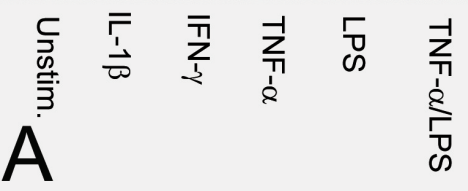

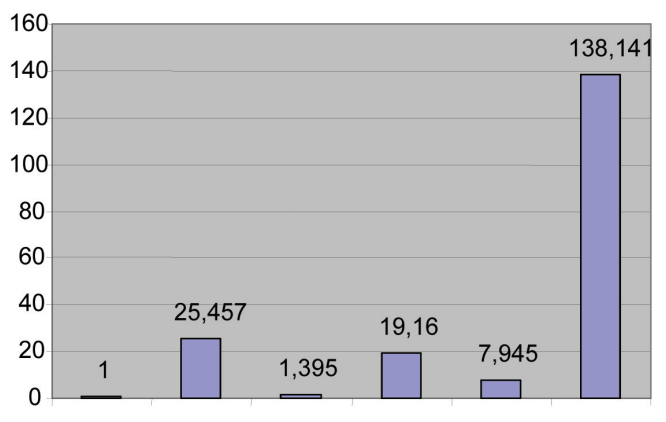

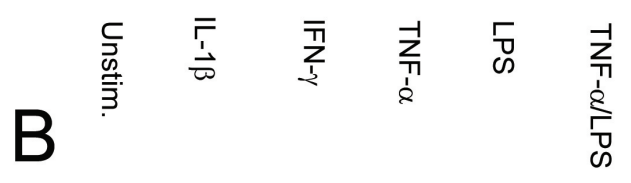

Abbildung 4.7: Bestätigung der Hochregulation von PS-PLA1 in HIMEC nach Stimulation mit TNF- $\alpha$. Abb. A: semiquantitative RT-PCR. Abb. B.: quantitative Realtime RT-PCR
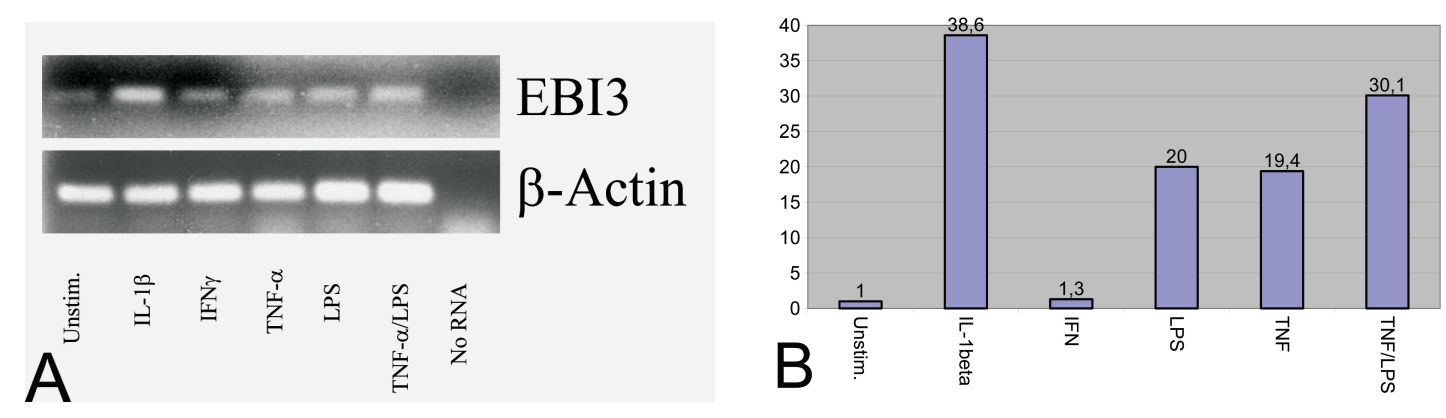

Abbildung 4.8: Bestätigung der Hochregulation von EBI3 in HIMEC nach Stimulation mit TNF- $\alpha$. Abb. A: semiquantitative RT-PCR. Abb. B.: quantitative Realtime RT-PCR 


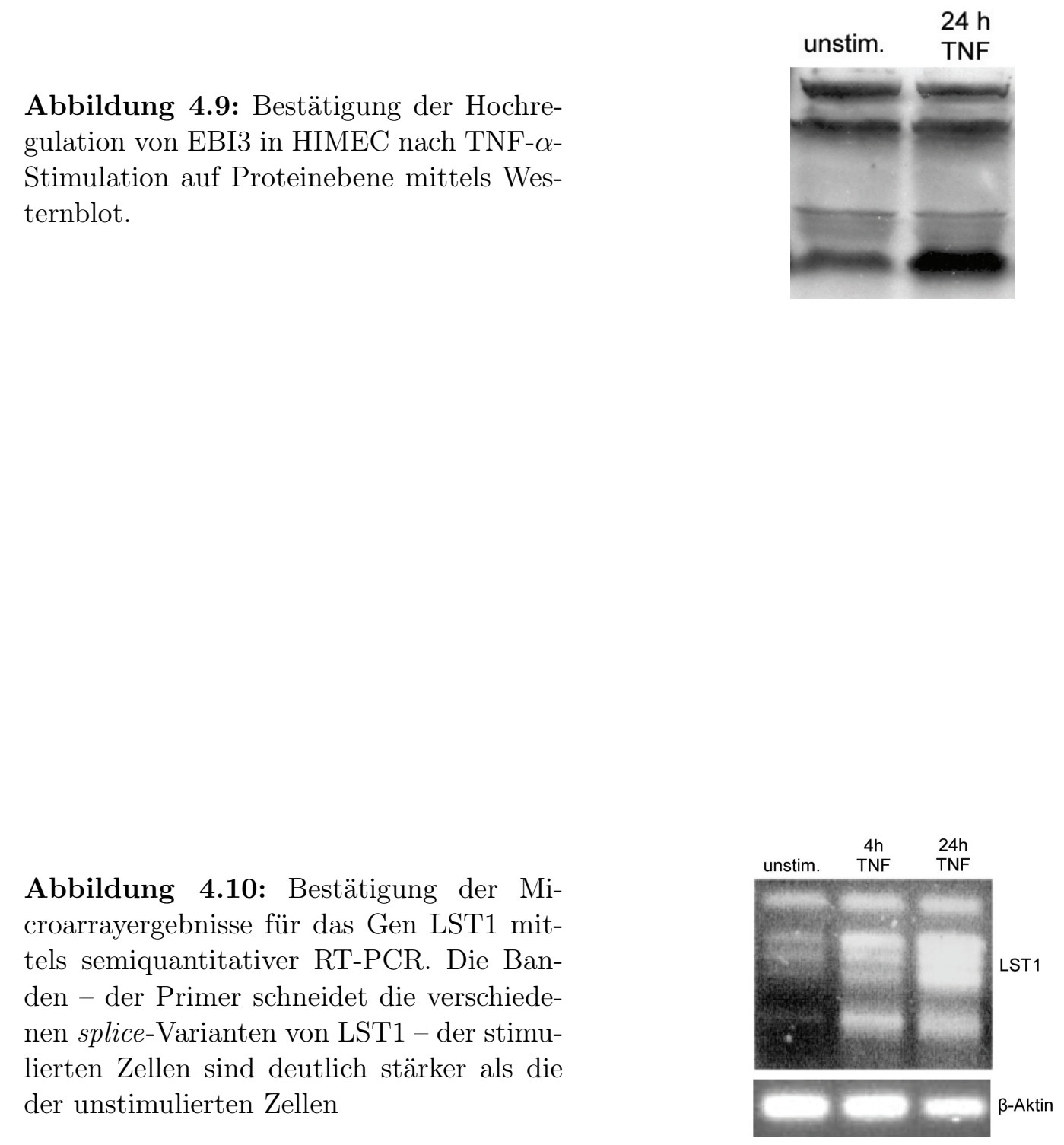




\section{Diskussion}

\subsection{Validität der Datenbasis}

In dieser Arbeit wurde das Genexpressionsprofil humaner intestinaler mikrovaskulärer Endothelzellen (HIMEC) vor und nach Stimulation mit dem proinflammatorischen Zytokin TNF- $\alpha$ untersucht. Die Daten der analog kultivierten und stimulierten mikrovaskulären Endothelzellinie HMEC-1 dienten zum Vergleich.

DNA-Microarrays wurden zuvor bereits mehrfach zur Ermittlung der Genexpressionsprofile von Endothelzellen eingesetzt [116, 200, 52, 184]. Hierbei kamen neben HUVEC auch Primärzellkulturen aus Haut, Leber, Hirn, Aorta und anderer Organe zum Einsatz. Bei ähnlichen Versuchsaufbauten fielen jedoch deutliche Unterschiede in den Genexpressionsprofilen auf. Neben der bekannten Variabilität innerhalb von HUVEC-Kulturen [187] war die Qualität des Versuchsdesigns bei den einzelnen Studien sehr unterschiedlich [184]. Nach Churchill ist die Validität der ermittelten Daten besonders bei DNAMicroarrayexperimenten stark von der Qualität des Versuchsaufbaus abhängig [28].

Einer der Hauptfaktoren für das Erreichen von validen, signifikanten Daten bei MicroarrayExperimenten ist eine ausreichende Anzahl von Wiederholungen der einzelnen Experimente. Weiterhin ist die Anzahl der im Versuchsansatz vorhandenen „technischen Replikationen“ eines Gens von Bedeutung. Die Verwendung von „mismatch probes“ dient zur Vermeidung von Fehlhybridisierungen und falsch-positiven Ergebnissen. Zudem sollte eine möglichst hohe Anzahl von Genen auf dem Microarray repräsentiert sein, um ein möglichst umfassendes Genexpressionsprofil zu erstellen.

In der Vergangenheit wurde z.T. ganz auf Versuchswiederholungen verzichtet bzw. nur eine Wiederholung durchgeführt. Eine Ermittlung von statistischen Signifikanzen ist bei

solchen Versuchsansätze nicht möglich. Mit der in dieser Arbeit durchgeführten dreifachen Versuchswiederholung ist eine solche statistischen Auswertung möglich.

Bei POLACEK et al. wurde abweichend von anderen Arbeiten die sehr große Anzahl 
von 1150 Genen als differenziell reguliert ermittelt [128]. Diese hohe Anzahl signifikant regulierter Gene wurde auf den Aufbau der verwendeten Microarrays zurückgeführt. Diese enthielten nur zwei technische Replikationen pro Gen und keine „mismatch probes“. Trotz der ausreichenden Anzahl von Versuchswiederholungen $(n=3)$ konnte mit den verwendeten Arrays daher kein valides Expressionsprofil erstellt werden. Diese Expressionsdaten wurden nur zu $66 \%$ mittels anderer Verfahren verifiziert. ViEMANN et al. hingegen erzielten einen Verifikationsgrad von fast $100 \%$. Sie verwendeten Microarrays vom Typ Affymetrix HG-U133A mit ausreichender technischer Replikation durch multiple Oligonukleotidsonden für jedes Gen und mismatch probes. Die verwendeten HG-U133A Microarrays enthalten Daten von 13.220 bekannten Genen und 10.000 ESTs [1]. Somit decken die ermittelten Expressionsprofile einen Großteil des menschlichen Genoms ab.

Im Rahmen der vorliegenden Arbeit wurden HG-U133A-Microarrays verwendet und durch eine ausreichende Zahl von Experiment-Wiederholungen die Voraussetzungen für die Ermittlung eines validen Genexpressionsprofils geschaffen. Die Datenverarbeitung mit dem Programm GeneData Expressionist Analyst Pro ermöglichte durch die Normalisierung der experimentellen Daten der Einzelexperimente, die Zusammenfassung der Experimente zu Clustern und eine strenge statistische Auswertung der Ergebnisse eine verlässliche Auswertung. Der Analyst Pro ist auch durch die Möglichkeit der zahlenmäßigen Erfassung von On/Off-Phänomenen den übrigen Softwareprodukten zur Analyse von Microarraydaten überlegen. Die stichprobenartige Überprüfung der Ergebnisse mittels Realtime RT-PCR, FACS und Westernblot konnte bei allen Genen die Microarraydaten bestätigen. Von Bedeutung ist auch, daß zur Validierung der Ergebnisse vor allem Gene, deren Expression in Endothelzellen bislang nicht bekannt war, ausgewählt wurden.

Die zum Vergleich ermittelten Expressionsprofile der mikrovaskulären Referenzzellinie HMEC-1 erfüllen die hohen Qualitätsansprüche der HIMEC-Studie nicht, da aufgrund fehlender Wiederholungen der Einzelexperimente eine statistische Auswertung nicht möglich ist. Auch Variabilitäten der Genexpression, wie z.B. bei On/Off-Phänomenen wichtig, finden hier keine Beachtung. Allerdings wird bei Experimenten mit einer immortalisierten Zellinie wie HMEC-1 keine derartige Variabilität wie bei Primärkulturen erwartet. Die Wahl der HG-U133A-Microarrays mit den erwähnten technischen Replikationen und mismatch probes stellt eine hohe Datenqualität sicher. Die Verwendung der HMEC-1 Genexpressionsprofile erscheint trotz fehlender statistischer Auswertung zum orientierenden Vergleich mit den validen HIMEC-Daten sinnvoll. Gegenüber Genexpressionsdaten von HMEC-1 aus der Literatur haben diese Daten den Vorteil, daß die Referenzzellen unter den gleichen Bedingungen kultiviert und stimuliert wurden wie die intestinalen Primär- 
kulturen.

\subsection{Literaturanalyse des Genexpressionsprofils von HIMEC}

In der vorliegenden Arbeit wurde erstmals das Genexpressionsprofil humaner intestinaler mikrovaskulärer Endothelzellen nach Stimulation mit dem proinflammatorischen Zytokin TNF- $\alpha$ beschrieben. Es wurde die signifikante Hochregulation oder Anschaltung von 62 bzw. 68 Genen nach vierstündiger Stimulation und von 115 bzw. 52 Genen nach 24 Stunden TNF- $\alpha$-Behandlung gezeigt. Signifikant herunterreguliert wurden 13 bzw. 44 Gene, die Expression von 3 bzw. 18 Genen wurde ausgeschaltet. Durch Stimulation mikrovaskulärer Endothelzellen der Kolonmukosa, welche eine Schlüsselrolle in der Pathogenese der CED spielen, mit TNF- $\alpha$, einem bei CED pathogenetisch wichtigem Zytokin, konnten Hinweise auf ihre funktionelle Bedeutung im Rahmen der chronischen Entzündung gezeigt werden.

Um Gene mit potentieller Bedeutung im Gastrointestinaltrakt zu identifizieren, wurde das Expressionsprofil der mikrovaskulären Referenzendothelzellinie HMEC-1 unter identischen Versuchsbedingungen ermittelt. Aufgrund der bekannten Heterogenität von Endothelzellen waren Unterschiede der Genexpressionsprofile der beiden mikrovaskulären Zellpopulationen waren zu erwarten. Gene, die in HIMEC anders reguliert werden als in HMEC-1 könnten Hinweise auf die Rolle des Endothels im Rahmen der Entstehung von CED geben. Unter Berücksichtigung der organspezifischen Heterogenität der Endothelzellen wäre eine im Bereich der Darmmukosa angreifende spezifische immunmodulatorische Therapie denkbar.

Der in dieser Arbeit beschriebene deutliche Unterschied zwischen den Expressionsprofilen zweier mikrovaskulärer Zellpopulationen ist größer als erwartet (siehe Abbildung 4.6, Seite 50). Eine Übereinstimmng von weniger als $50 \%$ der hochregulierten bzw. angeschalteten Gene und weniger als $10 \%$ der herunterregulierten Gene wäre ensprechend der Ergebnisse von RIBATTi et al. zwischen den Endothelien funktionell völlig unterschiedlicher Organe (z.B. Leber und Gehirn) eher erwartet worden [136]. Bei der vorliegenden Arbeit stammten die Zellen aus Darmschleimhaut (HIMEC) und Haut (HMEC-1). CHI et al. zeigten für diese zwei mikrovaskulären Endothelzellpopulationen eine relative Ähnlichkeit der unstimulierten Genexpressionsprofile [26]. Durch Einfügen von Genomsequenzen von Tumorzellen wurde das Expressionsprofil der HMEC-1 Zellinie anscheinend grundlegend 
verändert.

Die vorliegende Arbeit wurde mit HMEC-1 Zellen durchgeführt, da sie ein Standardmodell für Mikrovaskulatur darstellen und konstant verfügbar sind [195]. Durch den Einsatz von Primärkulturen mikrovaskulärer Endothelzellen anderer Organe hätte ein nicht durch Immortalisierung verändertes Vergleichs-Genexpressionsprofil ermittelt werden können.

Weiterhin wurden in dieser Arbeit HIMEC aus chirurgischen Darmresektaten nicht an CED erkrankter Patienten isoliert. BINION et al. beschrieben die unterschiedliche Leukozyten-Bindungsfähigkeit von HIMEC gesunder und an CED erkrankter Patienten $[16,17]$. Die Autoren führten diese Eigenschaft auf einen im Laufe der CED „erworbenen Defekt" der Zellen zurück. Daher erscheinen HIMEC aus Darmresektaten gesunder Patienten zunächst als Modell der CED nicht sinnvoll. Allerdings muß zum Nachweis eines erworbenen Defektes der Genexpression zunächst das normale Expressionsprofil von HIMEC ermittelt werden. Ein Vergleich dieses Profils mit dem Expressionsprofil von HIMEC aus Darmabschnitten von CED-Patienten zur Identifikation der für den von BINION beschriebenen Defekt verantwortlichen Gene wird in Folgeexperimenten unternommen werden.

Im Folgenden werden eine Auswahl der in HIMEC differenziell regulierten Gene und ihre potentielle Relevanz für CED diskutiert. Entsprechend der im Ergebnisteil erwähnten GENE ONTOLOGY Einteilung der Gene nach ihrer biologischen Funktion werden die ausgewählten Gene gruppenweise beschrieben [6]. Der Schwerpunkt der Analyse lag bei den bisher noch nicht für Endothel oder Darmendothel beschriebenen Genen sowie den nur im Darm, jedoch nicht in der Referenzzellinie regulierten neuen spezifischen Kandidatengenen.

\subsubsection{Oberflächenrezeptoren}

Zur Rekrutierung von Leukozyten produzieren Endothelzellen für das Organ und die Umgebung spezifische Muster von Oberflächenadhäsionsmolekülen und Chemokinen. Durch die Stimulation mit dem proinflammatorischen Zytokin TNF- $\alpha$ werden für die jeweiligen Endothelzellen spezifische Muster dieser Moleküle differenziell reguliert. HiLlyer et al. sehen in diesen spezifischen, heterogenen Expressionsmustern eine Erklärung der sich von Gewebe zu Gewebe unterscheidenden im Rahmen einer Entzündungsreaktion rekrutierten Leukozytenpopulationen [64]. Die Analyse dieser Expressionsmuster bei HIMEC kann zu einem genaueren Verständnis der Vorgänge bei der CED führen.

Erwartungsgemäß werden durch die Stimulation mit dem proinflammatorischen Zyto- 
kin TNF- $\alpha$ Oberflächenadhäsionsmoleküle, die der Rekrutierung und Extravasation von Leukozyten dienen, hochreguliert. Die Regulation von E-Selektin, VCAM-1 und ICAM-1 wurde in HIMEC und HMEC-1 nachgewiesen und ist für alle Endothelzellen bekannt. Die ICAM-1 und E-Selektin-Expression ist bei CED erhöht [54], eine Blockade oder Hemmung der Translokation von ICAM-1 kann bei der Therapie von CED mittels antisense-Oligonukleotiden positive Effekte zeigen [196]. Antikörper gegen VLA4, den Liganden von VCAM-1, führen bei entzündlichen Erkrankungen zu einer Besserung [69].

Das Adhäsionsmolekül CD44 spielt bei chronisch entzündlichen Erkrankungen wie CED eine Rolle als Adhäsionsmolekül auf aktivierten T-Lymphozyten. CD44 bindet auf Endothelzellen durch TNF- $\alpha$ oder IL-15 Stimulation hochregulierte Hyaluronsäure [41]. Eine Blockade von CD44 führt über Apoptoseinduktion in T-Zellen zu einem Schutz gegen schwere Kolitis im Mausmodell [193]. Für HUVEC ist eine Hochregulation von CD44 nach TNF- $\alpha$-Stimulation auf Endothelzellen beschrieben [81], für Darmendothelzellen nicht. Nach CHI et al. ist die Expression von CD44 in unstimulierten Endothelzellen auf das Endothel von Arterien beschränkt [26]. Die hier beschriebene Hochregulation des Gens um den Faktor 4,16 nach 24 Stunden ist als eher gering anzusehen.

Das Gen für CD58 (lymphocyte function-associated antigen-3 (LFA-3) wurde nur in HIMEC schwach (Faktor 3,7 nach 4 Std.) hochreguliert. LFA-3 ist als kostimulatorisches Molekül von T-Lymphozyten bekannt. Durch LFA-3 wird antigenunabhängig eine maximale Zytokinsekretion, Proliferation und Aktivierung von T-Zellen induziert. Eine konstitutive Expression auf intestinalem Epithel ist bekannt [99]. Über die Interaktion LFA-3/CD2 können intestinale Epithelzellen intraepitheliale T-Lymphozyten stimulieren [83]. MESTAS et al. zeigten die Expression von LFA-3 in aktivierten Endothelzellen, eine Blockade von LFA-3 führte zu einer deutlich verminderten T-Zellaktivierung [106].

Das Gen für CD74 (MHC class II invariant chain) wurde sowohl in HIMEC als auch in HMEC-1 hochreguliert. CD74 ist für die Beladung von MHC II Molekülen in endosomalen Kompartimenten wichtig [35]. In der Darmwand von CED-Patienten ist die CD74-mRNA erhöht [87]. Für Endothelzellen ist eine CD74-Expression bisher nicht beschrieben.

Das nur in HIMEC auf RNA-Ebene schwach (Faktor 3,25 nach 4 Stunden) hochregulierte CD83 ist als Marker reifer dendritischer Zellen (DC) bekannt. Für Endothelzellen wurde eine Expression von CD83 bisher nicht berichtet [113].

Der CSF2RB (colony stimulating factor 2 receptor beta (granulocyte-macrophage)) wurde nur in HIMEC hochreguliert, er ist ein Teil des Rezeptors für das Zytokin granulocyte macrophage colony stimulating factor (GMCSF) und wird auf aktivierten Endothelzellen exprimiert. Seine Aktivierung fördert die Proliferation von Endothelzellen [38]. 
Der G-protein-coupled receptor 56 (GPR56) ist ein orphan receptor, also ein Rezeptor, dessen Ligand noch unbekannt ist. Über eine Funktion im Rahmen entzündlicher Reaktionen ist derzeit noch nichts bekannt [96]. GPR56 wurde durch TNF- $\alpha$ in HIMEC zu beiden Zeitpunkten, in HMEC-1 nur nach 4 Stunden Stimulation hochreguliert. Ähnliches gilt für das nur bei HIMEC, hier aber stärker als GPR56 (Faktor 12,24 gegenüber 5,8 bei vierstündiger Stimulation) hochregulierte Gen G-protein-coupled receptor (GPR), ein chemokine orphan receptor.

Sowohl nach 4- als auch 24-stündiger Stimulation wurde die Expression des Interleukin3-Rezeptors (IL3R) in HIMEC angeschaltet. Er gehört wie der Rezeptor für das Zytokin GMCSF zur Hämatopoietin-Rezeptorfamilie. Diese Rezeptoren besitzen eine für das Zytokin spezifische $\alpha$-Untereinheit und eine gemeinsame $\beta$-Untereinheit [102]. Diese $\beta$ Untereinheit des GMCSF-Rezeptors, das Gen CSF2RB wurde wie IL3R nur in HIMEC hochreguliert. Diese Hochregulation erfolgte erst nach 24 Stunden, während IL3R schon nach vier Stunden deutlich (10-25x) angeschaltet wurde. Die Aktivierung des IL3R in Endothelzellen führt ähnlich wie eine Aktivierung durch GMCSF zu einer erhöhten Proliferation und Angiogenese [34]. Eine Rolle des IL3R bei CED ist bisher nicht bekannt, bei einer akuten Shigelleninfektion jedoch wird die mukosale Expression des IL3R, aber nicht des GMCSF-Rezeptors herunterreguliert [133]. Eine Änderung der Expression des Interleukin 5 Rezeptors, auch ein Mitglied der Hämatopoietin-Rezeptorfamilie, konnte für HIMEC oder HMEC-1 nicht nachgewiesen werden. Dieses Phänomen hängt eventuell mit der Nachbarschaft von IL3R und CSFR auf dem X-Chromosomen zusammen, das Gen für IL5R befindet sich auf Chromosom 3 [102].

Das Gen monocyte to macrophage differentiation-associated (MMD) wurde nur nach vierstündiger Stimulation in HIMEC schwach (Faktor 4,52) hochreguliert. MMD wurde als Rezeptormolekül reifer Makrophagen beschrieben, seine Funktion in Endothelzellen ist unklar [135].

Das Gen für coxsackie virus and adenovirus receptor (CAR) wurde in beiden Endothelzellpopulationen durch TNF- $\alpha$-Stimulation herunterreguliert. CAR ist der endotheliale Oberflächenrezeptor für Adenoviren, VINCENT et al. zeigten die Herunterregulation von CAR in Zytokin-stimulierten Endothelzellen. Die Autoren postulierten einen protektiven Einfluß der CAR-Herunterregulation gegenüber adenoviraler Infektion bei Entzündungszuständen [185]. 


\subsubsection{Zytokine}

Durch Stimulation mit TNF- $\alpha$ wurden in beiden Endothelzellarten Zytokine hochreguliert oder angeschaltet. Die Hochregulation von IL15 und Lymphotoxin $\beta$ in HIMEC und HMEC-1 ist bereits bekannt.

Das Epstein-Barr virus induced gene 3 (EBI3) wurde nur in HIMEC deutlich (4h TNF: 10-15x; 24h TNF. 25-50x) angeschaltet. EBI3, strukturell verwandt mit IL12p40 wird von intestinalen Epithelzellen, aktivierten dendritischen Zellen, B-Zellen und in der Plazenta exprimiert. Zusammen mit dem IL12p35 verwandten Molekül p28 bildet es das Zytokin Interleukin 27. IL27 stimuliert die klonale Vermehrung von naiven CD4-T-Zellen, hat Bedeutung in der Th2-Immunantwort und fördert zusammen mit IL12 die IFN- $\gamma$ Produktion von T-Zellen. Nach MAASER et al. produziert das intestinale Epithel zwar EBI3, aber nicht p28. Die Autoren vermuten daher eine Rolle für einen anderen, noch unbekannten Reaktionspartner für EBI3 im Epithel [100]. Auch in HIMEC konnte eine differenzielle Expression von p28 und anderen Mitgliedern der IL12-Familie nicht nachgewiesen werden. Eine Expression von EBI3 ist außer für intestinales Epithel und Endothel nur für Plazenta und Blutzellen bekannt. Eine wichtige Rolle von EBI3 bei intestinalen Entzündungsprozessen ist daher zu diskutieren.

\subsubsection{Chemokine}

Wie oben erwähnt, sahen HiLlyer et al. in dem Chemokin-Expressionsmuster der Endothelzellen einen Schlüssel zum Verständnis der Rekrutierung einer gewebsspezifischen Leukozytenpopulation im Rahmen einer Entzündung [64].

In HIMEC und HMEC-1 wurden eine Anzahl von Chemokinen der CC- und CXCFamilien durch TNF- $\alpha$-Stimulation hochreguliert. In HIMEC, aber nicht in HMEC-1 wurden die Chemokine CXCL6 (GCP-2) und CX3CL1 (Fractalkine) hochreguliert bzw. angeschaltet. CCL2 (MCP-1) hingegen wurde nur in HMEC-1 reguliert.

Das Chemokin GCP-2 bindet wie IL8 an den Rezeptor CXCR1. GiJsBers et al. konnten die vermehrte Expression von GCP-2 im mikrovaskulären intestinalen Endothel bei CED zeigen. Bei diesen in vivo Beobachtungen wurde gezeigt, daß mit GCP-2 strukturell (CXCL5 (ENA-78)) oder funktionell (CXCL8 (IL8)) verwandte Chemokine nicht erhöht waren, während sie bei in vitro Beobachtungen an stimulierten Endothelzellkulturen deutlich stärker erhöht waren als GCP-2 [50]. Diese Beobachtung konnte in der vorliegenden Arbeit bestätigt werden. Die scheinbar prominente Rolle von GCP-2 in den in vivo Studien zusammen mit der nur in HIMEC gezeigten Hochregulierung unterstreicht die Rolle 
von GCP-2 als potentielles Kandiatengen.

Die differenzielle Expression von Fractalkine (CX3CL1) ist nur für wenige Endothelzellarten beschrieben, darunter makrovaskuläre ECs und das mikrovaskuläre intestinale Endothel [63]. Fractalkine ist das einzige bekannte Chemokin der CX3C-Familie. Es initiiert über seine Bindung an den Rezeptor CX3CR1 intrazelluläre Prozesse, die u.a. zur Expression von Adhäsionsmolekülen führen. Weiterhin ist Fraktalkine durch seine feste Bindung an den Rezeptor direkt an der Adhäsion von CX3CR1-positiven Leukozyten an das Endothel beteiligt. Eine Hochregulation der Fractalkine-Expression in der intestinalen Mukosa bei CED konnte von MÜHLHOFER et al. gezeigt werden [115]. Da Fractalkine so selektiv exprimiert wird, wäre auch dieses Chemokin als Kandidatengen für eine immunmodulatorische Therapie denkbar. Allerdings fanden CoOK et al. bei Fractalkine-knockout Mäusen keinen Unterschied im Verlauf einer DSS-induzierten Kolitis [29].

Das Chemokin CCL2 (MCP-1) wurde nur bei HMEC-1, nicht bei HIMEC hochreguliert. Allerdings ist eine erhöhte Expression von MCP-1 bei CED bekannt [10]. Diese erhöhte MCP-1 Expression ist allerdings nur für Epithelzellen und intraepithelialen Leukozyten bekannt, im Stroma, wo die Mikrovaskulatur lokalisiert ist, wurde MCP-1 jedoch nicht nachgewiesen.

\subsubsection{Entzündungsreaktion}

Durch Stimulation mit dem proinflammatorischen Zytokin TNF- $\alpha$ wurden in den untersuchten Endothelzellen Mediatoren der Entzündungsreaktion hochreguliert oder angeschaltet.

Das Enzym Cyclooxygenase 2 (COX-2) wurde nur in HIMEC hochreguliert. Eine Hochregulation von COX-2 durch TNF- $\alpha$-Stimulation war bereits für mikrovaskuläre Hirnendothelzellen gezeigt worden [101]. COX-2 vermittelt die Prostaglandinsynthese aus der Arachidonsäure. Prostaglandine wirken proinflammatorisch. Mikrogefäßen von intestinalen Tumoren zeigen eine erhöhte COX2-Expression, eine COX-2-Hemmung führt zu einer Hemmung der Tumorangiogenese [168]. Durch die Inhibition von COX-2 durch Cyclosporin A oder Natriumbutyrat wird die Angiogenese von HIMEC gehemmt [131]. Die für COX-2 in HIMEC ermittelten Regulationswerte waren nicht signifikant (4h TNF: $\mathrm{p}=$ 0,069, 24h TNF: $\mathrm{p}=0,053)$, aufgrund der Vorbeobachtungen der Gruppe von BINION wird eine Hochregulation von COX-2 in HIMEC aber als wahrscheinlich angesehen.

Weiterhin wurden zwei Phospholipasen hochreguliert. Die phosphatidylserinspezifische Phospholipase A1 (PS-PLA1) wurde in HIMEC und HMEC-1 nach 24-stündiger TNF- $\alpha$ - 
Stimulation um den Faktor 10-25 angeschaltet, die Phospholipase A2 Typ IV A (PLA2) wurde nur in HIMEC hochreguliert. Eine Hochregulation der PLA2 durch TNF- $\alpha$-Stimulation in Endothelzellen ist bekannt [174], die fehlende Hochregulation in HMEC-1 ist überraschend. Eine endotheliale Expression der PS-PLA1 konnte bisher nicht gezeigt werden. PS-PLA1 vermittelt die Bildung von Acyllysophosphatidylserin (LysoPS) aus dem Phosphatidylserin der Zellmembranen apoptotischer Zellen oder aktivierter Thrombozyten [4]. LysoPS aktiviert Mastzellen und T-Zellen. Hosono et al. zeigten eine durch Lyso-PS induzierte Ausschüttung von Histamin aus Mastzellen [66]. Für ein von Schistosomen produziertes Lyso-PS konnte eine Wirkung auf den Toll-like receptor 2 (TLR2) nachgewiesen werden [183]. Aufgrund der großen Homologien dieser Lipidmediatoren ist eine Wirkung des durch PS-PLA1 produzierten Lyso-PS auf andere Rezeptoren dieser Familie denkbar.

Das Gen leukocyte specific transcript 1 (LST1) wurde nur in HIMEC nach 24-stündiger Stimulation deutlich (25-50x) angeschaltet. Eine konstitutive Expression von LST1 wurde bisher in Leukozyten, dendritischen Zellen, Milz, Lunge, Tonsille und einer Leberzellinie nachgewiesen. In Monozyten kann die Expression von LST1 durch IFN- $\gamma$-Stimulation deutlich gesteigert werden. Das Gen liegt in der major histocompatibility complex (MHC) Klasse IV Region auf Chromosom 6. Diese Region kodiert für Gene mit besonderer Bedeutung bei Entzündungsreaktionen, u.a. TNF- $\alpha$ und Lymphotoxin- $\beta$. LST1 besitzt eine Vielzahl von Spleißvarianten mit unterschiedlichen, z.T. noch unbekannten Funktionen [139]. Neben einer Induktion von langen Filopodien und Morphologieänderungen in LST1transfizierten Zellen [132] wurde eine Hemmung der Lymphozytenproliferation beobachtet [139]. LeHner et al. zeigten die Interaktion einer LST1-Spleißvariante mit dem I $\kappa \mathrm{B} \alpha$ ubiquitinierenden Cactin-Komplex [89]. Eine Förderung der Ubiquitinierung führt zu einer Aktivierung des NF $\kappa$ B-Signalwegs, über welchen die Bildung verschiedener Entzündungsmediatoren reguliert werden [184].

\subsubsection{Transkriptionsfaktoren und Signaltransduktion}

Durch TNF- $\alpha$-Stimulation wurden in HIMEC und HMEC-1 mehrere Gene hochreguliert oder angeschaltet, die Transkriptionsfaktoren sind oder eine Funktion in der Signaltransduktion haben.

Bei beiden Endothelzellpopulationen wurden wie erwartet Komponenten des NF $\kappa$ BSignalwegs reguliert [184]. NF- $\kappa \mathrm{B} 2, \mathrm{I} \kappa \mathrm{B} \alpha$ und $\mathrm{I} \kappa \mathrm{B} \epsilon$ wurden in beiden Zellinien hochreguliert, NF- $\kappa$ B 1 nur bei HMEC-1. Ein Großteil von den in Endothelzellen durch TNF- $\alpha$ - 
Stimulation hochregulierten Gene ist vom NF- $\kappa$ B-Signalweg abhängig [184]. Durch Hochregulation des diesen Signalweg inhibierenden Gens $\mathrm{I} \kappa \mathrm{B} \alpha$ kommt es zu einer negativen Rückkopplung. Die Induktion von $\mathrm{I} \kappa \mathrm{B} \epsilon$ hat auch eine rückkoppelnde Funktion, allerdings eher im Sinne eines Regelkreislaufes, um bei längerdauernder Aktivierung des NF- $\kappa$ BSignalwegs eine gleichmäßige Funktion sicherzustellen [65]. So erklärt sich die später als bei $\mathrm{I} \kappa \mathrm{B} \alpha$ stattfindende Hochregulation des Gens $\mathrm{I} \kappa \mathrm{B} \epsilon$. Die nur in der Zellinie HMEC1 und nicht bei HIMEC gefundene Hochregulation von NF- $\kappa \mathrm{B} 1$ scheint angesichts der geringen Regulation $(3,04 \mathrm{x})$ eher durch die bei der Auswertung der Versuche gewählte Ausschlussgrenze (Regulationsfaktor $>3 \mathrm{x}$ ) begründbar als durch eine in HIMEC veränderte Signalkaskade. Auch in HIMEC wurden viele NF- $\kappa$ B-abhängige Gene reguliert.

S100A11 (Calgizzarin), ein Mitglied der Calcium-bindenden S100-Proteinfamilie, wurde nur in HIMEC hochreguliert. S100A11 wirkt hemmend auf die Zellproliferation. Durch einen hohen Calciumspiegel wird S100A11 phosphoryliert und an Nucelolin gebunden in den Zellkern transportiert. Dort hemmt es die Transkription über den p21 ${ }^{\mathrm{CIP} 1 / \mathrm{WAF}}$ Mediator [149]. Die S100A11-Expression sinkt bei maligner Transformation von Zellen. Die S100A11-Expression im gesunden Drüsengewebe ist bekannt, nicht aber im Endothel [78]. Die genaue Funktion von S100A11 im mikrovaskulären Endothel ist nicht geklärt. Eine Hemmung der Zellproliferation auf einen proinflammatorischen Stimulus ist mit einem Kontext von hochregulierten Proliferations- und Angiogenesegenen nicht in Einklang zu bringen. Zur Klärung der Rolle dieses Gens in der intestinalen Immunantwort sind weitergehende Studien notwendig.

Der Transkriptionsfaktor NK3 transcription factor related, locus 1 (drosophila) (NKX3.1) wurde nur in HIMEC durch TNF- $\alpha$-Stimulation hochreguliert. Die Expression von NKX3.1 ist in Prostata, Hoden und Karzinomen der Mamma und Prostata sowie geringer in Tonsillen und Nieren beschrieben. In der Prostata hat NKX3.1 einen wachstumshemmenden und differenzierungsfördernden Effekt auf Epithelzellen [46]. Eine NKX3.1-Expression ist in Endothelzellen oder intestinalem Gewebe nicht bekannt.

Das Gen Nibrin, welches nur in HIMEC hochreguliert wurde, ist an Reparationsvorgängen von DNA-Doppelstrangbrüchen beteiligt. Nach DNA-Doppelstrangbrüchen wird $N i$ brin phosphoryliert und in einem MRE11/Rad50/Nibrin-Komplex in den Zellkern transportiert. Dort ist es an der Kontinuitätswiederherstellung der DNA beteiligt. Ein Mangel oder eine Mutation von Nibrin löst eine erhöhte Empfindlichkeit gegenüber ionisierender Strahlung mit dem Krankheitsbild des Nijmegen breakage syndrome aus [25]. Eine differenzielle Expression von Nibrin in TNF- $\alpha$-stimulierten makrovaskulären Endothelzellen (HUVEC) wurde gezeigt [184]. Da TNF- $\alpha$ indirekt DNA-Doppelstrangbrüche auslösen 
kann, wenn auch in geringerem Maße als ionisierende Strahlung, erscheint die Hochregulation von Nibrin in HIMEC plausibel [201]. Die nicht gesteigerte Expression in HMEC-1 läßst sich nicht erklären. Angesichts des geringen Regulationsfaktors bei HIMEC (Faktor 3,22 bzw. 4,24) kann aufgrund des gewählten Einschlusskriteriums Regulationsfaktor > 3 eine Regulation des Gens in HMEC-1 durch den Auswertungsmodus verloren gegangen sein.

Follistatin-like 3 (secreted glycoprotein) (FSTL3) wurde nur in HIMEC nach vierstündiger TNF- $\alpha$-Stimulation hochreguliert. FSTL3 bindet Activin und bone morphogenetic proteins (BMP) und inhibiert so ihre Wirkung. Da BMP2 (siehe unten) durch TNF$\alpha$-Stimulation ebenfalls nur in HIMEC zum selben Zeitpunkt und mit einem ähnlichen Faktor hochreguliert wurde, erscheint ein Zusammenhang der Regulation beider Gene im Rahmen der intestinalen Immunantwort möglich. Bisher war eine Expression von FSTL3 nur in Hoden und in geringerem Maße in Herz, Nieren und Lunge bekannt [179]. Welche Funktion das Gen in der intestinalen Mikrovaskulatur hat, ist nicht geklärt. Die paradox erscheinende Herunterregulation von Follistatin nach 24-stündiger Stimulation in HIMEC ist eventuell durch einen negativen Rückkopplungsmechanismus zu erklären.

Der Transkriptionsfaktor nuclear factor of activated T-cells 1 (NFAT1) wurde nur in HIMEC schwach $(3,62 \mathrm{x})$ nach vierstündiger Stimulation hochreguliert. NFAT1 wird nach Aktivierung von T-Zellen durch Calcineurin dephosphoryliert, in den Zellkern transloziert und bindet dort an die enhancer-Regionen von Zytokinen, Chemokinen und Rezeptoren [73]. Dieser Signalweg wird durch die Substanzen Cyclosporin A und FK506 gehemmt, welche beide im Rahmen der CED-Therapie eingesetzt werden [120]. Neben Blutzellen ist NFAT auch in Chondrozyten, Myozyten, Adipozyten und Endothelzellen beschrieben, dort wirkt es auf die Zell-Differenzierung. Beim Endothel ist der NFAT-Signalweg wichtig für die Angiogenese, z.B. durch VEGF [199]. Die fehlende Hochregulation von NFAT1 in HMEC-1 scheint wie beim Gen Nibrin möglicherweise eher verfahrensbedingt zu sein als durch eine biologische Diversität begründet.

Das Gen Jagged 1, ein Notch-Ligand, wurde nur in HIMEC schwach nach vierstündiger Stimulation hochreguliert (3,23x). Eine Aktivierung des Notch-Signalwegs führt zu einer Differenzierung und Proliferation von Zellen. Jagged 1 wurde immunhistochemisch im Darmendothel und -Epithel nachgewiesen, ebenso Notch [152]. Eine Stimulation von Endothelzellen mit Jagged 1 hat eine mesenchymale Umwandlung der Zellen mit Herunterregulation von endothelialen Genen wie PECAM-1 und der endothelialen NO-Synthase und Hochregulation von mesenchymalen Genen wie Aktin und Fibronektin zur Folge [119]. Bei Angiogeneseprozessen wurde eine signifikante Hochregulation von Jagged 1 in Endo- 
thelzellen gezeigt [13]. Da in HIMEC auch andere Gene mit möglicher Funktion im Rahmen der Angiogenese und Proliferation durch TNF- $\alpha$-Stimulation vermehrt exprimiert werden, überrascht eine Hochregulation von Jagged 1 nicht. Allerdings erfolgt die Hochregulation der anderen Gene zumeist erst nach 24-stündiger Stimulation. Da Jagged 1 aber am Anfang des Notch-vermittelten Signalwegs steht, ist die alleinige Hochregulation nach vierstündiger Stimulation erklärbar.

Eine Induktion von Jagged 1 erfolgt über den NF $\kappa$ B-Signalweg oder über den Transkriptionsfaktor p63, ein Mitglied der p53-Familie [11, 155]. Mitglieder der NF $\kappa$ B-Familie wurden beim Zeitpunkt 4 Std. in beiden Endothelzellarten hochreguliert, p63 nur in HIMEC nach 24-stündiger Stimulation. Die Expression von p63 ist konstitutiv nur in Epithelzellen bekannt, p63 ist wie die verwandten Gene p53 und p73 an der zellulären Antwort auf DNA-Schädigung beteiligt. Anders als bei p53 hingegen löst ein Mangel an p63 keine maligne Transformation von Zellen sondern eine Hemmung der Differenzierung aus [114].

Der Transkriptionsfaktor basic helix-loop-helix domain containing, class B, 2 (bHLHB2,DEC1) ist ein Zielgen des Notch-Signalwegs . Das Gen wurde wie der Notch-Ligand Jagged 1 nur in HIMEC zu beiden Zeitpunkten deutlich angeschaltet (4h TNF: 10-25x, 24h TNF: 5-10x). Eine Expression der Gene der helix-loop-helix-Familie ist für viele Zellarten bekannt, in Chondrozyten wurde ein Einfluß von bHLHB2 auf die Differenzierung der Zellen nachgewiesen. Eine Rolle im Endothel oder bei Entzündungsreaktionen ist für bHLHB2 nicht bekannt. bHLHB2 hemmt die eigene Transkription im Sinne einer negativen Rückkopplung [162]. Daher kann der abnehmende Anschaltungsfaktor für bHLHB2 sowohl durch die auf den früheren Zeitpunkt beschränkte Hochregulation des Notch-Liganden Jagged 1 als auch auf den Rückkopplungsmechanismus zurückgeführt werden.

Das Gen für inhibitor of DNA binding 1, dominant negative helix-loop-helix protein (ID1) wurde in HIMEC und HMEC-1 nach 24-stündiger Stimulation herunterreguliert. ID1 hemmt Transkriptionsfaktoren der helix-loop-helix-Familie und hat einen negativen Einfluß auf Zellproliferation und -differenzierung. Die Herunterregualtion von ID1 führt also zu einer Förderung der Proliferation über Transkriptionsfaktoren wie bHLHB2.

Das Gen für T-box 1 (Tbx1) wurde in beiden Endothelzellpopulationen herunterreguliert. Tbx1 gehört zur Familie der T-box Transkriptionsfaktoren, die eine wichtige Rolle in der Entwicklung spielen. Eine Expression von Tbx1 ist für den Aortenbogen bekannt, Mutationen im Tbx1-Gen führen dort zu Fehlbildungen [192]. Die Funktion von Tbx1 im mikrovaskulären Endothel ist bisher unbekannt. 


\subsubsection{Apoptose und Zellproliferation}

Durch TNF- $\alpha$-Stimulation werden in Endothelzellen pro- und antiapoptotische Gene differenziell reguliert. Die Hochregulation von Mitgliedern der Familie TNF-induzierter Gene in beiden Endothelzellpopulationen wurde bei dieser Arbeit erwartet. Unterschiede zwischen HIMEC und der Referenzzellinie HMEC-1 bestehen in einer nur in HIMEC stattfindenden Hochregulation von Caspase 1 (CASP1) und in der Regulation von Caspase 8 (CASP8).

KING et al. postulierten eine Rolle der CASP1 bei der durch Serumentzug-induzierten Apoptose von Endothelzellen [75]. Da die Hochregulation der CASP1 erst nach 24-stündiger Stimulation in serumarmem Medium erfolgte und die Endothelzellen zuvor bereits über einen Zeitraum von 16 Stunden in serumarmen Medium (1\% FCS gegenüber 10 \% FCS in normalem Endothelzellmedium) kultiviert wurden, läßt sich die Hochregulation in den empfindlicheren HIMEC gegenüber den HMEC-1 erklären. Andererseits ist eine proinflammatorische Funktion der CASP1 durch Aktivierung von IL-1 $\beta$ und Interleukin 18 sowie des NF $\kappa$ B-Signalwegs bekannt [85]. Weder IL-1 $\beta$ noch Interleukin 18 werden in HIMEC hochreguliert, die Transkription vieler hochregulierter Gene wird aber über den $\mathrm{NF} \kappa \mathrm{B}-\mathrm{Weg}$ vermittelt. Ob die Aktivierung und Hochregulation von $\mathrm{NF} \kappa \mathrm{B}$ auf die TNF$\alpha$-Stimulation zurückzuführen ist oder ob CASP1 auch eine Rolle bei der Initiation der intestinalen Entzündungsreaktion über $\mathrm{NF} \kappa \mathrm{B}$ spielt ist, muß im Rahmen weiterer Studien geklärt werden.

Die Initiatorcaspase 8 wurde in HIMEC und HMEC-1 hochreguliert, in HIMEC allerdings nur nach vierstündiger Stimulation und ca. 50 \% schwächer als in HMEC-1. Nach Bindung von apoptoseinduzierenden Rezeptoren der TNF-Familie (TNFR, Fas, TRAILR) an ihre Liganden (TNF- $\alpha$, FasL, TRAIL) erfolgt die Rekrutierung von FADD (Fasassociated death domain protein) und der Procaspase 8, die durch den resultierenden DISC (death-inducing signaling complex) zu CASP8 gespalten wird. CASP 8 aktiviert die Effektorcaspasen 3, 6 und 7 direkt und über mitochondriales Cytochrom C. Die Caspaseaktivierung wird über $\mathrm{NF} \kappa \mathrm{B}$-abhängige inhibitor of apoptosis proteins (IAP) gehemmt [190]. In HMEC-1 wird nach 24-stündiger Stimulation anders als in HIMEC das Gen TRAIL, das auch zur Aktivierung von CASP8 beitragen kann, hochreguliert. Die Hochregulation von CASP8 nach 24 Stunden in HMEC-1 kann also auch über den TRAIL-Signalweg vermittelt werden, der bei intestinalen Endothelzellen keine Rolle zu spielen scheint. 


\subsubsection{Zellmetabolismus}

In der funktionellen Gruppe Zellmetabolismus wurden die Gene zusammengefaßt, die am Stoffwechsel der Endothelzelle, dem Abbau oder Aufbau von Materie beteiligt sind. Von den Genen dieser Gruppe wurde ein größerer Teil nur in HIMEC hochreguliert oder angeschaltet.

Das Enzym Acetylcholinesterase (AChE) wurde nur in HIMEC schwach (5-10x) angeschaltet. Acetylcholin (ACh) führt in Endothelzellen zu NO-Produktion, die Expression des ACh abbauenden Enzyms AChE wurde für mikrovaskuläre Endothelzellen des Gehirns gezeigt. Die genaue Funktion der AChE in Endothelzellen hingegen ist nicht bekannt [76]. Die bei mikrovaskulären Endothelzellen aus der Mukosa von CED-Patienten gefundene verminderte vasodilatatorische Potenz ist bisher auf einen Verlust der induzierbaren NO-Synthase zurückgeführt worden [60]. Ein NO-Mangel mit folgender Vasokonstriktion und Durchblutungsverminderung kann möglicherweise auch auf einen vermehrten AChAbbau durch AChE und daraus resultierende verminderte NO-Produktion zurückgeführt werden. Weiterhin wurde nur in HIMEC nach 24-stündiger TNF- $\alpha$-Stimulation die endotheliale NO-Synthase ausgeschaltet (Faktor 5-10x), was auch zu einer verminderten NOProduktion beitragen kann. An eNOS-defizienten Mäusen konnte ein protektiver Einfluß von eNOS bei einer experimentellen Kolitis gezeigt werden [182]. Eine Ausschaltung des für eNOS kodierenden Gens in den mikrovaskulären Endothelzellen der intestinalen $\mathrm{Mu}-$ kosa kann daher ein Faktor bei der erhöhten Entzündungsaktivität sein.

Die Expression des Gens GTP binding protein 1 (GTPBP1) wurde nur in HIMEC zu beiden Zeitpunkten deutlich (10-25x) angeschaltet. GTPBP1 gehört zur Familie der GTPasen, welche Aufgaben bei der Proliferation und Differenzierung von Zellen, der Proteinsynthese, dem intrazellulären Transport und der Regulation des Zellskeletts haben. Das Gen wurde bisher in IFN- $\gamma$-stimulierten Makrophagen, Gehirn und Thymus nachgewiesen [80]. Die genaue Funktion von GTPBP1 in Endothelzellen ist nicht bekannt.

Das Enzym gamma glutamyl hydrolase (GGH) zeigte nur in HIMEC eine schwache (Faktor 5,08) Hochregulation. GGH ist eine ubiquitär vorkommendes Enzym mit Wirkung im Folsäurestoffwechsel, es baut Polyglutamate ab. Eine hohe Expression von GGH ist mit einem Wirkungsverlust der zytotoxischen Substanz Methotrexat (MTX) durch vermehrten Abbau der Wirkform des MTX assoziiert [97]. MTX wird gelegentlich in der CED-Therapie verwendet, die Therapieerfolge hingegen sind deutlich schlechter als bei anderen chronisch entzündlichen Erkrankungen wie z.B. rheumatoider Arthritis [178]. Ein Grund hierfür könnte möglicherweise in der Hochregulation der GGH in intestinalen 
Endothelzellen liegen.

Mit PA28 $\beta$ und dem Gen proteasome subunit, beta type 9 wurden nur in HIMEC Bestandteile des Proteasoms hochreguliert. Das Proteasom ist in TNF- $\alpha$-stimulierten Endothelzellen für seine Beteiligung im NF $\kappa$ B-Signalweg bekannt. Der (in HIMEC und HMEC1 durch TNF- $\alpha$-Stimulation hochregulierte) Inhibitor $\mathrm{I} \kappa \mathrm{B} \alpha$ bindet in unstimulierten Zellen an $\mathrm{NF} \kappa \mathrm{B}$. In der akuten Entzündungsreaktion wird $\mathrm{I} \kappa \mathrm{B} \alpha$ durch die Proteasomeinheit $26 \mathrm{~S}$ abgebaut und in der Folge der Transkriptionsfaktor NF $\kappa \mathrm{B}$ aktiviert. Eine Inhibition des Proteasoms verhindert über die Hemmung des NF $\kappa$ B-Signalwegs eine Hochregulation von Adhäsionsmolekülen auf den Endothelzellen und vermindert so die Extravasation von Leukozyten [70].

Das Cathepsin H wurde nur in HIMEC schwach (Faktor 3,68) nach 24-stündiger TNF- $\alpha$ Stimulation hochreguliert. Die Expression von Cathepsin H ist für viele Gewebe bekannt. Im Endothel wurde das Gen bisher nur in der Leber gezeigt, eine Hochregulation durch inflammatorische Stimuli ist nicht bekannt. Das Enzym hat eine Matrix-degradierende Wirkung und ist ein Marker für invasive, fortgeschrittene Tumore [33]. Daher kann eine Rolle von Cathepsin H bei der Angiogenese im Rahmen einer Entzündungsreaktion vermutet werden.

Die lanosterol synthase (2,3-oxidosqualene-lanosterol cyclase) (LSS) ist ein an der Synthese von Lanosterol (einem Vorläufermolekül von Cholesterin), Vitamin D und anderen Steroiden beteiligtes Enzym [198]. Es wurde nur in HIMEC nach 24-stündiger Stimulation schwach hochreguliert. Eine denkbare Funktion der LSS in einer aktivierten Endothelzelle ist die Beteiligung an der Cholesterin-Synthese für die Zellmembran im Rahmen von Differenzierung und Proliferation der Zellen. Diese Hypothese wird gestützt durch die in beiden Endothelzellpopulationen erfolgte Hochregulation eines weiteren Enzyms mit Beteiligung an der Cholesterinsynthese, der Hydroxymethylglutaryl-Coenzym A Synthase 1 (HMGCS1). Eine Hochregulation von Enzymen der Cholesterinsynthese bei in vitro Versuchen zur Angiogenese wurde bereits von BELL et al. gezeigt [13].

Nur in HIMEC herunterreguliert wurde das Gen für hydroxysteroid (17-beta) dehydrogenase 2 (17 $\beta$ HSD). $17 \beta$ HSD inaktiviert Testosteron und Östrogen, es wird ubiquitinär exprimiert. Die Rolle der Herunterregulation des Gens bei entzündlichen Reaktionen ist bislang unbekannt [110].

Das für cytochrome b reductase 1 (CYBRD1) kodierende Gen wurde nur in HIMEC ausgeschaltet. Eine Expression von CYBRD1 ist bislang nur für Enterozyten bekannt, im Duodenum ist das Enzym für seine Rolle im Eisen-Stoffwechsel bekannt. CYBRD1 reduziert Eisen und Kupfer, diese Metalle können nur in der reduzierten Form aufgenommen 
werden [77]. Durch eine Ausschaltung des Gens wird die Eisen- und Kupferaufnahme der Zellen reduziert. Die Rolle dieser Aufnahmehemmung im Rahmen entzündlicher Reaktionen ist bislang ungeklärt.

\subsubsection{Transport und lonenkanäle}

Durch TNF- $\alpha$-Stimulation wurden in HIMEC und der mikrovaskulären Zellinie HMEC-1 Gene hochreguliert bzw. angeschaltet, die beim intra- oder interzellulären Stofftransport der Endothelzellen beteilgt sind. Nur in HIMEC wurden die Gene putative mitochondrial solute carrier (SLC), solute carrier family 2 (faciliated glucose transporter) member 2 (SLC2A3,GLUT3), solute carrier family 21 (organic anion transporter) member 9 (SLC21A9,OATP-B) und likely ortholog of mouse mitochondrial solute carrier protein (MCSP) angeschaltet. Diese Anschaltung der Genexpression erfolgte bis auf SLC erst nach 24-stündiger TNF- $\alpha$-Stimulation und nur schwach (5-10x). SLC21A9, ein Transportmolekül für organische Anionen wurde zuerst in der Plazenta beschrieben, die Expression in der Brustdrüse ist ebenfalls bekannt [126]. MSCP, ein Homolog eines mitochondrialen solute carrier Proteins, wurde in der Milz nachgewiesen, die genaue Funktion und eine Expression in anderen Geweben ist bisher unbekannt [94]. GLUT3 ist einer der sechs Transportern, welche die Diffusion von Glucose erleichtern. Er wurde bisher für die Axonmembran von Neuronen beschrieben und stellt dort eine adäquate Glucoseversorgung der Zelle sicher [121]. Für Endothelzellen ist eine Expression des Transportermoleküls GLUT1 beschrieben. Allerdings wurde eine Expression on GLUT3 auf der apikalen Seite von intestinalen Epithelzellen (Caco-2) in vitro gezeigt. Eine erhöhte Expression von GLUT1 und GLUT 3 in Tumoren des GIT wurde bereits beschrieben [59]. Hier wird ein Zusammenhang der erhöhten Expression mit Umbauvorgängen in der Zelle vermutet. Derartige Umbauvorgänge und Zellproliferationen, wenn auch in geringerem Umfang als bei der malignen Transformation einer Zelle, finden auch im Rahmen der Aktivierung einer Endothelzelle statt. Die Aktivierung des Transportmoleküls nach 24-stündiger TNF- $\alpha$-Stimulation gibt Hinweise auf erhöhten Energiebedarf z.B. in der Angiogenese.

Das Gen chlorid intracellular channel 2 (CLIC2) wurde nur in HIMEC angeschaltet. Die Familie der CLIC hat Aufgaben beim Chloridaustausch und somit bei der Aufrechterhaltung der Membranintegrität, des intrazellulären pH-Wertes und des Zellvolumens. Sie finden sich in den intrazellulären Membranen von z.B. Zellkern, ER und Mitochondrien. Eine Expression von CLIC in Endothelzellen ist bisher nicht bekannt [42]. Eine Funktion von CLIC2 bei HIMEC kann in der Aufrechterhaltung der Zellintegrität bei der 
Proliferation vermutet werden.

Das für Connexin 37 (Cx37) kodierende Gen wurde nur in HIMEC nach 4-stündiger TNF- $\alpha$-Stimulation schwach (-3,86x)herunterreguliert und nach 24-stündiger Stimulation ausgeschaltet (10-25x). Cx37 ist ein in allen Endothelzellen exprimiertes gap junctionProtein. Zusammen mit Cx40 ermöglicht es den interzellulären Stoffaustausch und hat eine wichtige Rolle bei der Entwicklung von Blutgefäßen. Cx37/Cx40-defiziente Tiere zeigen eine starke Mißbildung der Gefäße mit kavernenähnlichen Ausbuchtungen und Blutstauungen [166]. Da die Funktionen von Cx37 und Cx40 ähnlich sind, ist dieser Effekt nur bei Ausschaltung beider Gene zu beobachten. Bei dieser Arbeit wurde eine Änderung der Expression von Cx40 nicht beobachtet. Daher scheint ein Effekt der Ausschaltung von Cx37 fraglich.

Weiterhin wurde das Gen für carbonic anhydrase IV (CAR IV) nach 24-stündiger Stimulation in HIMEC ausgeschaltet. Die CAR IV ist für Endothelzellen beschrieben. Durch Hydrierung von $\mathrm{CO}_{2}$ reguliert sie die Bicarbonatkonzentration und damit den pH-Wert. Bei Ansäuerung des extrazellulären Milieus ist eine Hochregulation von CAR IV gezeigt worden [141]. Mizoguchi et al. zeigten die Herunterregulation von CAR IV in intestinalen Epithelzellen bei experimenteller Kolitis. Eine Inhibition der CAR IV Aktivität führte zu einer Verbesserung der Kolitis, die Autoren postulierten eine entzündungsfördernde Rolle der CAR IV [111]. Eine Ausschaltung des CAR IV-Gens in Endothelzellen ist bislang nicht bekannt, eine entzündungshemmende Wirkung kann vermutet werden.

\subsubsection{Modifikatoren der extrazellulären Matrix}

In beiden Endothelzellpopulationen wurden durch TNF- $\alpha$-Stimulation Gene hochreguliert oder angeschaltet, die für Enzyme der extrazellulären Matrix kodieren. Sowohl in HIMEC als auch in HMEC-1 wurden die Matrixmetalloproteinasen (MMP) 1 und 10 hochreguliert bzw. angeschaltet. Auffällig war die deutlich stärkere und spätere Anschaltung von MMP1 in HIMEC (Faktor > 50 nach 24 Std. TNF- $\alpha$ ). Auch bei MMP10 erfolgte eine stärkere Hochregulation des Gens bei HIMEC erst nach 24-stündiger TNF- $\alpha$-Stimulation. Die Hochregulation der MMP-Expression in mikrovaskulären Endothelzellen durch proinflammatorische Stimuli ist bekannt. MMPs werden zur Desintegration der Basalmembran benötigt und stellen somit eine Vorraussetzung für die Angiogenese dar [68]. Eine Erhöhung der Expressionslevel der tissue inhibitors of metalloproteinases (TIMP), die gleichzeitig mit der Hochregulation der MMPs stattfindet [68], konnte in dieser Arbeit nicht beobachtet werden. 
Nur in HIMEC wurde das bone morphogenetic protein 2 (BMP2) nach 4-stündiger TNF- $\alpha$ Stimulation schwach $(5,57 x)$ hochreguliert. Die BMPs sind TGF- $\beta$ strukturell verwandte Wachstumsfaktoren mit einer matrixaufbauenden Wirkung. Eine Hochregulation von BMP2 durch TNF- $\alpha$-Stimulation wurde für HUVEC beschrieben [184]. BMP2 wird im Rahmen von chronischen Entzündungen der Luftwege hochreguliert [144]. Eine Rolle von BMP2 in der intestinalen Entzündung ist daher denkbar, möglicherweise als Mediator der bei CED auftretenden Fibrose. Allerdings wurde auch nach 4 Stunden das Gen follistatin-like 3 hochreguliert, für das eine neutralisierende Bindung von BMPs bekannt ist [179]. Die genaue Funktion der eigentlich wiedersprüchlichen Hochregulation dieser beider Gene ist in zukünftigen Versuchen zu klären.

\subsubsection{Weitere regulierte Gene}

Durch TNF- $\alpha$-Stimulation wurden in HIMEC noch weitere Gene, die keiner der funktionellen Gruppen des Gene Ontology Consortiums zugeordnet werden konnten, differenziell reguliert.

Das Gen proline-serine-threonine phosphatase interacting protein 2 (PSTPIP2) wurde nach 4- und 24-stündiger Stimulation nur in HIMEC reguliert. Für PSTPIP2 ist eine konstitutive Expression in mehreren Zellarten bekannt, eine Induzierbarkeit des Gens oder eine Expression im Endothel wurde jedoch bisher nicht gezeigt. PSTPIP2 interagiert mit protein thyrosine phosphatases (PTP) vom PEST-Typ, eine Funktion im Rahmen der Regulation des Zytoskeletts wird vermutet [194].

Pleckstrin homology domain containing, family $C$ (with FERM domain) member 1 (PLEKHC1,Mig-2) wurde nur nach 4-stündiger Stimulation in HIMEC schwach (4,24x) hochreguliert. Mig-2 wirkt auf die Modulation der Zellform und den Aufbau des Aktingerüsts durch Interaktion mit Migfilin, einem mit der extrazellulären Matrix interagierenden Protein. Mig-2 wird ubiquitär konstitutiv exprimiert [180]. Auch in HIMEC ist eine Wirkung von Mig-2 auf die Änderung der Zellform durch TNF- $\alpha$-Stimulation möglich. Diese Zellformänderung tritt innerhalb weniger Stunden konsekutiv mit der frühen Hochregulation des Gens auf. In HMEC-1 hingegen konnte weder eine derartige Änderung der Zellform noch eine Regulation von Mig-2 gezeigt werden.

Weiterhin wurde nur in HIMEC das Gen Lysyl-oxidase like 2 (LOXL2) nach 24stündiger Stimulation angeschaltet (10-15x). Das bis auf Leukozyten ubiquitär exprimierte LOXL2 gehört zur Familie der Lysyl-Oxidasen, die über eine kupferbindende Domäne katalytische Funktion ausübt und möglicherweise eine Rolle bei der Regulation von Zell- 
proliferation und Entwicklung spielt [156]. Angesichts der deutlichen, hochsignifikanten Anschaltung dieses Gens nur in den intestinalen Endothelzellen sind weitere Versuche zur Klärung der Funktion von LOXL2 bei der intestinalen Entzündung notwendig.

Das für tissue factor pathway inhibitor (TFPI) kodierende Gen wurde nur in HIMEC schwach $(-3,56 \mathrm{x})$ nach 24-stündiger TNF- $\alpha$ Stimulation herunterreguliert. TFPI ist ein wichtiger Inhibitor des extrinsischen Gerinnungssystems. Eine Herunterregulation dieses Gens hat eine verstärkte Blutgerinnung und Thrombenentstehung zur Folge [40]. Eine Rolle der TFPI-Herunterregulation in HIMEC bei der Enstehung der für CED charakteristischen mikrovaskulären Thrombose und Ischämie ist denkbar.

\subsection{Fazit und Ausblick}

Durch den Vergleich des Genexpressionsprofil humaner intestinaler mikrovaskulärer Endothelzellen (HIMEC) mit dem der mikrovaskulären Referenzzellinie HMEC-1 konnte die Heterogenität zweier mikrovaskulärer Endothelzellpopulationen gezeigt werden. Mehr als $50 \%$ der in den Endothelzellen durch TNF- $\alpha$-Stimulation hochregulierten Gene und mehr als $80 \%$ der herunterregulierten Gene wurde nur in einer der beiden Zellarten reguliert. Der Vergleich der Expressionsprofile ergab eine Anzahl von neuen darmspezifischen Kandidatengene, deren weitere Charakterisierung in Zukunft neue Hinweise auf die Rolle des mikrovaskulären Endothels bei intestinalen Entzündungen geben könnte. Die Validität der ermittelten Expressionsdaten wurde gezeigt. Dabei gilt es zu beachten, daß eine erhöhte Expression eines Gens nicht automatisch eine erhöhte Proteinproduktion und gesteigerte Funktion zur Folge hat. Weiterführende Versuche zur Translation und Funktionsfähigkeit der produzierten Proteine und Enzyme sind notwendig.

Allerdings macht es trotz der bekannten Heterogenität von Endothelzellen biologisch wenig Sinn, daß Gene, die in mikrovaskulären Endothelzellen der Haut exprimiert werden, nicht auch in mikrovaskulären Endothelzellen anderer Herkunft (z.B. Darm) exprimiert werden. Die beobachtete fehlende Expression einiger Gene in HIMEC ist daher möglicherweise auf einen durch die Immortalisierung bedingten bzw. einen erworbenen Defekt der HMEC-1 Referenzzellen zurückzuführen. Daher ist zu folgern, daß nur Primärendothelzellkulturen wie HIMEC aussagekräftige Modelle für Untersuchungen der Rolle des Endothels in verschiedenen Organen darstellen.

Weiterhin sollte in Zukunft ein Vergleich der ermittelten Expressionsprofile von HIMEC aus gesundem Darmgewebe mit HIMEC von CED-Patienten stattfinden. BINION et al. 
hatten für HIMEC aus Darmgewebe von CED-Patienten einen „erworbenen Defekt" der Genexpression postuliert, der in stimulierten HIMEC zu einer erhöhten Leukozytenbindungskapazität und einer erniedrigten vasodilatatorischen Potenz führt [16, 17, 15]. Durch den Vergleich von Expressionsprofilen mittels DNA-Microarrays erscheint eine Identifikation derjenigen Gene, die für den „Defekt“ verantwortlich sind, möglich. Diese Versuche könnten zu einem weitergehenden Verständnis der Veränderungen im mikrovaskulären Endothel bei der Pathogenese der CED führen. 


\section{Anhang A}

\section{Rohdaten der}

\section{DNA-Microarrayuntersuchung}

\section{A.1 Hochregulierte bzw. angeschaltete Gene}

\section{A.1.1 Nach Stimulation mit TNF- $\alpha$ über vier bzw. 24 Stunden in HIMEC und HMEC-1 hochregulierte Gene}

Tabelle A.1: Durch Stimulation mit TNF- $\alpha$ nach 4 Std. und 24 Std. in sowohl HIMEC als auch HMEC-1 hochregulierte Gene

\begin{tabular}{|c|c|c|c|c|c|c|}
\hline Genbezeichnung & HIMEC $4 \mathrm{~h}$ & $p(4 h)$ & HIMEC 24h & $\mathrm{p}(24 \mathrm{~h})$ & HMEC $4 \mathrm{~h}$ & HMEC 24h \\
\hline selectin E (endothelial adhesion molecule 1) & 82,52 & $1,56 \mathrm{E}+07$ & 23,36 & 0,001 & $7,691 \mathrm{~A}$ & \\
\hline vascular cell adhesion molecule 1 & 24,41 & 0,007 & 22,54 & 0,007 & 69,22 & 50,88 \\
\hline chemokine (C-X-C motif) ligand 5 & & & 21,55 & 0,018 & 11,01 & 14,52 \\
\hline $\begin{array}{l}\text { intercellular adhesion molecule } 1 \text { (CD54), } \\
\text { human rhinovirus receptor }\end{array}$ & 12,55 & 0,004 & 13,17 & 0,004 & 22,13 & 13,44 \\
\hline $\begin{array}{l}\text { intercellular adhesion molecule } 1 \text { (CD54), } \\
\text { human rhinovirus receptor }\end{array}$ & 11,27 & 0,002 & 11,67 & 0,001 & 22,07 & 17,4 \\
\hline matrix metalloproteinase 10 (stromelysin 2$)$ & 4,33 & 0,092 & 11,56 & 0,010 & $20,6 \mathrm{~A}$ & $12,28 \mathrm{~A}$ \\
\hline interleukin 8 & 15,32 & 0,015 & 11,22 & 0,022 & $120,8 \mathrm{~A}$ & $85,14 \mathrm{~A}$ \\
\hline $\begin{array}{l}\text { lymphotoxin beta (TNF superfamily, mem- } \\
\text { ber 3) }\end{array}$ & 14,42 & 0,009 & 9,53 & 0,013 & $8,662 \mathrm{~A}$ & \\
\hline interleukin 8 & 11,32 & 0,012 & 9,02 & 0,017 & $111,4 \mathrm{~A}$ & $69,9 \mathrm{~A}$ \\
\hline $\begin{array}{l}\text { intercellular adhesion molecule } 1 \text { (CD54), } \\
\text { human rhinovirus receptor }\end{array}$ & 7,13 & 0,002 & 8,82 & 0,005 & $17,42 \mathrm{~A}$ & $9,283 \mathrm{~A}$ \\
\hline superoxide dismutase 2, mitochondrial & 5,87 & 0,002 & 8,51 & $6,89 \mathrm{E}+07$ & 18,68 & 22,48 \\
\hline $\begin{array}{l}\text { tumor necrosis factor, alpha-induced protein } \\
3\end{array}$ & 11,08 & $3,42 \mathrm{E}+07$ & 8,33 & $3,32 \mathrm{E}+07$ & 27,26 & 15,14 \\
\hline $\begin{array}{l}\text { GTP cyclohydrolase } 1 \text { (dopa-responsive dys- } \\
\text { tonia) }\end{array}$ & 14,43 & $5,17 \mathrm{E}+07$ & 8,24 & $8,63 \mathrm{E}+07$ & 7,65 & 4,51 \\
\hline superoxide dismutase 2, mitochondrial & 6,19 & 0,007 & 8,09 & 0,003 & 16,08 & 16,32 \\
\hline TNF-induced protein & 30,31 & $1,63 \mathrm{E}+07$ & 8,03 & $6,60 \mathrm{E}+07$ & 4,96 & \\
\hline $\begin{array}{l}\text { chemokine (C-X-C motif) ligand } 1 \text { (melano- } \\
\text { ma growth stimulating activity, alpha) }\end{array}$ & 7,92 & 0,010 & 7,75 & 0,014 & $20,65 \mathrm{~A}$ & $15,71 \mathrm{~A}$ \\
\hline
\end{tabular}




\section{Anhang A Rohdaten der DNA-Microarrayuntersuchung}

Tabelle A.1: Hochregulation in HIMEC und HMEC-1 (Forts.)

\begin{tabular}{|c|c|c|c|c|c|c|}
\hline Gen & HIMEC 4h & $p(4 h)$ & HIMEC 24h & $p(24 h)$ & HMEC 4h & HMEC 24h \\
\hline $\begin{array}{l}\text { CD74 antigen (invariant polypeptide of } \\
\text { major histocompatibility complex, class II } \\
\text { antigen-associated) }\end{array}$ & & & 7,75 & 0,002 & & $12,17 \mathrm{~A}$ \\
\hline $\begin{array}{l}\text { tumor necrosis factor, alpha-induced protein } \\
2\end{array}$ & 15,73 & $5,87 \mathrm{E}+09$ & 7,7 & $1,30 \mathrm{E}+08$ & 19,37 & 5,52 \\
\hline interleukin 15 & 6,42 & 0,011 & 6,45 & 0,007 & 3,54 & 3,19 \\
\hline $\begin{array}{l}\text { guanylate binding protein } 1, \text { interferon- } \\
\text { inducible, } 67 \mathrm{kDa}\end{array}$ & 12,62 & 0,002 & 6,15 & 0,006 & 10,79 & 6,01 \\
\hline Wilms' tumour 1-associating protein & 4,96 & $4,86 \mathrm{E}+07$ & 5,76 & $1,77 \mathrm{E}+07$ & 4,33 & \\
\hline TNFAIP3 interacting protein 1 & 4,63 & 0,002 & 5,64 & 0,001 & 8,67 & 5,65 \\
\hline Wilms' tumour 1-associating protein & 5,12 & $6,25 \mathrm{E}+07$ & 5,07 & $7,50 \mathrm{E}+07$ & 5,95 & \\
\hline cathepsin S & & & 5,01 & $2,56 \mathrm{E}+07$ & 3,08 & 10,46 \\
\hline interferon regulatory factor 1 & 6,3 & $1,48 \mathrm{E}+07$ & 4,9 & $2,05 \mathrm{E}+07$ & 5,29 & \\
\hline G protein-coupled receptor 56 & 5,8 & 0,012 & 4,87 & 0,012 & 3,33 & \\
\hline $\begin{array}{l}\text { guanylate binding protein } 1, \text { interferon- } \\
\text { inducible, } 67 \mathrm{kDa}\end{array}$ & 10,89 & $5,96 \mathrm{E}+07$ & 4,87 & $5,66 \mathrm{E}+07$ & 11,1 & 6,34 \\
\hline natural killer cell transcript 4 & & & 4,81 & 0,002 & $48,81 \mathrm{~A}$ & $76,64 \mathrm{~A}$ \\
\hline $\begin{array}{l}\text { nuclear factor of kappa light polypeptide ge- } \\
\text { ne enhancer in B-cells inhibitor, alpha }\end{array}$ & 5,89 & 0,005 & 4,77 & 0,008 & 9,63 & 8,17 \\
\hline $\begin{array}{l}\text { tumor necrosis factor, alpha-induced protein } \\
3\end{array}$ & 6,93 & 0,003 & 4,7 & 0,001 & $12,22 \mathrm{~A}$ & $6,541 \mathrm{~A}$ \\
\hline major histocompatibility complex, class I, C & & & 4,64 & 0,012 & & 3,76 \\
\hline H2A histone family, member $\mathrm{O}$ & & & 4,47 & 0,004 & & 5 \\
\hline hypothetical protein MGC5618 & 4,42 & 0,002 & 4,38 & 0,001 & 13,49 & 11,61 \\
\hline $\begin{array}{l}\text { receptor-interacting serine-threonine kinase } \\
2\end{array}$ & 8,38 & 0,003 & 4,31 & 0,030 & $6,507 \mathrm{~A}$ & \\
\hline hypothetical protein FLJ11259 & 3,16 & 0,004 & 4,27 & 0,001 & 4,18 & 3,42 \\
\hline basement membrane-induced gene & & & 4,12 & 0,002 & & 3,05 \\
\hline EH-domain containing 1 & 5,44 & 0,005 & 4,12 & 0,003 & 5,78 & \\
\hline $\begin{array}{l}\text { lectin, galactoside-binding, soluble, } 9 \text { (galec- } \\
\text { tin 9) }\end{array}$ & & & 4,01 & $1,82 \mathrm{E}+07$ & & $27,68 \mathrm{~A}$ \\
\hline colony stimulating factor 1 (macrophage) & 4,72 & 0,002 & 3,97 & 0,004 & 3,97 & 3,14 \\
\hline major histocompatibility complex, class I, F & & & 3,92 & 0,004 & & 3,03 \\
\hline TNF-induced protein & 11,73 & 0,003 & 3,9 & 0,003 & 3,94 & \\
\hline $\begin{array}{l}\text { nuclear factor of kappa light polypeptide ge- } \\
\text { ne enhancer in B-cells } 2(\mathrm{p} 49 / \mathrm{p} 100)\end{array}$ & 5,1 & 0,001 & 3,83 & 0,007 & 7,95 & 6,58 \\
\hline $\begin{array}{l}\text { 3-hydroxy-3-methylglutaryl-Coenzyme A } \\
\text { synthase } 1 \text { (soluble) }\end{array}$ & & & 3,82 & $9,20 \mathrm{E}+08$ & & 4,19 \\
\hline $\begin{array}{l}\text { interferon, alpha-inducible protein (clone } \\
\text { IFI-15K) }\end{array}$ & & & 3,68 & 0,067 & 3,67 & 8,43 \\
\hline $\begin{array}{l}\text { receptor-interacting serine-threonine kinase } \\
2\end{array}$ & 4,5 & 0,004 & 3,41 & 0,010 & 7,1 & \\
\hline EH-domain containing 1 & 5,95 & $3,69 \mathrm{E}+07$ & 3,22 & 0,004 & 4,65 & \\
\hline hypothetical protein FLJ20035 & & & 3,22 & 0,019 & & 7,12 \\
\hline $\begin{array}{l}\text { Major histocompatibility complex, class I, J } \\
\text { (pseudogene) }\end{array}$ & & & 3,21 & 0,005 & & 3,38 \\
\hline $\begin{array}{l}\text { nuclear factor of kappa light polypeptide ge- } \\
\text { ne enhancer in B-cells inhibitor, epsilon }\end{array}$ & & & 3,15 & $4,43 \mathrm{E}+07$ & 3,78 & 3,03 \\
\hline activating transcription factor 3 & 8,93 & $6,58 \mathrm{E}+07$ & 3,08 & 0,009 & 3,17 & \\
\hline $\begin{array}{l}\text { ATPase, Ca }++ \text { transporting, plasma mem- } \\
\text { brane } 1\end{array}$ & 3,57 & 0,068 & 3,02 & 0,115 & 4,29 & \\
\hline chemokine (C-C motif) ligand 8 & & & $8,144 \mathrm{~A}$ & 0,038 & $34,5 \mathrm{~A}$ & $29,82 \mathrm{~A}$ \\
\hline phospholipase A1 member A & & & $24,38 \mathrm{~A}$ & 0,001 & & $11,66 \mathrm{~A}$ \\
\hline interferon-induced protein 35 & & & $5,205 \mathrm{~A}$ & 0,009 & & 5,45 \\
\hline TNF receptor-associated factor 1 & $19,07 \mathrm{~A}$ & $5,07 \mathrm{E}+08$ & $13,64 \mathrm{~A}$ & $3,08 \mathrm{E}+08$ & $21,26 \mathrm{~A}$ & $10,94 \mathrm{~A}$ \\
\hline growth factor receptor-bound protein 10 & 3,51 & 0,001 & & & 3,2 & \\
\hline chemokine (C-C motif) ligand 20 & 75,4 & 0,024 & $37,44 \mathrm{~A}$ & 0,041 & $66,7 \mathrm{~A}$ & $48,93 \mathrm{~A}$ \\
\hline chemokine (C-X-C motif) ligand 10 & & & $7,38 \mathrm{~A}$ & 0,039 & $35,93 \mathrm{~A}$ & $52,06 \mathrm{~A}$ \\
\hline chemokine (C-C motif) ligand 5 & $5,289 \mathrm{~A}$ & 0,005 & $27,72 \mathrm{~A}$ & $7,75 \mathrm{E}+07$ & & $29,38 \mathrm{~A}$ \\
\hline hypothetical protein FLJ21079 & & & $5,911 \mathrm{~A}$ & 0,068 & 5,01 & \\
\hline jun B proto-oncogene & 3,08 & 0,027 & & & 3,09 & 3,15 \\
\hline EH-domain containing 1 & 3,83 & $9,66 \mathrm{E}+07$ & & & 3,63 & \\
\hline SAM domain and HD domain 1 & & & $5,304 \mathrm{~A}$ & 0,024 & & 4,06 \\
\hline peptide transporter 3 & & & $33,61 \mathrm{~A}$ & $7,77 \mathrm{E}+07$ & & 5,89 \\
\hline CASP8 and FADD-like apoptosis regulator & 3,59 & 0,004 & & & 7,52 & 5,15 \\
\hline
\end{tabular}


Tabelle A.1: Hochregulation in HIMEC und HMEC-1 (Forts.)

\begin{tabular}{|c|c|c|c|c|c|c|}
\hline Gen & HIMEC $4 \mathrm{~h}$ & $p(4 h)$ & HIMEC 24h & p (24h) & HMEC 4h & HMEC 24h \\
\hline chemokine (C-X-C motif) ligand 2 & $9,506 \mathrm{~A}$ & 0,002 & $16,11 \mathrm{~A}$ & 0,003 & $19,26 \mathrm{~A}$ & $11,02 \mathrm{~A}$ \\
\hline chemokine (C-C motif) ligand 5 & $29,09 \mathrm{~A}$ & 0,024 & $118,6 \mathrm{~A}$ & 0,008 & $15,33 \mathrm{~A}$ & $94,33 \mathrm{~A}$ \\
\hline bone marrow stromal cell antigen 2 & & & $27,45 \mathrm{~A}$ & 0,016 & & $29,78 \mathrm{~A}$ \\
\hline $\begin{array}{l}\text { matrix metalloproteinase } 1 \text { (interstitial col- } \\
\text { lagenase) }\end{array}$ & & & $53,24 \mathrm{~A}$ & 0,005 & $12,45 \mathrm{~A}$ & $24,57 \mathrm{~A}$ \\
\hline $\begin{array}{l}\text { myxovirus (influenza virus) resistance } 1, \\
\text { interferon-inducible protein p78 (mouse) }\end{array}$ & & & $10,43 \mathrm{~A}$ & 0,044 & 7,3 & 21,3 \\
\hline chemokine (C-X-C motif) ligand 11 & $7,663 \mathrm{~A}$ & 0,079 & $56,66 \mathrm{~A}$ & 0,010 & $6,773 \mathrm{~A}$ & $29,68 \mathrm{~A}$ \\
\hline tripartite motif-containing 14 & & & $5,096 \mathrm{~A}$ & 0,005 & & 3,42 \\
\hline CASP8 and FADD-like apoptosis regulator & 3,65 & 0,008 & & & 8,74 & 5,34 \\
\hline chemokine (C-X-C motif) ligand 11 & & & $28,52 \mathrm{~A}$ & 0,003 & $8,967 \mathrm{~A}$ & $27,81 \mathrm{~A}$ \\
\hline $\begin{array}{llll}\text { mitogen-activated } & \text { protein } & \text { kinase } & \text { kinase } \\
\text { kinase } 5 & & & \\
\end{array}$ & 4,15 & 0,006 & & & 3,7 & 3,26 \\
\hline interferon, gamma-inducible protein 30 & & & $15,3 \mathrm{~A}$ & $6,26 \mathrm{E}+07$ & & 4,87 \\
\hline Down syndrome critical region gene 1 & 5,37 & 0,003 & & & 3,11 & \\
\hline hypothetical protein DKFZp434J037 & 3,56 & 0,017 & & & 4,94 & 3,43 \\
\hline $\begin{array}{l}\text { phosphoprotein regulated by mitogenic pa- } \\
\text { thways }\end{array}$ & 3,28 & 0,141 & & & 6,76 & 4,25 \\
\hline hypothetical protein FLJ90005 & 3,94 & 0,011 & & & 4,03 & \\
\hline chemokine (C-X-C motif) ligand 3 & $14,73 \mathrm{~A}$ & $5,44 \mathrm{E}+07$ & $21,05 \mathrm{~A}$ & $2,04 \mathrm{E}+09$ & $19,45 \mathrm{~A}$ & \\
\hline interferon stimulated gene $20 \mathrm{kDa}$ & $18,77 \mathrm{~A}$ & 0,009 & $54,65 \mathrm{~A}$ & 0,003 & $10,45 \mathrm{~A}$ & $26,21 \mathrm{~A}$ \\
\hline $\begin{array}{l}\text { tumor necrosis factor receptor superfamily, } \\
\text { member } 9\end{array}$ & & & $6,152 \mathrm{~A}$ & 0,009 & & 3,2 \\
\hline baculoviral IAP repeat-containing 3 & $20,08 \mathrm{~A}$ & 0,011 & $15,13 \mathrm{~A}$ & 0,016 & $12,9 \mathrm{~A}$ & $8,268 \mathrm{~A}$ \\
\hline EH-domain containing 1 & $8,186 \mathrm{~A}$ & 0,052 & $5,868 \mathrm{~A}$ & 0,093 & 3,97 & \\
\hline LIM domain protein & $7,849 \mathrm{~A}$ & 0,015 & $6,99 \mathrm{~A}$ & 0,016 & $9,373 \mathrm{~A}$ & \\
\hline zinc finger homeobox $1 \mathrm{~b}$ & $17,01 \mathrm{~A}$ & 0,071 & $12,48 \mathrm{~A}$ & 0,082 & 3,43 & \\
\hline complement component $1, \mathrm{r}$ subcomponent & & & $13,14 \mathrm{~A}$ & $4,26 \mathrm{E}+07$ & & 3,71 \\
\hline complement component $1, \mathrm{~s}$ subcomponent & & & $23,48 \mathrm{~A}$ & 0,001 & & $21,07 \mathrm{~A}$ \\
\hline $\begin{array}{l}\text { tumor necrosis factor receptor superfamily, } \\
\text { member } 11 \mathrm{~b} \text { (osteoprotegerin) }\end{array}$ & $10,27 \mathrm{~A}$ & 0,053 & $9,129 \mathrm{~A}$ & 0,059 & $316,8 \mathrm{~A}$ & $98,01 \mathrm{~A}$ \\
\hline baculoviral IAP repeat-containing 2 & 3,91 & $5,46 \mathrm{E}+07$ & & & 3,19 & \\
\hline interferon stimulated gene $20 \mathrm{kDa}$ & & & $7,658 \mathrm{~A}$ & $5,16 \mathrm{E}+07$ & & $7,286 \mathrm{~A}$ \\
\hline chemokine (C-X-C motif) ligand 5 & & & $134,1 \mathrm{~A}$ & 0,004 & $22,11 \mathrm{~A}$ & $29,21 \mathrm{~A}$ \\
\hline
\end{tabular}

\section{A.1.2 Nach Stimulation mit TNF- $\alpha$ über vier bzw. 24 Stunden nur in HIMEC hochregulierte Gene}

Tabelle A.2: Durch Stimulation mit TNF- $\alpha$ nach 4 Std. und 24 Std. nur in HIMEC hochregulierte Gene

\begin{tabular}{|c|c|c|c|c|}
\hline Genbezeichnung & HIMEC $4 \mathrm{~h}$ & p (4h) & HIMEC 24h & p (24h) \\
\hline G protein-coupled receptor & 12,24 & 0,001 & 8,33 & 0,002 \\
\hline chemokine (C-X3-C motif) ligand 1 & 10,2 & 0,037 & 9,95 & 0,013 \\
\hline follistatin-like 3 (secreted glycoprotein) & 9,24 & $2,83 \mathrm{E}+07$ & & \\
\hline $\begin{array}{l}\text { prostaglandin-endoperoxide synthase } 2 \text { (prostaglandin G/H synthase and } \\
\text { cyclooxygenase) }\end{array}$ & 8,96 & 0,069 & 7,5 & 0,110 \\
\hline $\begin{array}{lcccccc}\text { Homo } & \text { sapiens } & \text { mRNA; } & \text { cDNA } & \text { DKFZp586D1122 } & \text { (from } & \text { clone } \\
\text { DKFZp586D1122) } & & & & & \\
\end{array}$ & 6,62 & $5,35 \mathrm{E}+07$ & & \\
\hline $\begin{array}{lclllll}\text { Homo sapiens } & \text { mRNA; } & \text { cDNA } & \text { DKFZp586D1122 } & \text { (from } & \text { clone } \\
\text { DKFZp586D1122) } & & & & & \\
\end{array}$ & 5,69 & $9,46 \mathrm{E}+08$ & & \\
\hline KIAA0084 protein & 5,64 & $6,25 \mathrm{E}+07$ & 4,3 & $4,01 \mathrm{E}+07$ \\
\hline retinal degeneration $\mathrm{B}$ beta & 5,6 & 0,003 & & \\
\hline cysteine and glycine-rich protein 2 & 5,57 & 0,031 & 3,26 & 0,083 \\
\hline bone morphogenetic protein 2 & 5,57 & 0,025 & & \\
\hline bone morphogenetic protein 2 & 5,17 & 0,028 & & \\
\hline palladin & 4,81 & 0,020 & & \\
\hline KIAA0692 protein & 4,76 & $6,57 \mathrm{E}+08$ & & \\
\hline chemokine (C-X-C motif) ligand 6 (granulocyte chemotactic protein 2) & 4,75 & 0,041 & 10,21 & 0,0319 \\
\hline
\end{tabular}


Tabelle A.2: Hochregulation nur in HIMEC (Forts.)

\begin{tabular}{|c|c|c|c|c|}
\hline Gen & HIMEC 4h & p (4h) & HIMEC 24h & p (24h) \\
\hline Homo sapiens cDNA FLJ25677 fis, clone TST04054 & 4,71 & 0,005 & & \\
\hline proline-serine-threonine phosphatase interacting protein 2 & 4,59 & 0,002 & 7,86 & 0,001 \\
\hline guanylate binding protein 2 , interferon-inducible & 4,54 & 0,003 & & \\
\hline monocyte to macrophage differentiation-associated & 4,52 & 0,005 & & \\
\hline zinc finger protein RINZF & 4,49 & 0,005 & & \\
\hline mitogen inducible 2 & 4,24 & $5,67 \mathrm{E}+07$ & & \\
\hline KIAA0692 protein & 4,21 & 0,001 & & \\
\hline poliovirus receptor & 4,11 & 0,001 & & \\
\hline Nijmegen breakage syndrome 1 (nibrin) & 3,85 & 0,001 & 5,25 & $2,57 \mathrm{E}+07$ \\
\hline MO25 protein & 3,84 & 0,003 & & \\
\hline phospholipase A2, group IVA (cytosolic, calcium-dependent) & 3,82 & 0,041 & 5,16 & 0,036 \\
\hline CD58 antigen, (lymphocyte function-associated antigen 3 ) & 3,7 & $6,86 \mathrm{E}+07$ & & \\
\hline mitogen-activated protein kinase kinase 3 & 3,67 & 0,002 & & \\
\hline WW45 protein & 3,64 & 0,006 & & \\
\hline nuclear factor of activated T-cells, cytoplasmic, calcineurin-dependent 1 & 3,62 & 0,022 & & \\
\hline CCAAT/enhancer binding protein $(\mathrm{C} / \mathrm{EBP})$, delta & 3,56 & 0,060 & 3,13 & 0,104 \\
\hline hairy/enhancer-of-split related with YRPW motif 1 & 3,54 & 0,026 & & \\
\hline glutaredoxin (thioltransferase) & 3,53 & $2,63 \mathrm{E}+07$ & & \\
\hline $\begin{array}{l}\text { protein phosphatase } 2 \text { (formerly 2A), regulatory subunit A (PR 65), beta } \\
\text { isoform }\end{array}$ & 3,47 & 0,006 & & \\
\hline NK3 transcription factor related, locus 1 (Drosophila) & 3,42 & $2,40 \mathrm{E}+07$ & 4,75 & $6,38 \mathrm{E}+07$ \\
\hline human immunodeficiency virus type I enhancer binding protein 2 & 3,41 & 0,021 & & \\
\hline RAB27A, member RAS oncogene family & 3,36 & 0,003 & & \\
\hline palladin & 3,35 & 0,066 & & \\
\hline palladin & 3,35 & 0,033 & & \\
\hline pannexin 1 & 3,29 & 0,010 & & \\
\hline CD58 antigen, (lymphocyte function-associated antigen 3 ) & 3,28 & $8,52 \mathrm{E}+08$ & & \\
\hline CD58 antigen, (lymphocyte function-associated antigen 3 ) & 3,28 & 0,003 & & \\
\hline cysteine and glycine-rich protein 2 & 3,26 & 0,017 & & \\
\hline CD83 antigen (activated B lymphocytes, immunoglobulin superfamily) & 3,25 & 0,008 & & \\
\hline jagged 1 (Alagille syndrome) & 3,23 & 0,013 & & \\
\hline Nijmegen breakage syndrome 1 (nibrin) & 3,22 & 0,002 & 4,24 & $1,42 \mathrm{E}+07$ \\
\hline human immunodeficiency virus type I enhancer binding protein 2 & 3,18 & 0,003 & & \\
\hline DKFZP586N0721 protein & 3,17 & $2,42 \mathrm{E}+07$ & & \\
\hline cytoplasmic linker 2 & 3,16 & 0,002 & & \\
\hline DnaJ (Hsp40) homolog, subfamily B, member 6 & 3,13 & 0,004 & & \\
\hline $\begin{array}{l}\text { protein phosphatase } 2 \text { (formerly } 2 \mathrm{~A} \text { ), regulatory subunit A (PR 65), beta } \\
\text { isoform }\end{array}$ & 3,12 & 0,001 & & \\
\hline guanylate cyclase 1, soluble, beta 3 & 3,1 & 0,003 & & \\
\hline mitogen inducible 2 & 3,09 & $6,39 \mathrm{E}+07$ & & \\
\hline exostoses (multiple) 1 & 3,08 & 0,006 & & \\
\hline dishevelled associated activator of morphogenesis 1 & 3,07 & 0,068 & & \\
\hline erythrocyte membrane protein band 4.1 -like 3 & 3,04 & 0,060 & & \\
\hline E3 ubiquitin ligase SMURF2 & 3,03 & 0,043 & & \\
\hline hypothetical protein FLJ20234 & & & 3,41 & $2,78 \mathrm{E}+07$ \\
\hline tumor protein $\mathrm{p} 63$ & & & 3,89 & 0,004 \\
\hline Nijmegen breakage syndrome 1 (nibrin) & & & 4,2 & 0,004 \\
\hline likely ortholog of mouse mitochondrial solute carrier protein & & & $9,58 \mathrm{~A}$ & 0,045 \\
\hline ATPase, $\mathrm{Na}+/ \mathrm{K}+$ transporting, beta 1 polypeptide & & & 3,68 & 0,086 \\
\hline leukocyte specific transcript 1 & & & $42,09 \mathrm{~A}$ & 0,001 \\
\hline Human metallothionein-If gene (hMT-If) & & & 3,79 & 0,007 \\
\hline acetylcholinesterase (YT blood group) & & & $8,24 \mathrm{~A}$ & 0,003 \\
\hline uridine monophosphate kinase & & & 3,01 & 0,012 \\
\hline chromosome 1 open reading frame 24 & & & 7,74 & $4,53 \mathrm{E}+07$ \\
\hline LPS-induced TNF-alpha factor & $14,34 \mathrm{~A}$ & 0,015 & $14,02 \mathrm{~A}$ & 0,025 \\
\hline gamma-glutamyl hydrolase (conjugase, folylpolygammaglutamyl hydrolase) & & & 5,08 & 0,026 \\
\hline S100 calcium binding protein A11 (calgizzarin) & & & 5,86 & 0,013 \\
\hline basic helix-loop-helix domain containing, class B, 2 & $12,53 \mathrm{~A}$ & 0,087 & $15,73 \mathrm{~A}$ & 0,037 \\
\hline major histocompatibility complex, class I, B [BLAST] & & & 3,28 & 0,003 \\
\hline $\begin{array}{l}\text { Homo sapiens, Similar to RNA helicase-related protein, clone MGC:9246 } \\
\text { IMAGE: } 3892441, \text { mRNA, complete cds }\end{array}$ & & & 3,41 & 0,006 \\
\hline interleukin 3 receptor, alpha (low affinity) & $12,49 \mathrm{~A}$ & 0,004 & $21,62 \mathrm{~A}$ & 0,002 \\
\hline cathepsin $\mathrm{H}$ & & & 3,68 & 0,007 \\
\hline major histocompatibility complex, class I, B & & & 3,31 & 0,013 \\
\hline
\end{tabular}


Tabelle A.2: Hochregulation nur in HIMEC (Forts.)

\begin{tabular}{|c|c|c|c|c|}
\hline Gen & HIMEC 4h & p (4h) & HIMEC 24h & $\mathrm{p}(24 \mathrm{~h})$ \\
\hline HSPC037 protein & & & $6,09 \mathrm{~A}$ & 0,168 \\
\hline KIAA1199 protein & & & $5,03 \mathrm{~A}$ & 0,073 \\
\hline leukocyte specific transcript 1 & & & $31,49 \mathrm{~A}$ & 0,001 \\
\hline B-cell CLL/lymphoma 3 & $10,78 \mathrm{~A}$ & $8,18 \mathrm{E}+07$ & $9,351 \mathrm{~A}$ & $5,88 \mathrm{E}+07$ \\
\hline hypothetical protein LOC57333 & & & 3,4 & 0,016 \\
\hline adenylate kinase 3 & & & 3,21 & 0,033 \\
\hline $\begin{array}{l}\text { MCM5 minichromosome maintenance deficient } 5 \text {, cell division cycle } 46 \text { (S. } \\
\text { cerevisiae) }\end{array}$ & & & $6,407 \mathrm{~A}$ & 0,104 \\
\hline leukocyte specific transcript 1 & & & $21,21 \mathrm{~A}$ & 0,002 \\
\hline insulin induced gene 1 & & & 3,28 & 0,012 \\
\hline musculin (activated B-cell factor-1) & & & $6,148 \mathrm{~A}$ & 0,011 \\
\hline sarcospan (Kras oncogene-associated gene) & & & $5,282 \mathrm{~A}$ & 0,028 \\
\hline synaptogyrin 3 & $5,356 \mathrm{~A}$ & 0,091 & $5,813 \mathrm{~A}$ & 0,062 \\
\hline Nijmegen breakage syndrome 1 (nibrin) & & & 3,17 & 0,001 \\
\hline tumor necrosis factor receptor superfamily, member $6 \mathrm{~b}$, decoy & & & $5,118 \mathrm{~A}$ & 0,006 \\
\hline proteoglycan 1, secretory granule & & & 5,64 & 0,026 \\
\hline acetylcholinesterase (YT blood group) & & & $7,429 \mathrm{~A}$ & 0,004 \\
\hline transgelin 2 & & & 3,3 & 0,019 \\
\hline tumor protein p63 & & & $6,534 \mathrm{~A}$ & 0,023 \\
\hline mevalonate (diphospho) decarboxylase & & & $5,828 \mathrm{~A}$ & 0,070 \\
\hline hypothetical protein FLJ10357 & & & $5,457 \mathrm{~A}$ & 0,021 \\
\hline Homo sapiens metallothionein $1 \mathrm{H}$-like protein mRNA, complete cds & & & 3,53 & 0,010 \\
\hline fatty-acid-Coenzyme A ligase, long-chain 3 & & & 3,18 & 0,008 \\
\hline Notch homolog 2 (Drosophila) & & & 3,34 & 0,041 \\
\hline cathepsin S & & & 4,83 & 0,005 \\
\hline Epstein-Barr virus induced gene 3 & $14,77 \mathrm{~A}$ & 0,009 & $44,28 \mathrm{~A}$ & 0,003 \\
\hline butyrophilin, subfamily 3, member A3 & $5,41 \mathrm{~A}$ & 0,019 & $8,562 \mathrm{~A}$ & 0,006 \\
\hline $\begin{array}{l}\text { colony stimulating factor } 2 \text { receptor, beta, low-affinity (granulocyte- } \\
\text { macrophage) }\end{array}$ & & & 6,03 & 0,015 \\
\hline hypothetical protein FLJ20220 & $9,543 \mathrm{~A}$ & 0,005 & $16,77 \mathrm{~A}$ & 0,002 \\
\hline major histocompatibility complex, class I, F & & & 3,56 & 0,005 \\
\hline tumor suppressing subtransferable candidate 3 & & & 5,38 & 0,019 \\
\hline leukocyte specific transcript 1 & & & $35,07 \mathrm{~A}$ & 0,001 \\
\hline hypothetical protein MAC30 & & & 4,6 & 0,007 \\
\hline $\begin{array}{l}\text { caspase } 1 \text {, apoptosis-related cysteine protease (interleukin 1, beta, conver- } \\
\text { tase) }\end{array}$ & & & 5,6 & $1,47 \mathrm{E}+07$ \\
\hline colony stimulating factor 2 (granulocyte-macrophage) & $38,13 \mathrm{~A}$ & 0,005 & $20,61 \mathrm{~A}$ & 0,005 \\
\hline cytochrome b-5 & & & 3,26 & 0,007 \\
\hline tumor necrosis factor receptor superfamily, member 9 & & & $7,441 \mathrm{~A}$ & 0,003 \\
\hline synaptojanin 2 & & & $8,055 \mathrm{~A}$ & 0,047 \\
\hline basement membrane-induced gene & & & 3,57 & $9,67 \mathrm{E}+07$ \\
\hline CD44 antigen (homing function and Indian blood group system) & & & 4,16 & 0,003 \\
\hline Homo sapiens cDNA: FLJ23105 fis, clone LNG07677 & & & $7,862 \mathrm{~A}$ & 0,060 \\
\hline lysyl oxidase-like 2 & & & $14,41 \mathrm{~A}$ & 0,007 \\
\hline proteoglycan 1 , secretory granule & & & 8,37 & 0,012 \\
\hline heme oxygenase (decycling) 1 & & & 3,2 & 0,011 \\
\hline butyrophilin, subfamily 3 , member A3 & & & 3,39 & 0,002 \\
\hline butyrophilin, subfamily 3 , member $\mathrm{A} 3$ & & & 4,59 & 0,002 \\
\hline hypothetical protein FLJ22167 & & & 3,68 & 0,005 \\
\hline $\begin{array}{l}\text { caspase } 1 \text {, apoptosis-related cysteine protease (interleukin 1, beta, conver- } \\
\text { tase) }\end{array}$ & & & 5,21 & $4,81 \mathrm{E}+07$ \\
\hline $\begin{array}{l}\text { caspase } 1 \text {, apoptosis-related cysteine protease (interleukin 1, beta, conver- } \\
\text { tase) }\end{array}$ & & & 6,07 & $3,44 \mathrm{E}+07$ \\
\hline insulin induced gene 1 & & & 4,38 & 0,001 \\
\hline putative mitochondrial solute carrier & $6,135 \mathrm{~A}$ & 0,004 & $5,917 \mathrm{~A}$ & 0,005 \\
\hline $\begin{array}{l}\text { caspase } 1 \text {, apoptosis-related cysteine protease (interleukin 1, beta, conver- } \\
\text { tase) }\end{array}$ & & & 4,15 & $3,04 \mathrm{E}+07$ \\
\hline leukocyte specific transcript 1 & & & $38,69 \mathrm{~A}$ & 0,001 \\
\hline LPS-induced TNF-alpha factor & $7,942 \mathrm{~A}$ & 0,046 & $6,244 \mathrm{~A}$ & 0,068 \\
\hline chloride intracellular channel 2 & & & $12,39 \mathrm{~A}$ & 0,029 \\
\hline interleukin 15 & $7,977 \mathrm{~A}$ & 0,004 & $7,378 \mathrm{~A}$ & 0,004 \\
\hline metallothionein $1 \mathrm{X}$ & & & 4,26 & 0,005 \\
\hline $\begin{array}{l}\text { proteasome (prosome, macropain) subunit, beta type, } 9 \text { (large multifunctio- } \\
\text { nal protease } 2 \text { ) }\end{array}$ & & & 7,97 & $4,27 \mathrm{E}+07$ \\
\hline CD44 antigen (homing function and Indian blood group system) & & & 4,03 & 0,081 \\
\hline
\end{tabular}


Tabelle A.2: Hochregulation nur in HIMEC (Forts.)

\begin{tabular}{|c|c|c|c|c|}
\hline Gen & HIMEC 4h & p (4h) & HIMEC 24h & $p(24 h)$ \\
\hline ATPase, $\mathrm{Na}+/ \mathrm{K}+$ transporting, beta 1 polypeptide & & & 4,57 & 0,187 \\
\hline solute carrier family 2 (facilitated glucose transporter), member 3 & & & $7,142 \mathrm{~A}$ & 0,007 \\
\hline chromosome 1 open reading frame 24 & & & $12,62 \mathrm{~A}$ & 0,006 \\
\hline 7-dehydrocholesterol reductase & & & 3,15 & 0,002 \\
\hline proteasome (prosome, macropain) activator subunit 2 (PA28 beta) & & & 4,94 & $5,73 \mathrm{E}+07$ \\
\hline chemokine (C-X3-C motif) ligand 1 & $16,42 \mathrm{~A}$ & 0,014 & $20,33 \mathrm{~A}$ & 0,005 \\
\hline lysyl oxidase-like 2 & & & 4,93 & 0,012 \\
\hline fatty acid desaturase 2 & & & 3,81 & 0,003 \\
\hline sequestosome 1 & & & 3,39 & $9,93 \mathrm{E}+07$ \\
\hline $\begin{array}{l}\text { proteasome (prosome, macropain) subunit, beta type, } 8 \text { (large multifunctio- } \\
\text { nal protease } 7 \text { ) }\end{array}$ & & & $7,077 \mathrm{~A}$ & 0,039 \\
\hline GTP-binding protein & $15,7 \mathrm{~A}$ & $1,15 \mathrm{E}+07$ & $5,316 \mathrm{~A}$ & 0,003 \\
\hline sterol-C4-methyl oxidase-like & & & 3,12 & 0,003 \\
\hline leukocyte specific transcript 1 & & & $11,56 \mathrm{~A}$ & 0,002 \\
\hline solute carrier family 21 (organic anion transporter), member 9 & & & $6,622 \mathrm{~A}$ & 0,005 \\
\hline lanosterol synthase (2,3-oxidosqualene-lanosterol cyclase) & & & 3,42 & 0,002 \\
\hline
\end{tabular}

\section{A.1.3 Nach Stimulation mit TNF- $\alpha$ über vier bzw. 24 Stunden nur in HMEC-1 hochregulierte Gene}

Tabelle A.3: Durch Stimulation mit TNF- $\alpha$ nach 4 Std. und 24 Std. nur in HMEC-1 hochregulierte Gene

\begin{tabular}{|c|c|c|}
\hline Genbezeichnung & HMEC 4h & HMEC 24h \\
\hline chemokine (C-C motif) ligand 2 & 18,64 & 18,97 \\
\hline $\begin{array}{l}\text { serine (or cysteine) proteinase inhibitor, clade } \mathrm{E} \text { (nexin, plasminogen activator inhibitor type } 1 \text { ), } \\
\text { member } 1\end{array}$ & 17,91 & 11,57 \\
\hline chromosome 8 open reading frame 4 & 12,5 & 4,01 \\
\hline $\begin{array}{l}\text { serine (or cysteine) proteinase inhibitor, clade } \mathrm{E} \text { (nexin, plasminogen activator inhibitor type 1), } \\
\text { member } 1\end{array}$ & 11,42 & 8,01 \\
\hline follistatin & 7,84 & 3,11 \\
\hline transforming growth factor, beta 2 & 6,9 & 3,48 \\
\hline pentaxin-related gene, rapidly induced by IL-1 beta & 6,82 & 4,12 \\
\hline ephrin-A1 & 6,8 & 3,16 \\
\hline vascular endothelial growth factor $\mathrm{C}$ & 6,64 & 6,99 \\
\hline jagged 1 (Alagille syndrome) & 6,39 & \\
\hline tumor necrosis factor (ligand) superfamily, member 7 & 6,28 & 3,9 \\
\hline hypothetical protein FLJ20986 & 6,04 & \\
\hline enhancer of filamentation 1 (cas-like docking; Crk-associated substrate related) & 5,9 & \\
\hline 2'-5'-oligoadenylate synthetase-like & 5,83 & 10,55 \\
\hline interferon-induced protein with tetratricopeptide repeats 1 & 5,77 & 11,78 \\
\hline EH-domain containing 1 & 5,56 & \\
\hline retinoic acid- and interferon-inducible protein $(58 \mathrm{kD})$ & 5,5 & 4,29 \\
\hline cylindromatosis (turban tumor syndrome) & 5,43 & 3,19 \\
\hline lysyl oxidase & 5,35 & 5,42 \\
\hline interferon-induced protein 44 & 5,28 & 15,69 \\
\hline tumor necrosis factor (ligand) superfamily, member 10 & 5,22 & 6,79 \\
\hline Homo sapiens CD44 isoform RC (CD44) mRNA, complete cds & 5,17 & 3,49 \\
\hline interferon-induced protein with tetratricopeptide repeats 4 & 5,01 & 6,29 \\
\hline plasminogen activator, urokinase receptor & 5 & 5,37 \\
\hline transporter 1, ATP-binding cassette, sub-family B (MDR/TAP) & 4,99 & 6,56 \\
\hline transforming growth factor, beta 2 & 4,85 & \\
\hline diphtheria toxin receptor (heparin-binding epidermal growth factor-like growth factor) & 4,72 & 3,43 \\
\hline human immunodeficiency virus type I enhancer binding protein 1 & 4,68 & \\
\hline KIAA0062 protein & 4,52 & \\
\hline BMP-2 inducible kinase & 4,49 & \\
\hline ATPase, $\mathrm{Ca}++$ transporting, plasma membrane 1 & 4,38 & \\
\hline uridine phosphorylase & 4,32 & \\
\hline
\end{tabular}




\section{Anhang A Rohdaten der DNA-Microarrayuntersuchung}

Tabelle A.3: Hochregulation nur in HMEC-1 (Forts.)

\begin{tabular}{|c|c|c|}
\hline Gen & HMEC 4h & HMEC 24h \\
\hline neural precursor cell expressed, developmentally down-regulated 4-like & 4,27 & \\
\hline hypothetical protein FLJ20073 & 4,22 & 4,52 \\
\hline lysyl oxidase & 4,13 & 4,75 \\
\hline 2',5'-oligoadenylate synthetase $1,40 / 46 \mathrm{kDa}$ & 4,11 & 12,18 \\
\hline interleukin 6 (interferon, beta 2$)$ & 4,07 & 3,81 \\
\hline H.sapiens mRNA for HMGI-C protein [BLAST] & 4,05 & \\
\hline immediate early response 3 & 4,02 & 3,52 \\
\hline jagged 1 (Alagille syndrome) & 3,92 & \\
\hline v-jun sarcoma virus 17 oncogene homolog (avian) & 3,91 & \\
\hline solute carrier family 7 (cationic amino acid transporter, $y+$ system), member 1 & 3,9 & \\
\hline endothelial cell-specific molecule 1 & 3,85 & \\
\hline LIM domain protein & 3,83 & \\
\hline v-maf musculoaponeurotic fibrosarcoma oncogene homolog F (avian) & 3,8 & 3,52 \\
\hline tubulin, beta polypeptide & 3,77 & 3,33 \\
\hline hypothetical protein FLJ20986 & 3,77 & \\
\hline CASP8 and FADD-like apoptosis regulator & 3,71 & 3,21 \\
\hline tissue factor pathway inhibitor 2 & 3,64 & \\
\hline glutamine-fructose-6-phosphate transaminase 2 & 3,64 & \\
\hline CD47 antigen (Rh-related antigen, integrin-associated signal transducer) & 3,62 & 4,34 \\
\hline core promoter element binding protein & 3,62 & \\
\hline ATP-binding cassette, sub-family G (WHITE), member 1 & 3,6 & \\
\hline prostaglandin E receptor 4 (subtype EP4) & 3,58 & 5,01 \\
\hline dickkopf homolog 1 (Xenopus laevis) & 3,58 & 3,28 \\
\hline core promoter element binding protein & 3,57 & \\
\hline cytochrome P450, subfamily I (dioxin-inducible), polypeptide 1 (glaucoma 3 , primary infantile) & 3,54 & \\
\hline BH3 interacting domain death agonist & 3,51 & \\
\hline thrombospondin 1 & 3,49 & \\
\hline mesenchyme homeo box 2 (growth arrest-specific homeo box) & 3,49 & \\
\hline hypothetical protein FLJ23548 & 3,49 & \\
\hline tissue factor pathway inhibitor 2 & 3,45 & \\
\hline $\begin{array}{l}\text { serine (or cysteine) proteinase inhibitor, clade E (nexin, plasminogen activator inhibitor type 1), } \\
\text { member } 2\end{array}$ & 3,44 & \\
\hline protein tyrosine phosphatase, non-receptor type 12 & 3,44 & \\
\hline UDP-Gal:betaGlcNAc beta 1,4- galactosyltransferase, polypeptide 1 & 3,42 & \\
\hline deleted in lymphocytic leukemia, 2 & 3,41 & \\
\hline pre-B-cell colony-enhancing factor & 3,4 & \\
\hline SPRY domain-containing SOCS box protein SSB-1 & 3,37 & \\
\hline cysteine-rich, angiogenic inducer, 61 & 3,31 & 3,13 \\
\hline transforming growth factor, beta 2 & 3,3 & \\
\hline dual specificity phosphatase 6 & 3,3 & \\
\hline inositol 1,4,5-triphosphate receptor, type 2 & 3,28 & \\
\hline cysteine knot superfamily $1, \mathrm{BMP}$ antagonist 1 & 3,27 & \\
\hline GLI pathogenesis-related 1 (glioma) & 3,26 & \\
\hline CASP8 and FADD-like apoptosis regulator & 3,24 & \\
\hline tripartite motif-containing 16 & 3,23 & 3,33 \\
\hline CD44 antigen (homing function and Indian blood group system) & 3,21 & \\
\hline dual-specificity tyrosine-(Y)-phosphorylation regulated kinase 2 & 3,18 & \\
\hline TGFB inducible early growth response & 3,15 & \\
\hline apolipoprotein L, 3 & 3,14 & \\
\hline ras homolog gene family, member $\mathrm{E}$ & 3,13 & \\
\hline neuropilin 2 & 3,12 & 5,62 \\
\hline signal transducer and activator of transcription $1,91 \mathrm{kDa}$ & 3,11 & 10,82 \\
\hline solute carrier family 4 , sodium bicarbonate cotransporter, member 7 & 3,11 & \\
\hline KIAA1046 protein & 3,07 & \\
\hline neuron navigator 2 & 3,05 & \\
\hline KIAA1053 protein & 3,05 & \\
\hline nuclear factor of kappa light polypeptide gene enhancer in B-cells 1 (p105) & 3,04 & \\
\hline FOS-like antigen 1 & 3,04 & \\
\hline MAD, mothers against decapentaplegic homolog 3 (Drosophila) & 3,03 & \\
\hline thrombospondin 1 & 3,01 & \\
\hline 2'-5'-oligoadenylate synthetase $2,69 / 71 \mathrm{kDa}$ & & 4,27 \\
\hline neuregulin 1 & $10,3 \mathrm{~A}$ & \\
\hline tumor necrosis factor, alpha-induced protein 6 & $9,326 \mathrm{~A}$ & \\
\hline dihydropyrimidinase-like 3 & & 4,3 \\
\hline
\end{tabular}




\section{Anhang A Rohdaten der DNA-Microarrayuntersuchung}

Tabelle A.3: Hochregulation nur in HMEC-1 (Forts.)

\begin{tabular}{|c|c|c|}
\hline Gen & HMEC 4h & HMEC 24h \\
\hline 2'-5'-oligoadenylate synthetase $3,100 \mathrm{kDa}$ & & 6,31 \\
\hline hypothetical protein MGC34648 & & 10,73 \\
\hline signal transducer and activator of transcription $1,91 \mathrm{kDa}$ & & 4,52 \\
\hline interferon, alpha-inducible protein (clone IFI-6-16) & & 3,8 \\
\hline B-cell CLL/lymphoma 2 & $14,32 \mathrm{~A}$ & \\
\hline proteolipid protein 1 (Pelizaeus-Merzbacher disease, spastic paraplegia 2, uncomplicated) & & $7,982 \mathrm{~A}$ \\
\hline BCL2-related protein A1 & $108,7 \mathrm{~A}$ & \\
\hline interferon regulatory factor 7 & & 6,31 \\
\hline protein kinase $\mathrm{C}$, alpha & $7,852 \mathrm{~A}$ & \\
\hline ceruloplasmin (ferroxidase) & & $662,2 \mathrm{~A}$ \\
\hline tripartite motif-containing 22 & & 7,44 \\
\hline $\begin{array}{l}\text { v-rel reticuloendotheliosis viral oncogene homolog B, nuclear factor of kappa light polypeptide } \\
\text { gene enhancer in B-cells } 3 \text { (avian) }\end{array}$ & $7,117 \mathrm{~A}$ & $5,186 \mathrm{~A}$ \\
\hline HIV-1 Tat interactive protein $2,30 \mathrm{kDa}$ & & 3,87 \\
\hline signal transducer and activator of transcription $1,91 \mathrm{kDa}$ & & 3,99 \\
\hline protocadherin 8 & $9,516 \mathrm{~A}$ & \\
\hline cyclin-E binding protein 1 & & 7,1 \\
\hline chromosome 1 open reading frame 29 & & $488,2 \mathrm{~A}$ \\
\hline $2^{\prime}, 5$ '-oligoadenylate synthetase $1,40 / 46 \mathrm{kDa}$ & & 8,28 \\
\hline laminin, gamma 2 & & $8,179 \mathrm{~A}$ \\
\hline TNF receptor-associated factor 4 & & $7,023 \mathrm{~A}$ \\
\hline H2B histone family, member $\mathrm{T}$ & & 3,15 \\
\hline HLA-G histocompatibility antigen, class I, G & & 3,07 \\
\hline signal transducer and activator of transcription $1,91 \mathrm{kDa}$ & & 3,59 \\
\hline leucine aminopeptidase 3 & & 3,22 \\
\hline interferon, alpha-inducible protein 27 & & 36,53 \\
\hline hypothetical protein FLJ20637 & & $14,4 \mathrm{~A}$ \\
\hline hypothetical protein PRO2893 & $6,19 \mathrm{~A}$ & \\
\hline T cell receptor alpha locus & $23,7 \mathrm{~A}$ & \\
\hline $\begin{array}{l}\text { Homo sapiens T-cell receptor alpha delta locus from bases } 250472 \text { to } 501670 \text { (section } 2 \text { of } 5 \text { ) of } \\
\text { the Complete Nucleotide Sequence }\end{array}$ & & $7,009 \mathrm{~A}$ \\
\hline CD44 antigen (homing function and Indian blood group system) & $13,64 \mathrm{~A}$ & \\
\hline Homo sapiens mRNA; cDNA DKFZp586D0522 (from clone DKFZp586D0522) & $23,55 \mathrm{~A}$ & \\
\hline LIM domain protein & $8,202 \mathrm{~A}$ & \\
\hline ubiquitously transcribed tetratricopeptide repeat gene, $\mathrm{X}$ chromosome & $7,497 \mathrm{~A}$ & \\
\hline GATA binding protein 6 & $5,432 \mathrm{~A}$ & \\
\hline p53-regulated apoptosis-inducing protein 1 & $9,627 \mathrm{~A}$ & \\
\hline neurofibromin 1 (neurofibromatosis, von Recklinghausen disease, Watson disease) & $21,23 \mathrm{~A}$ & \\
\hline melanoma differentiation associated protein-5 & $7,857 \mathrm{~A}$ & $15,25 \mathrm{~A}$ \\
\hline $28 \mathrm{kD}$ interferon responsive protein & & $13,83 \mathrm{~A}$ \\
\hline ubiquitin specific protease 18 & & $9,095 \mathrm{~A}$ \\
\hline ATP-binding cassette, sub-family A (ABC1), member 1 & & $5,062 \mathrm{~A}$ \\
\hline tumor necrosis factor (ligand) superfamily, member 18 & $7,521 \mathrm{~A}$ & \\
\hline superoxide dismutase 2, mitochondrial & $7,619 \mathrm{~A}$ & \\
\hline phospholipid scramblase 1 & & 4,39 \\
\hline 2'-5'-oligoadenylate synthetase $2,69 / 71 \mathrm{kDa}$ & & 13,29 \\
\hline protein kinase, interferon-inducible double stranded RNA dependent & & 3,63 \\
\hline RAB9, member RAS oncogene family, pseudogene 1 [BLAST] & & $14,39 \mathrm{~A}$ \\
\hline multimerin & & $5,925 \mathrm{~A}$ \\
\hline leukemia inhibitory factor (cholinergic differentiation factor) & $41,86 \mathrm{~A}$ & $17,37 \mathrm{~A}$ \\
\hline nuclear antigen Sp100 & & 3,44 \\
\hline fibroblast growth factor 5 & $8,113 \mathrm{~A}$ & \\
\hline testicular soluble adenylyl cyclase & $16,17 \mathrm{~A}$ & \\
\hline asparagine synthetase & & 3,17 \\
\hline adaptor-related protein complex 1, mu 1 subunit & & 3,59 \\
\hline $\begin{array}{l}\text { tumor necrosis factor (ligand) superfamily, member } 4 \text { (tax-transcriptionally activated glycoprotein } \\
1,34 \mathrm{kDa})\end{array}$ & $5,677 \mathrm{~A}$ & $9,532 \mathrm{~A}$ \\
\hline tumor necrosis factor (ligand) superfamily, member 10 & & 3,88 \\
\hline tumor necrosis factor receptor superfamily, member 11b (osteoprotegerin) & $21,65 \mathrm{~A}$ & \\
\hline matrix metalloproteinase 12 (macrophage elastase) & $6,357 \mathrm{~A}$ & \\
\hline ubiquitin-conjugating enzyme E2L 6 & & 3,33 \\
\hline KIAA1053 protein & $6,093 \mathrm{~A}$ & \\
\hline hypothetical protein PRO2214 & & 3,34 \\
\hline signal transducer and activator of transcription $1,91 \mathrm{kDa}$ & & 3,52 \\
\hline
\end{tabular}


Tabelle A.3: Hochregulation nur in HMEC-1 (Forts.)

\begin{tabular}{|c|c|c|}
\hline Gen & HMEC 4h & HMEC 24h \\
\hline A kinase (PRKA) anchor protein 7 & $5,079 \mathrm{~A}$ & \\
\hline nuclear factor of kappa light polypeptide gene enhancer in B-cells $2(\mathrm{p} 49 / \mathrm{p} 100)$ & $12,65 \mathrm{~A}$ & $9,878 \mathrm{~A}$ \\
\hline phospholipid scramblase 1 & & 3,18 \\
\hline tumor necrosis factor (ligand) superfamily, member 15 & $5,88 \mathrm{~A}$ & \\
\hline Ras-induced senescence 1 & $6,715 \mathrm{~A}$ & \\
\hline tumor necrosis factor, alpha-induced protein 2 & $7,647 \mathrm{~A}$ & \\
\hline transporter 2, ATP-binding cassette, sub-family B (MDR/TAP) & & 3,66 \\
\hline Integrin associated protein & & 3,2 \\
\hline lysosomal-associated membrane protein 3 & & 6,48 \\
\hline glycoprotein A repetitions predominant & $5,027 \mathrm{~A}$ & \\
\hline Nuclease sensitive element binding protein 1 & & $23,87 \mathrm{~A}$ \\
\hline XIAP associated factor-1 & & $8,46 \mathrm{~A}$ \\
\hline vipirin & & $35,9 \mathrm{~A}$ \\
\hline myxovirus (influenza virus) resistance 2 (mouse) & & $25,26 \mathrm{~A}$ \\
\hline solute carrier family 2 (facilitated glucose transporter), member 6 & $5,569 \mathrm{~A}$ & \\
\hline lipase, endothelial & $7,269 \mathrm{~A}$ & \\
\hline Homo sapiens cDNA FLJ39071 fis, clone NT2RP7015789, highly similar to Zinc finger protein 267 & & 3,06 \\
\hline LIM protein (similar to rat protein kinase C-binding enigma) & $6,595 \mathrm{~A}$ & \\
\hline diphtheria toxin receptor (heparin-binding epidermal growth factor-like growth factor) & $6,16 \mathrm{~A}$ & \\
\hline lymphocyte antigen 6 complex, locus $\mathrm{E}$ & & 4,06 \\
\hline ubiquitin D & $90,46 \mathrm{~A}$ & $213,3 \mathrm{~A}$ \\
\hline claudin 1 & $18,69 \mathrm{~A}$ & \\
\hline $\begin{array}{l}\text { phosphoribosylglycinamide formyltransferase, phosphoribosylglycinamide synthetase, phosphori- } \\
\text { bosylaminoimidazole synthetase }\end{array}$ & & 3,22 \\
\hline fibroblast growth factor 5 & $6,325 \mathrm{~A}$ & \\
\hline nuclear antigen $\mathrm{Sp} 100$ & & 3,26 \\
\hline tumor necrosis factor, alpha-induced protein 6 & $42,86 \mathrm{~A}$ & $11,36 \mathrm{~A}$ \\
\hline interleukin 1 , beta & $6,066 \mathrm{~A}$ & $5,762 \mathrm{~A}$ \\
\hline RNA helicase & $7,62 \mathrm{~A}$ & $9,955 \mathrm{~A}$ \\
\hline muscle, skeletal, receptor tyrosine kinase & $5,378 \mathrm{~A}$ & \\
\hline tenascin $\mathrm{C}$ (hexabrachion) & $17,19 \mathrm{~A}$ & $7,676 \mathrm{~A}$ \\
\hline FLN29 gene product & & $8,221 \mathrm{~A}$ \\
\hline 2'-5'-oligoadenylate synthetase-like & & 4,9 \\
\hline methyl-CpG binding domain protein 2 & $9,335 \mathrm{~A}$ & $5,694 \mathrm{~A}$ \\
\hline inhibin, beta A (activin A, activin AB alpha polypeptide) & $5,551 \mathrm{~A}$ & \\
\hline programmed death ligand 2 & $21,21 \mathrm{~A}$ & $18,28 \mathrm{~A}$ \\
\hline Homo sapiens clone 24739 mRNA sequence & $15,41 \mathrm{~A}$ & \\
\hline interleukin 7 & & $22,19 \mathrm{~A}$ \\
\hline hypothetical protein MGC34648 & & 8,55 \\
\hline intersectin 1 (SH3 domain protein) & & 3,23 \\
\hline interleukin 1 , beta & $7,913 \mathrm{~A}$ & $8,042 \mathrm{~A}$ \\
\hline Kruppel-associated box protein & & $5,838 \mathrm{~A}$ \\
\hline insulin-like growth factor binding protein 5 & $6,916 \mathrm{~A}$ & $7,155 \mathrm{~A}$ \\
\hline insulin-like growth factor binding protein 5 & $9,022 \mathrm{~A}$ & $10,45 \mathrm{~A}$ \\
\hline
\end{tabular}

\section{A.2 Herunterregulierte bzw. ausgeschaltete Gene}

\section{A.2.1 Nach Stimulation mit TNF- $\alpha$ über vier bzw. 24 Stunden in HIMEC und HMEC-1 herunterregulierte Gene}

Tabelle A.4: Durch Stimulation mit TNF- $\alpha$ nach 4 Std. und 24 Std. in sowohl HIMEC als auch HMEC-1 herunterregulierte Gene

\begin{tabular}{|c|c|c|c|c|c|c|}
\hline Genbezeichnung & HIMEC $4 \mathrm{~h}$ & p (4h) & HIMEC 24h & $p(24 h)$ & HMEC 4h & HMEC 24h \\
\hline coxsackie virus and adenovirus receptor & 3,346999884 & 0,002082 & 5,462999821 & 0,0005652 & & 5,012000084 \\
\hline T-box 1 & 9,013999939 & 0,009611 & 4,997000217 & 0,00784 & 3,65199995 & \\
\hline
\end{tabular}


Tabelle A.4: Herunterregulation in HIMEC und HMEC-1 (Forts.)

\begin{tabular}{|l|l|l|l|l|l|l|}
\hline Gen & HIMEC 4h & p (4h) & HIMEC 24h & p (24h) & HMEC 4h & HMEC 24h \\
\hline $\begin{array}{l}\text { inhibitor of DNA binding 1, dominant nega- } \\
\text { tive helix-loop-helix protein }\end{array}$ & & & 4,386000156 & 0,01546 & \\
\hline $\begin{array}{l}\text { programmed cell death 4 (neoplastic trans- } \\
\text { formation inhibitor) }\end{array}$ & & & 3,247999907 & 0,009244 & 3,282999992 & \\
\hline
\end{tabular}

\section{A.2.2 Nach Stimulation mit TNF- $\alpha$ über vier bzw. 24 Stunden nur in HIMEC herunterregulierte Gene}

Tabelle A.5: Durch Stimulation mit TNF- $\alpha$ nach 4 Std. und 24 Std. nur in HIMEC herunterregulierte Gene

\begin{tabular}{|c|c|c|c|c|}
\hline Genbezeichnung & HIMEC $4 \mathrm{~h}$ & $\mathrm{p}(4 \mathrm{~h})$ & HIMEC 24h & p (24h) \\
\hline hydroxysteroid (17-beta) dehydrogenase 2 & & & 10,46000004 & 0,001624 \\
\hline follistatin & & & 8,774999619 & 0,01169 \\
\hline semaphorin $3 \mathrm{C}$ & & & 8,548000336 & 0,041540001 \\
\hline doublecortin and CaM kinase-like 1 & & & 7,638000011 & 0,0001397 \\
\hline KIAA0644 gene product & 4,929999828 & 0,03452 & 7,02699995 & 0,009811 \\
\hline progesterone receptor membrane component 2 & 3,325000048 & 0,002837 & 6,06799984 & 0,005247 \\
\hline cyclin-dependent kinase inhibitor 1C (p57, Kip2) & & & 5,889999866 & 0,0009057 \\
\hline hypothetical protein FLJ10970 & 7,506999969 & 0,001358 & 5,56400013 & 0,001716 \\
\hline selenoprotein $\mathrm{P}$, plasma, 1 & & & 5,449999809 & 0,02052 \\
\hline peroxisome proliferative activated receptor, gamma & & & 5,441999912 & 0,005454 \\
\hline microfibrillar-associated protein 3-like & & & 5,198999882 & 0,0002442 \\
\hline Arg/Abl-interacting protein ArgBP2 & & & 5,18900013 & 0,02142 \\
\hline KIAA0960 protein [BLAST] & & & 5,177000046 & 0,00635 \\
\hline transmembrane 4 superfamily member 10 & & & 5,072999954 & 0,009533 \\
\hline nidogen (enactin) & & & 4,980000019 & 0,0002159 \\
\hline follistatin & & & 4,769999981 & 0,019619999 \\
\hline growth hormone receptor & & & 4,278999805 & 0,002571 \\
\hline endomucin & & & 4,032000065 & 0,021989999 \\
\hline serine/threonine kinase 38 like & & & 3,993999958 & $6,205 \mathrm{E}-05$ \\
\hline nidogen (enactin) & & & 3,914000034 & 0,008151 \\
\hline butyrylcholinesterase & & & 3,861000061 & 0,043019999 \\
\hline leptin receptor & & & 3,644999981 & $4,161 \mathrm{E}-05$ \\
\hline transient receptor potential cation channel, subfamily $\mathrm{C}$, member 6 & & & 3,608999968 & 0,009286 \\
\hline $\begin{array}{l}\text { tissue factor pathway inhibitor (lipoprotein-associated coagulation inhibi- } \\
\text { tor) }\end{array}$ & & & 3,562000036 & 0,025760001 \\
\hline BTB (POZ) domain containing 3 & & & 3,546999931 & 0,04685 \\
\hline Kv channel interacting protein 1 & & & 3,546000004 & 0,01412 \\
\hline $\begin{array}{l}\text { CTD (carboxy-terminal domain, RNA polymerase II, polypeptide A) small } \\
\text { phosphatase-like }\end{array}$ & & & 3,407999992 & 0,01416 \\
\hline DEAD (Asp-Glu-Ala-Asp) box polypeptide 10 & & & 3,364000082 & 0,02722 \\
\hline programmed cell death 4 (neoplastic transformation inhibitor) & & & 3,292000055 & 0,004319 \\
\hline chromosome 14 open reading frame 116 & & & 3,28399992 & 0,000115 \\
\hline progesterone receptor membrane component 2 & & & 3,230000019 & 0,00892 \\
\hline chondroitin beta1,4 $\mathrm{N}$-acetylgalactosaminyltransferase & & & 3,214999914 & 0,04005 \\
\hline fat-like cadherin FATJ & & & 3,198999882 & 0,01226 \\
\hline I-mfa domain-containing protein & & & 3,127000093 & 0,01119 \\
\hline similar to KIAA0393 protein & & & 3,117000103 & 0,001772 \\
\hline $\begin{array}{l}\text { MADS box transcription enhancer factor 2, polypeptide C (myocyte enhan- } \\
\text { cer factor } 2 \mathrm{C} \text { ) }\end{array}$ & & & 3,09800005 & 0,01437 \\
\hline very low density lipoprotein receptor & & & 3,085999966 & 0,009527 \\
\hline calcineurin A alpha & & & 3,078000069 & 0,001001 \\
\hline DnaJ (Hsp40) homolog, subfamily B, member 4 & & & 3,068000078 & 0,003113 \\
\hline paternally expressed 10 & & & 3,055999994 & 0,006873 \\
\hline paternally expressed 10 & & & 3,053999901 & 0,001054 \\
\hline transforming growth factor beta 1 induced transcript 4 & & & 3,051000118 & 0,02832 \\
\hline macrophage expressed gene 1 & 4,868000031 & 0,006307 & & \\
\hline
\end{tabular}


Tabelle A.5: Herunterregulation nur in HIMEC (Forts.)

\begin{tabular}{|c|c|c|c|c|}
\hline Gen & HIMEC $4 \mathrm{~h}$ & $p(4 h)$ & HIMEC 24h & p (24h) \\
\hline tripartite motif-containing 16 & 4,040999889 & 0,007073 & & \\
\hline gap junction protein, alpha $4,37 \mathrm{kDa}$ (connexin 37 ) & 3,862999916 & 0,006723 & $15,890 \mathrm{~A}$ & 0,02217 \\
\hline homeo box D1 & 3,413000107 & 0,008306 & & \\
\hline B cell RAG associated protein & 3,256000042 & 0,01223 & & \\
\hline LDL receptor adaptor protein & 3,128000021 & 0,02438 & & \\
\hline nuclear factor of activated T-cells, cytoplasmic, calcineurin-dependent 3 & 3,085000038 & 0,002754 & & \\
\hline UDP-Gal:betaGlcNAc beta 1,3-galactosyltransferase, polypeptide 2 & 3,072000027 & 0,002618 & $19,040 \mathrm{~A}$ & 0,03111 \\
\hline gap junction protein, alpha $4,37 \mathrm{kDa}$ (connexin 37$)$ & & & $29,469 \mathrm{~A}$ & 0,01568 \\
\hline carbonic anhydrase IV & & & $21,309 \mathrm{~A}$ & 0,004546 \\
\hline cytochrome b reductase 1 & & & $15,619 \mathrm{~A}$ & 0,001483 \\
\hline chromosome 2 open reading frame 23 & & & $11,239 \mathrm{~A}$ & 0,01424 \\
\hline v-maf musculoaponeurotic fibrosarcoma oncogene homolog (avian) & $6,843 \mathrm{~A}$ & 0,046530001 & $9,102 \mathrm{~A}$ & 0,0451 \\
\hline receptor (calcitonin) activity modifying protein 2 & & & $8,104 \mathrm{~A}$ & 0,046730001 \\
\hline nitric oxide synthase 3 (endothelial cell) & & & $7,590 \mathrm{~A}$ & 0,0001644 \\
\hline LDL receptor adaptor protein & $7,335 \mathrm{~A}$ & 0,016890001 & $7,408 \mathrm{~A}$ & 0,01877 \\
\hline cyclin-dependent kinase inhibitor 1C (p57, Kip2) & & & $7,349 \mathrm{~A}$ & 0,002885 \\
\hline cyclin-dependent kinase inhibitor 1C (p57, Kip2) & & & $7,111 \mathrm{~A}$ & 0,023460001 \\
\hline cyclin-dependent kinase inhibitor 1C (p57, Kip2) & & & $5,947 \mathrm{~A}$ & 0,001683 \\
\hline olfactomedin-like 3 & & & $5,627 \mathrm{~A}$ & 0,001566 \\
\hline $\begin{array}{l}\text { v-myc myelocytomatosis viral related oncogene, neuroblastoma derived (avi- } \\
\text { an) }\end{array}$ & & & $5,165 \mathrm{~A}$ & 0,029449999 \\
\hline KIAA0644 gene product & & & $5,144 \mathrm{~A}$ & 0,001491 \\
\hline hypothetical protein CG003 & $5,879 \mathrm{~A}$ & 0,000213 & & \\
\hline
\end{tabular}

\section{A.2.3 Nach Stimulation mit TNF- $\alpha$ über vier bzw. 24 Stunden nur in HMEC-1 herunterregulierte Gene}

Tabelle A.6: Durch Stimulation mit TNF- $\alpha$ nach 4 Std. und 24 Std. nur in HMEC-1 herunterregulierte Gene

\begin{tabular}{|c|c|c|}
\hline Genbezeichnung & HMEC 4h & HMEC 24h \\
\hline CUG triplet repeat, RNA binding protein 2 & & $34,720 \mathrm{~A}$ \\
\hline lethal giant larvae homolog 2 (Drosophila) & & $20,670 \mathrm{~A}$ \\
\hline CDNA FLJ14019 fis, clone HEMBA1002503 & & $13,920 \mathrm{~A}$ \\
\hline brain-specific angiogenesis inhibitor 2 & & $13,359 \mathrm{~A}$ \\
\hline zinc finger protein 516 & & $12,800 \mathrm{~A}$ \\
\hline nuclear receptor subfamily 2 , group $\mathrm{C}$, member 1 & & $10,865 \mathrm{~A}$ \\
\hline ribosomal protein L7 & & $10,840 \mathrm{~A}$ \\
\hline loss of heterozygosity, 11 , chromosomal region 2 , gene A & & $9,312 \mathrm{~A}$ \\
\hline Homo sapiens cDNA FLJ11556 fis, clone HEMBA1003079 & $9,734 \mathrm{~A}$ & $9,003 \mathrm{~A}$ \\
\hline chromosome 19 open reading frame 2 & & $8,618 \mathrm{~A}$ \\
\hline CD163 antigen & & $7,429 \mathrm{~A}$ \\
\hline complement component 5 & & $7,385 \mathrm{~A}$ \\
\hline TYRO3 protein tyrosine kinase & & $6,024 \mathrm{~A}$ \\
\hline leucine rich repeat containing 1 & & $5,981 \mathrm{~A}$ \\
\hline hypoxia inducible factor 3 , alpha subunit & & $5,616 \mathrm{~A}$ \\
\hline DEAD (Asp-Glu-Ala-Asp) box polypeptide 17 & & $5,350 \mathrm{~A}$ \\
\hline vesicle-associated membrane protein 1 (synaptobrevin 1$)$ & & $5,034 \mathrm{~A}$ \\
\hline ATP-binding cassette, sub-family A (ABC1), member 8 & & 5,627 \\
\hline biglycan & & 5,330 \\
\hline tetratricopeptide repeat domain 3 & & 3,986 \\
\hline TAF6-like RNA polymerase II, p300/CBP-associated factor (PCAF)-associated factor, 65kDa & & 3,927 \\
\hline erythrocyte membrane protein band 4.1 like 5 & & 3,908 \\
\hline glutathione peroxidase 3 (plasma) & & 3,805 \\
\hline glutathione peroxidase 3 (plasma) & & 3,737 \\
\hline small nuclear ribonucleoprotein polypeptide $\mathrm{N}$ & & 3,723 \\
\hline dynamin 1 & & 3,579 \\
\hline amphoterin induced gene 2 & & 3,505 \\
\hline
\end{tabular}




\section{Anhang A Rohdaten der DNA-Microarrayuntersuchung}

Tabelle A.6: Herunterregulation nur in HMEC-1 (Forts.)

\begin{tabular}{|c|c|c|}
\hline Gen & HMEC 4h & HMEC 24h \\
\hline biglycan & & 3,475 \\
\hline mesoderm specific transcript homolog (mouse) & & 3,381 \\
\hline junction plakoglobin & & 3,183 \\
\hline mitochondrial tumor suppressor 1 & 4,016 & 3,178 \\
\hline secretory carrier membrane protein 1 & & 3,083 \\
\hline KIAA0657 protein & & 3,068 \\
\hline coiled-coil domain containing 2 & $41,150 \mathrm{~A}$ & \\
\hline chromosome 5 open reading frame 4 & $15,810 \mathrm{~A}$ & \\
\hline thymus high mobility group box protein TOX & $15,319 \mathrm{~A}$ & \\
\hline adenosine deaminase, RNA-specific, B1 (RED1 homolog rat) & $10,970 \mathrm{~A}$ & \\
\hline ubiquitin-conjugating enzyme E2D 1 (UBC4/5 homolog, yeast) & $10,789 \mathrm{~A}$ & \\
\hline homeo box A1 & $10,779 \mathrm{~A}$ & \\
\hline tumor necrosis factor (ligand) superfamily, member 11 & $9,859 \mathrm{~A}$ & \\
\hline BRAF35/HDAC2 complex (80 kDa) & $9,251 \mathrm{~A}$ & \\
\hline amyotrophic lateral sclerosis 2 (juvenile) chromosome region, candidate 8 & $9,027 \mathrm{~A}$ & \\
\hline fibroblast growth factor 7 (keratinocyte growth factor) & $8,569 \mathrm{~A}$ & \\
\hline sushi-repeat-containing protein, X-linked 2 & $7,849 \mathrm{~A}$ & \\
\hline v-kit Hardy-Zuckerman 4 feline sarcoma viral oncogene homolog & $7,306 \mathrm{~A}$ & \\
\hline transient receptor potential cation channel, subfamily V, member 1 & $7,268 \mathrm{~A}$ & \\
\hline histone $1, \mathrm{H} 2 \mathrm{bk}$ & $6,317 \mathrm{~A}$ & \\
\hline EH-domain containing 3 & $6,265 \mathrm{~A}$ & \\
\hline stoned B-like factor & $5,848 \mathrm{~A}$ & \\
\hline islet cell autoantigen $1,69 \mathrm{kDa}$ & $5,712 \mathrm{~A}$ & \\
\hline HLA-B associated transcript 1 & $5,632 \mathrm{~A}$ & \\
\hline heterogeneous nuclear ribonucleoprotein D (AU-rich element RNA binding protein $1,37 \mathrm{kDa}$ ) & $5,242 \mathrm{~A}$ & \\
\hline X-ray repair complementing defective repair in Chinese hamster cells 2 & $5,184 \mathrm{~A}$ & \\
\hline zinc finger protein 211 & $5,019 \mathrm{~A}$ & \\
\hline ankyrin repeat domain 10 & 5,182 & \\
\hline chromosome 20 open reading frame 172 & 4,580 & \\
\hline KIAA0738 gene product & 4,429 & \\
\hline mitochondrial tumor suppressor 1 & 4,259 & \\
\hline DKFZP586A0522 protein & 3,989 & \\
\hline tribbles homolog 2 (Drosophila) & 3,847 & \\
\hline KIAA0738 gene product & 3,773 & \\
\hline frizzled homolog 2 (Drosophila) & 3,689 & \\
\hline hypothetical protein MGC13024 & 3,597 & \\
\hline pleckstrin homology-like domain, family A, member 1 & 3,490 & \\
\hline homeo box D4 & 3,481 & \\
\hline mitochondrial tumor suppressor 1 & 3,416 & \\
\hline ralA binding protein 1 & 3,358 & \\
\hline ferrochelatase (protoporphyria) & 3,253 & \\
\hline transcription factor Dp-2 (E2F dimerization partner 2) & 3,188 & \\
\hline nuclear receptor coactivator 1 & 3,184 & \\
\hline CDC-like kinase 1 & 3,158 & \\
\hline sphingomyelin phosphodiesterase, acid-like 3A & 3,133 & \\
\hline DnaJ (Hsp40) homolog, subfamily C, member 6 & 3,084 & \\
\hline erythropoietin receptor & 3,042 & \\
\hline
\end{tabular}




\section{Anhang B}

\section{Lebenslauf}

Name

Geburtstag, -ort

Eltern

Schule

Wehrdienst

Studium

Approbation

z.Zt.
Moritz Kebschull, Zahnarzt

05. September 1978 in Münster (Westf.)

Dres. med. dent. Nicola und Gert Kebschull, Zahnärzte

1985 - 1989 Josefschule 33442 Herzebrock

1989 - 1998 Einstein-Gymnasium 33378 Rheda-Wiedenbrück

Juni 1998 Abitur ebendort (Notendurchschnitt 1,0)

Juli 1998 - April 1999 als Sanitätssoldat beim 1. DeutschNiederländischen Korps in Coesfeld und Münster

SS 1999 - WS 2003/2004 Studium der Zahnmedizin an der WWU Münster

seit WS 1999/2000 Mitglied der Fachschaft Zahnmedizin, des Studierendenparlaments der WWU, seit SS 2000 (stellv.) Mitglied des FBR Medizin

WS 1999/2000 naturwiss. Vorprüfung (,gut“)

ab WS 2000 Stipendiat der Konrad-Adenauer-Stiftung, St. Augustin

SS 2001 zahnärztl. Vorprüfung (,sehr gut“)

März/April 2003 Studienaufenthalt an der Tokyo Ikashika Daigaku, Tokyo, Japan

28. Juni 2004 zahnärztliche Prüfung (,sehr gut")

29. Juni 2004

Weiterbildung im Fach Parodontologie 


\section{Anhang C}

\section{Danksagung}

Ich danke Herrn Priv.-Doz. Kucharzik für die Überlassung des hochinteressanten Themas und sein stets offenes Ohr für Fragen und Anregungen. Weiterhin möchte ich mich herzlich bei Herrn Dr. Heidemann für die Einführung in das wissenschaftliche Arbeiten, seine Mühe bei der Korrektur der vorliegenden Arbeit und seine überaus freundliche Begleitung dieses Projektes bedanken.

Weiterhin sei gedankt Herrn Dipl.-Biol. Koch, Frau Dipl.-Biol. Klimmek, Herrn Dr. Maaser, Frau Dr. Lebiedz, Frau Dr. Westphal und Herrn Dr. Floer für ihre kollegiale Unterstützung bei der Durchführung der dieser Arbeit zugrunde liegenden Versuche. Frau Elke Weber und Sonja Jansen danke ich für exzellente technische Unterstützung.

Besonders dankbar bin ich meiner Familie für ihre Unterstützung, die mein Studium und diese Arbeit erst ermöglicht hat. Der Konrad-Adenauer-Stiftung danke ich für ihre Unterstützung meines Studiums.

Meiner Freundin gilt besonderer Dank für ihre andauernde Unterstützung bei der Erstellung dieser Arbeit. 


\section{Literaturverzeichnis}

[1] Affymetrix. Gene Chip Expression Analysis. Affymetrix Corp., Santa Clara, CA, USA, 2003.

[2] William C Aird. Endothelial cell heterogeneity. Crit Care Med, 31(4 Suppl):S22130, Apr 2003.

[3] LJ Andries, DL Brutsaert, and SU Sys. Nonuniformity of endothelial constitutive nitric oxide synthase distribution in cardiac endothelium. Circ Res, 82(2):195-203, Feb 1998.

[4] Junken Aoki, Yuki Nagai, Hiroyuki Hosono, Keizo Inoue, and Hiroyuki Arai. Structure and function of phosphatidylserine-specific phospholipase A1. Biochim Biophys Acta, 1582(1-3):26-32, May 2002.

[5] Wadih Arap, Mikhail G Kolonin, Martin Trepel, Johanna Lahdenranta, Marina Cardó-Vila, Ricardo J Giordano, Paul J Mintz, Peter U Ardelt, Virginia J Yao, Claudia I Vidal, Limor Chen, Anne Flamm, Heli Valtanen, Lisa M Weavind, Marshall E Hicks, Raphael E Pollock, Gregory H Botz, Corazon D Bucana, Erkki Koivunen, Dolores Cahill, Patricia Troncoso, Keith A Baggerly, Rebecca D Pentz, Kim-Anh Do, Christopher J Logothetis, and Renata Pasqualini. Steps toward mapping the human vasculature by phage display. Nat Med, 8(2):121-7, Feb 2002.

[6] M Ashburner, CA Ball, JA Blake, D Botstein, H Butler, JM Cherry, AP Davis, K Dolinski, SS Dwight, JT Eppig, MA Harris, DP Hill, L Issel-Tarver, A Kasarskis, S Lewis, JC Matese, JE Richardson, M Ringwald, GM Rubin, and G Sherlock. Gene ontology: tool for the unification of biology. The Gene Ontology Consortium. Nat Genet, 25(1):25-9, May 2000. 
[7] R Auerbach, L Alby, LW Morrissey, M Tu, and J Joseph. Expression of organspecific antigens on capillary endothelial cells. Microvasc Res, 29(3):401-11, May 1985.

[8] Zheng F Ba, Joachim F Kuebler, Loring W Rue, Kirby I Bland, Ping Wang, and Irshad H Chaudry. Gender dimorphic tissue perfusion response after acute hemorrhage and resuscitation: role of vascular endothelial cell function. Am J Physiol Heart Circ Physiol, 284(6):H2162-9, Jun 2003.

[9] Zheng F Ba, Yukihiro Yokoyama, Balazs Toth, Loring W Rue, Kirby I Bland, and Irshad H Chaudry. Gender differences in small intestinal endothelial function: inhibitory role of androgens. Am J Physiol Gastrointest Liver Physiol, 286(3):G452-7, Mar 2004.

[10] Charmian Banks, Adrian Bateman, Richard Payne, Penny Johnson, and Nick Sheron. Chemokine expression in IBD. Mucosal chemokine expression is unselectively increased in both ulcerative colitis and Crohn's disease. J Pathol, 199(1):28-35, Jan 2003.

[11] J Bash, WX Zong, S Banga, A Rivera, DW Ballard, Y Ron, and C Gélinas. Rel/NFkappaB can trigger the Notch signaling pathway by inducing the expression of Jagged1, a ligand for Notch receptors. EMBO J, 18(10):2803-11, May 1999.

[12] M Bastaki, EE Nelli, P Dell `Era, M Rusnati, MP Molinari-Tosatti, S Parolini, R Auerbach, L Ruco, L Possati, and M Presta. Basic fibroblast growth factor-induced angiogenic phenotype in mouse endothelium. a study of aortic and microvascular endothelial cell lines. Atheroscler Thromb Vasc Biol, 17:454-464, 1997.

[13] SE Bell, A Mavila, R Salazar, KJ Bayless, S Kanagala, SA Maxwell, and GE Davis. Differential gene expression during capillary morphogenesis in 3D collagen matrices: regulated expression of genes involved in basement membrane matrix assembly, cell cycle progression, cellular differentiation and G-protein signaling. J Cell Sci, 114(Pt 15):2755-73, Aug 2001.

[14] MP Bevilacqua, JS Pober, ME Wheeler, RS Cotran, and MA Gimbrone. Interleukin 1 acts on cultured human vascular endothelium to increase the adhesion of polymorphonuclear leukocytes, monocytes, and related leukocyte cell lines. J Clin Invest, 76(5):2003-11, Nov 1985. 
[15] DG Binion, P Rafiee, KS Ramanujam, S Fu, PJ Fisher, MT Rivera, CP Johnson, MF Otterson, GL Telford, and KT Wilson. Deficient iNOS in inflammatory bowel disease intestinal microvascular endothelial cells results in increased leukocyte adhesion. Free Radic Biol Med, 29(9):881-8, Nov 2000.

[16] DG Binion, GA West, K Ina, NP Ziats, SN Emancipator, and C Fiocchi. Enhanced leukocyte binding by intestinal microvascular endothelial cells in inflammatory bowel disease. Gastroenterology, 112(6):1895-907, Jun 1997.

[17] DG Binion, GA West, EE Volk, JA Drazba, NP Ziats, RE Petras, and C Fiocchi. Acquired increase in leucocyte binding by intestinal microvascular endothelium in inflammatory bowel disease. Lancet, 352(9142):1742-6, Nov 1998.

[18] CP Braegger, S Nicholls, SH Murch, S Stephens, and TT MacDonald. Tumour necrosis factor alpha in stool as a marker of intestinal inflammation. Lancet, 339(8785):8991, Jan 1992.

[19] M Briskin, D Winsor-Hines, A Shyjan, N Cochran, S Bloom, J Wilson, LM McEvoy, EC Butcher, N Kassam, CR Mackay, W Newman, and DJ Ringler. Human mucosal addressin cell adhesion molecule-1 is preferentially expressed in intestinal tract and associated lymphoid tissue. Am J Pathol, 151(1):97-110, Jul 1997.

[20] T Børsum, I Hagen, T Henriksen, and B Carlander. Alterations in the protein composition and surface structure of human endothelial cells during growth in primary culture. Atherosclerosis, 44(3):367-78, Sep 1982.

[21] VL Burgio, S Fais, M Boirivant, A Perrone, and F Pallone. Peripheral monocyte and naive T-cell recruitment and activation in Crohn's disease. Gastroenterology, 109(4):1029-38, Oct 1995.

[22] WN Burnette. Western blotting: electrophoretic transfer of proteins from sodium dodecyl sulfate-polyacrylamide gels to unmodified nitrocellulose and radiographic detection with antibody and radioiodinated protein A. Anal Biochem., 112(2):195203, 1981.

[23] J Campisi, SH Kim, CS Lim, and M Rubio. Cellular senescence, cancer and aging: the telomere connection. Exp Gerontol, 36(10):1619-37, Nov 2001. 
[24] ND Carr, BR Pullan, and PF Schofield. Microvascular studies in non-specific inflammatory bowel disease. Gut, 27(5):542-9, May 1986.

[25] Karen Cerosaletti and Patrick Concannon. Independent roles for nibrin and Mre11/Rad50 in the activation and function of Atm. J Biol Chem, Jul 2004.

[26] J Chi, HY Chang, G Haraldsen, FL Jahnsen, OG Troyanskaya, DS Chang, Z Wang, SG Rockson, MVD Rijn, D Botstein, and PO Brown. Endothelial cell diversity revealed by global expression profiling. Proc Nat Acad Sci USA, 100:10623-10628, 2003.

[27] E Chiarantini, R Valanzano, AA Liotta, AP Cellai, S Fedi, I Ilari, D Prisco, F Tonelli, and $\mathrm{R}$ Abbate. Hemostatic abnormalities in inflammatory bowel disease. Thromb Res, 82(2):137-46, Apr 1996.

[28] Gary A Churchill. Fundamentals of experimental design for cDNA microarrays. Nat Genet, 32 Suppl:490-5, Dec 2002.

[29] DN Cook, SC Chen, LM Sullivan, DJ Manfra, MT Wiekowski, DM Prosser, G Vassileva, and SA Lira. Generation and analysis of mice lacking the chemokine fractalkine. Mol Cell Biol, 21(9):3159-65, May 2001.

[30] BB Crohn, L Ginzburg, and GD Oppenheimer. Regional ileitis: a pathologic and clinical entity. 1932. Mt Sinai J Med, 67(3):263-8, May 2000.

[31] Anna Csiszar, Zoltan Ungvari, Akos Koller, John G Edwards, and Gabor Kaley. Aging-induced proinflammatory shift in cytokine expression profile in coronary arteries. FASEB J, 17(9):1183-5, Jun 2003.

[32] E Dejana. Endothelial adherens junctions: implications in the control of vascular permeability and angiogenesis. J Clin Invest, 98:1949-1953, 1996.

[33] EC del Re, S Shuja, J Cai, and MJ Murnane. Alterations in cathepsin H activity and protein patterns in human colorectal carcinomas. Br J Cancer, 82(7):1317-26, Apr 2000.

[34] P Dentelli, L Del Sorbo, A Rosso, A Molinar, G Garbarino, G Camussi, L Pegoraro, and MF Brizzi. Human IL-3 stimulates endothelial cell motility and promotes in vivo new vessel formation. J Immunol, 163(4):2151-9, Aug 1999. 
[35] Johannes Martinus Dijkstra, Ikunari Kiryu, Bernd Köllner, Yasutoshi Yoshiura, and Mitsuru Ototake. MHC class II invariant chain homologues in rainbow trout (Oncorhynchus mykiss). Fish Shellfish Immunol, 15(2):91-105, Aug 2003.

[36] I Durrant, LC Benge, C Sturrock, AT Devenish, R Howe, S Roe, M Moore, G Scozzafava, LM Proudfoot, and TC Richardson. The application of enhanced chemiluminescence to membrane-based nucleic acid detection. Biotechniques, 8(5):564-70, May 1990.

[37] AM Dvorak, RA Monahan, JE Osage, and GR Dickersin. Crohn's disease: transmission electron microscopic studies. II. Immunologic inflammatory response. Alterations of mast cells, basophils, eosinophils, and the microvasculature. Hum Pathol, 11(6):606-19, Nov 1980.

[38] Karin Ebner, Alexander Bandion, Bernd R Binder, Rainer de Martin, and Johannes A Schmid. GMCSF activates NF-kappaB via direct interaction of the GMCSF receptor with IkappaB kinase beta. Blood, 102(1):192-9, Jul 2003.

[39] RL Edwards, JB Levine, R Green, M Duffy, E Mathews, W Brande, and FR Rickles. Activation of blood coagulation in Crohn's disease. Increased plasma fibrinopeptide A levels and enhanced generation of monocyte tissue factor activity. Gastroenterology, 92(2):329-37, Feb 1987.

[40] CT Esmon. Inflammation and thrombosis. J Thromb Haemost, 1(7):1343-8, Jul 2003.

[41] P Estess, A Nandi, M Mohamadzadeh, and MH Siegelman. Interleukin 15 induces endothelial hyaluronan expression in vitro and promotes activated T cell extravasation through a CD44-dependent pathway in vivo. J Exp Med, 190(1):9-19, Jul 1999.

[42] Libin Fan, Wei Yu, and Xueliang Zhu. Interaction of Sedlin with chloride intracellular channel proteins. FEBS Lett, 540(1-3):77-80, Apr 2003.

[43] WM Freeman, DJ Robertson, and KE Vrana. Fundamentals of DNA hybridization arrays for gene expression analysis. Biotechniques, 29(5):1042-6, 1048-55, Nov 2000.

[44] W Fries, E Pagiaro, E Canova, P Carraro, G Gasparini, F Pomerri, A Martin, C Carlotto, E Mazzon, GC Sturniolo, and G Longo. The effect of heparin on 
trinitrobenzene sulphonic acid-induced colitis in the rat. Aliment Pharmacol Ther, 12(3):229-36, Mar 1998.

[45] C Garlanda and E Dejana. Heterogenity of endothelial cells: Specific markers. Arteroscler Thromb Vasc Biol, 17:1193-1202, 1997.

[46] Edward P Gelmann, Cai Bowen, and Lukas Bubendorf. Expression of NKX3.1 in normal and malignant tissues. Prostate, 55(2):111-7, May 2003.

[47] GF Gerard, DK Fox, M Nathan, and JM D'Alessio. Reverse transcriptase. The use of cloned Moloney murine leukemia virus reverse transcriptase to synthesize DNA from RNA. Mol Biotechnol, 8(1):61-77, Aug 1997.

[48] Mary E Gerritsen, James E Tomlinson, Constance Zlot, Michael Ziman, and Stuart Hwang. Using gene expression profiling to identify the molecular basis of the synergistic actions of hepatocyte growth factor and vascular endothelial growth factor in human endothelial cells. Br J Pharmacol, 140(4):595-610, Oct 2003.

[49] L Ghitescu and M Robert. Diversity in Unity: the biochemical composition of the endothelial cell surface varies between the vascular beds. Microsc Res Tech, 57:381$389,2002$.

[50] Klara Gijsbers, Gert Van Assche, Sofie Joossens, Sofie Struyf, Paul Proost, Paul Rutgeerts, Karel Geboes, and Jo Van Damme. CXCR1-binding chemokines in inflammatory bowel diseases: down-regulated IL-8/CXCL8 production by leukocytes in Crohn's disease and selective GCP-2/CXCL6 expression in inflamed intestinal tissue. Eur J Immunol, 34(7):1992-2000, Jul 2004.

[51] TR Golub. Genome-wide views of cancer. N Engl J Med, 344(8):601-2, Feb 2001.

[52] Dolores Gomez and Nancy C Reich. Stimulation of primary human endothelial cell proliferation by IFN. J Immunol, 170(11):5373-81, Jun 2003.

[53] F Gonzalez-Crussi and W Hsueh. Experimental model of ischemic bowel necrosis. The role of platelet-activating factor and endotoxin. Am J Pathol, 112(1):127-35, Jul 1983.

[54] DN Granger. Cell adhesion and migration. II. Leukocyte-endothelial cell adhesion in the digestive system. Am J Physiol, 273(5 Pt 1):G982-6, Nov 1997. 
[55] PL Gross and WC Aird. The endothelium and thrombosis. Semin Thromb Hemost, $26(5): 463-78,2000$.

[56] J Guan, PV Guillot, and WC Aird. Characterization of the mouse von Willebrand factor promoter. Blood, 94(10):3405-12, Nov 1999.

[57] PV Guillot, J Guan, L Liu, JA Kuivenhoven, RD Rosenberg, WC Sessa, and WC Aird. A vascular bed-specific pathway. J Clin Invest, 103(6):799-805, Mar 1999.

[58] G Haraldsen, J Rugtveit, D Kvale, T Scholz, WA Muller, T Hovig, and P Brandtzaeg. Isolation and longterm culture of human intestinal microvascular endothelial cells. Gut, 37(2):225-34, Aug 1995.

[59] DS Harris, JW Slot, HJ Geuze, and DE James. Polarized distribution of glucose transporter isoforms in Caco-2 cells. Proc Natl Acad Sci U S A, 89(16):7556-60, Aug 1992.

[60] Ossama A Hatoum, David G Binion, Mary F Otterson, and David D Gutterman. Acquired microvascular dysfunction in inflammatory bowel disease: Loss of nitric oxide-mediated vasodilation. Gastroenterology, 125(1):58-69, Jul 2003.

[61] Ossama A Hatoum, Hiroto Miura, and David G Binion. The vascular contribution in the pathogenesis of inflammatory bowel disease. Am J Physiol Heart Circ Physiol, 285(5):H1791-6, Nov 2003.

[62] S Hemmerich, EC Butcher, and SD Rosen. Sulfation-dependent recognition of high endothelial venules (HEV)-ligands by L-selectin and MECA 79, and adhesionblocking monoclonal antibody. J Exp Med, 180(6):2219-26, Dec 1994.

[63] R Higuchi, C Fockler, G Dollinger, and R Watson. Kinetic PCR: Real time monitoring of DNA amplification reactions. Biotechnology, 11:1026-1030, 1993.

[64] P Hillyer, E Mordelet, G Flynn, and D Male. Chemokines, chemokine receptors and adhesion molecules on different human endothelia: discriminating the tissue-specific functions that affect leucocyte migration. Clin Exp Immunol, 134(3):431-41, Dec 2003. 
[65] Alexander Hoffmann, Andre Levchenko, Martin L Scott, and David Baltimore. The IkappaB-NF-kappaB signaling module: temporal control and selective gene activation. Science, 298(5596):1241-5, Nov 2002.

[66] H Hosono, J Aoki, Y Nagai, K Bandoh, M Ishida, R Taguchi, H Arai, and K Inoue. Phosphatidylserine-specific phospholipase A1 stimulates histamine release from rat peritoneal mast cells through production of 2-acyl-1-lysophosphatidylserine. J Biol Chem, 276(32):29664-70, Aug 2001.

[67] M Hudson, C Piasecki, EA Sankey, R Sim, AJ Wakefield, LJ More, AM Sawyerr, AP Dhillon, and RE Pounder. A ferret model of acute multifocal gastrointestinal infarction. Gastroenterology, 102(5):1591-6, May 1992.

[68] CJ Jackson and M Nguyen. Human microvascular endothelial cells differ from macrovascular endothelial cells in their expression of matrix metalloproteinases. Int J Biochem Cell Biol, 29(10):1167-77, Oct 1997.

[69] B Johnston, TB Issekutz, and P Kubes. The alpha 4-integrin supports leukocyte rolling and adhesion in chronically inflamed postcapillary venules in vivo. $J$ Exp Med, 183(5):1995-2006, May 1996.

[70] TJ Kalogeris, FS Laroux, A Cockrell, H Ichikawa, N Okayama, TJ Phifer, JS Alexander, and MB Grisham. Effect of selective proteasome inhibitors on TNF-induced activation of primary and transformed endothelial cells. Am J Physiol, 276(4 Pt 1):C856-64, Apr 1999.

[71] S Kanazawa, T Tsunoda, E Onuma, T Majima, M Kagiyama, and K Kikuchi. VEGF, basic-FGF, and TGF-beta in Crohn's disease and ulcerative colitis: a novel mechanism of chronic intestinal inflammation. Am J Gastroenterol, 96(3):822-8, Mar 2001.

[72] K Kauser and GM Rubanyi. Gender difference in endothelial dysfunction in the aorta of spontaneously hypertensive rats. Hypertension, 25(4 Pt 1):517-23, Apr 1995.

[73] Alexander Kiani, Ivonne Habermann, Michael Haase, Silvia Feldmann, Sabine Boxberger, Maria A. Sanchez-Fernandez, Christian Thiede, Martin Bornhäuser, and Gerhard Ehninger. Expression and regulation of NFAT (nuclear factors of activated 
T cells) in human CD34+ cells: down-regulation upon myeloid differentiation. $J$ Leukoc Biol, Aug 2004.

[74] H Kimura, S Miura, T Shigematsu, N Ohkubo, Y Tsuzuki, I Kurose, H Higuchi, Y Akiba, R Hokari, M Hirokawa, H Serizawa, and H Ishii. Increased nitric oxide production and inducible nitric oxide synthase activity in colonic mucosa of patients with active ulcerative colitis and Crohn's disease. Dig Dis Sci, 42(5):1047-54, May 1997.

[75] Andrea R King, Sheila E Francis, Collette J Bridgeman, Helen Bird, Moira K B Whyte, and David C Crossman. A role for caspase-1 in serum withdrawal-induced apoptosis of endothelial cells. Lab Invest, 83(10):1497-508, Oct 2003.

[76] CJ Kirkpatrick, F Bittinger, RE Unger, J Kriegsmann, H Kilbinger, and I Wessler. The non-neuronal cholinergic system in the endothelium: evidence and possible pathobiological significance. Jpn J Pharmacol, 85(1):24-8, Jan 2001.

[77] Martin Knöpfel and Marc Solioz. Characterization of a cytochrome b(558) ferric/cupric reductase from rabbit duodenal brush border membranes. Biochem Biophys Res Commun, 291(2):220-5, Feb 2002.

[78] Asami Kondo, Masakiyo Sakaguchi, Eiichi Makino, Masayoshi Namba, Shigeru Okada, and Nam ho Huh. Localization of S100C immunoreactivity in various human tissues. Acta Med Okayama, 56(1):31-4, Feb 2002.

[79] Joshua R Korzenik. Crohn's disease: future anti-tumor necrosis factor therapies beyond infliximab. Gastroenterol Clin North Am, 33(2):285-301, ix, Jun 2004.

[80] H Kudo, S Senju, H Mitsuya, and Y Nishimura. Mouse and human GTPBP2, newly identified members of the GP-1 family of GTPase. Biochem Biophys Res Commun, 272(2):456-65, Jun 2000.

[81] MA Kulseth, SO Kolset, and T Ranheim. Stimulation of serglycin and CD44 mRNA expression in endothelial cells exposed to TNF-alpha and IL-1alpha. Biochim Biophys Acta, 1428(2-3):225-32, Aug 1999.

[82] David J Kurz, Stephanie Decary, Ying Hong, Elisabeth Trivier, Alexander Akhmedov, and Jorge D Erusalimsky. Chronic oxidative stress compromises telomere 
integrity and accelerates the onset of senescence in human endothelial cells. J Cell Sci, 117(Pt 11):2417-26, May 2004.

[83] D Kvale, P Krajci, and P Brandtzaeg. Expression and regulation of adhesion molecules ICAM-1 (CD54) and LFA-3 (CD58) in human intestinal epithelial cell lines. Scand J Immunol, 35(6):669-76, Jun 1992.

[84] UK Laemmli. Cleavage of structural proteins during the assembly of the head of bacteriophage t4. Nature, 227:680-685, 1970.

[85] Mohamed Lamkanfi, Michael Kalai, Xavier Saelens, Wim Declercq, and Peter Vandenabeele. Caspase-1 activates nuclear factor of the kappa-enhancer in B cells independently of its enzymatic activity. J Biol Chem, 279(23):24785-93, Jun 2004.

[86] FS Laroux, KP Pavlick, RE Wolf, and MB Grisham. Dysregulation of intestinal mucosal immunity: implications in inflammatory bowel disease. News Physiol Sci, 16:272-7, Dec 2001.

[87] IC Lawrance, C Fiocchi, and S Chakravarti. Ulcerative colitis and Crohn's disease: distinctive gene expression profiles and novel susceptibility candidate genes. Hum Mol Genet, 10(5):445-56, Mar 2001.

[88] J LeCouter, J Kowalski, J Foster, P Hass, Z Zhang, L Dillard-Telm, G Frantz, L Rangell, L DeGuzman, GA Keller, F Peale, A Gurney, KJ Hillan, and N Ferrara. Identification of an angiogenic mitogen selective for endocrine gland endothelium. Nature, 412(6850):877-84, Aug 2001.

[89] Ben Lehner, Jennifer I Semple, Stephanie E Brown, Damian Counsell, R Duncan Campbell, and Christopher M Sanderson. Analysis of a high-throughput yeast twohybrid system and its use to predict the function of intracellular proteins encoded within the human MHC class III region. Genomics, 83(1):153-67, Jan 2004.

[90] PI Lelkes, VG Manolopoulos, M Silverman, S Zhang, S Karmiol, and BR Unsworth. On the possible role of endothelial cell heterogeneity in angiogenesis. In ME Maragoudakis, editor, Molecular, Cellular, and Clinical Aspects of Angiogenesis, pages 1-17. Plenum Press, 1996.

[91] SM Lesko, DW Kaufman, L Rosenberg, SP Helmrich, DR Miller, PD Stolley, and S Shapiro. Evidence for an increased risk of Crohn's disease in oral contraceptive users. Gastroenterology, 89(5):1046-9, Nov 1985. 
[92] C Letizia, M Boirivant, G De Toma, S Cerci, S Subioli, L Scuro, P Ferrari, and F Pallone. Plasma levels of endothelin-1 in patients with Crohn's disease and ulcerative colitis. Ital J Gastroenterol Hepatol, 30(3):266-9, Jun 1998.

[93] D Levy and WB Kannel. Cardiovascular risks: new insights from Framingham. Am Heart J, 116(1 Pt 2):266-72, Jul 1988.

[94] QZ Li, S Eckenrode, QG Ruan, CY Wang, JD Shi, RA McIndoe, and JX She. Rapid decrease of RNA level of a novel mouse mitochondria solute carrier protein (Mscp) gene at 4-5 weeks of age. Mamm Genome, 12(11):830-6, Nov 2001.

[95] RJ Lipshutz, SP Fodor, TR Gingeras, and DJ Lockhart. High density synthetic oligonucleotide arrays. Nat Genet, 21(1 Suppl):20-4, Jan 1999.

[96] M Liu, RM Parker, K Darby, HJ Eyre, NG Copeland, J Crawford, DJ Gilbert, GR Sutherland, NA Jenkins, and H Herzog. GPR56, a novel secretin-like human G-protein-coupled receptor gene. Genomics, 55(3):296-305, Feb 1999.

[97] GS Longo, R Gorlick, WP Tong, S Lin, P Steinherz, and JR Bertino. gammaGlutamyl hydrolase and folylpolyglutamate synthetase activities predict polyglutamylation of methotrexate in acute leukemias. Oncol Res, 9(5):259-63, 1997.

[98] A Lunderquist and H Knutsson. Angiography in Crohn's disease of the small bowel and colon. Am J Roentgenol Radium Ther Nucl Med, 101(2):338-44, Oct 1967.

[99] W Ma and JS Pober. Human endothelial cells effectively costimulate cytokine production by, but not differentiation of, naive CD4+ T cells. J Immunol, 161(5):215867, Sep 1998.

[100] Christian Maaser, Laurence J Egan, Mark P Birkenbach, Lars Eckmann, and Martin F Kagnoff. Expression of Epstein-Barr virus-induced gene 3 and other interleukin-12-related molecules by human intestinal epithelium. Immunology, 112(3):437-45, Jul 2004.

[101] KS Mark, WJ Trickler, and DW Miller. Tumor necrosis factor-alpha induces cyclooxygenase-2 expression and prostaglandin release in brain microvessel endothelial cells. J Pharmacol Exp Ther, 297(3):1051-8, Jun 2001. 
[102] Margarita Martinez-Moczygemba and David P Huston. Biology of common beta receptor-signaling cytokines: IL-3, IL-5, and GM-CSF. J Allergy Clin Immunol, 112(4):653-65; quiz 666, Oct 2003.

[103] SM McCormick, SG Eskin, LV McIntire, CL Teng, CM Lu, CG Russell, and KK Chittur. DNA microarray reveals changes in gene expression of shear stressed human umbilical vein endothelial cells. Proc Natl Acad Sci U S A, 98(16):8955-60, Jul 2001.

[104] TJ McGarrity, JS Manasse, KL Koch, and WA Weidner. Crohn's disease and massive lower gastrointestinal bleeding: angiographic appearance and two case reports. Am J Gastroenterol, 82(10):1096-9, Oct 1987.

[105] ME Mendelsohn and RH Karas. The protective effects of estrogen on the cardiovascular system. N Engl J Med, 340(23):1801-11, Jun 1999.

[106] J Mestas and CC Hughes. Endothelial cell costimulation of T cell activation through CD58-CD2 interactions involves lipid raft aggregation. J Immunol, 167(8):4378-85, Oct 2001.

[107] C Michiels. Endothelial cell functions. J Cell Physiol, 196:430-443, 2003.

[108] C Michiels, M Raes, A Houbion, and J Remacle. Association of antioxidant systems in the protection of human fibroblasts against oxygen derived free radicals. Free Radic Res Commun, 14(5-6):323-34, 1991.

[109] TM Millar, CR Stevens, N Benjamin, R Eisenthal, R Harrison, and DR Blake. Xanthine oxidoreductase catalyses the reduction of nitrates and nitrite to nitric oxide under hypoxic conditions. FEBS Lett, 427(2):225-8, May 1998.

[110] R Mindnich, G Möller, and J Adamski. The role of 17 beta-hydroxysteroid dehydrogenases. Mol Cell Endocrinol, 218(1-2):7-20, Apr 2004.

[111] Emiko Mizoguchi, Ramnik J Xavier, Hans-Christian Reinecker, Hirofumi Uchino, Atul K Bhan, Daniel K Podolsky, and Atsushi Mizoguchi. Colonic epithelial functional phenotype varies with type and phase of experimental colitis. Gastroenterology, 125(1):148-61, Jul 2003.

[112] AM Müller, M Nesslinger, G Skipka, and KM Müller. Expression of CD34 in pulmonary endothelial cells in vivo. Pathobiology, 70(1):11-7, 2002. 
[113] Anja Moldenhauer, Marcelo Nociari, George Lam, Abdulgabar Salama, Shahin Rafii, and Malcolm A S Moore. Tumor necrosis factor alpha-stimulated endothelium: an inducer of dendritic cell development from hematopoietic progenitors and myeloid leukemic cells. Stem Cells, 22(2):144-57, 2004.

[114] Ute M Moll and Neda Slade. p63 and p73: roles in development and tumor formation. Mol Cancer Res, 2(7):371-86, Jul 2004.

[115] A Muehlhoefer, LJ Saubermann, X Gu, K Luedtke-Heckenkamp, R Xavier, RS Blumberg, DK Podolsky, RP MacDermott, and HC Reinecker. Fractalkine is an epithelial and endothelial cell-derived chemoattractant for intraepithelial lymphocytes in the small intestinal mucosa. J Immunol, 164(6):3368-76, Mar 2000.

[116] T Murakami, C Mataki, C Nagao, M Umetani, Y Wada, M Ishii, S Tsutsumi, T Kohro, A Saiura, H Aburatani, T Hamakubo, and T Kodama. The gene expression profile of human umbilical vein endothelial cells stimulated by tumor necrosis factor alpha using DNA microarray analysis. J Atheroscler Thromb, 7(1):39-44, 2000.

[117] SH Murch, CP Braegger, WC Sessa, and TT MacDonald. High endothelin-1 immunoreactivity in Crohn's disease and ulcerative colitis. Lancet, 339(8790):381-5, Feb 1992.

[118] OH Nielsen, J Elmgreen, and I Ahnfelt-Rønne. Serum interferon activity in inflammatory bowel disease. Arachidonic acid release and lipoxygenation activated by alpha-class interferon in human neutrophils. Inflammation, 12(2):169-79, Apr 1988.

[119] Michela Noseda, Graeme McLean, Kyle Niessen, Linda Chang, Ingrid Pollet, Rachel Montpetit, Réza Shahidi, Katerina Dorovini-Zis, Linheng Li, Benjamin Beckstead, Ralph E Durand, Pamela A Hoodless, and Aly Karsan. Notch activation results in phenotypic and functional changes consistent with endothelial-to-mesenchymal transformation. Circ Res, 94(7):910-7, Apr 2004.

[120] Haruhiko Ogata and Toshifumi Hibi. Cytokine and anti-cytokine therapies for inflammatory bowel disease. Curr Pharm Des, 9(14):1107-13, 2003.

[121] AL Olson and JE Pessin. Structure, function, and regulation of the mammalian facilitative glucose transporter gene family. Annu Rev Nutr, 16:235-56, 1996. 
[122] B Osterud, MS Bajaj, and SP Bajaj. Sites of tissue factor pathway inhibitor (TFPI) and tissue factor expression under physiologic and pathologic conditions. On behalf of the Subcommittee on Tissue factor Pathway Inhibitor (TFPI) of the Scientific and Standardization Committee of the ISTH. Thromb Haemost, 73(5):873-5, May 1995.

[123] I Padol, JQ Huang, CM Hogaboam, and RH Hunt. Therapeutic effects of the endothelin receptor antagonist Ro 48-5695 in the TNBS/DNBS rat model of colitis. Eur J Gastroenterol Hepatol, 12(3):257-65, Mar 2000.

[124] C Page, M Rose, M Yacoub, and R Pigott. Antigenic heterogeneity of vascular endothelium. Am J Pathol, 141:677-683, 1991.

[125] A Perner and J Rask-Madsen. Review article: the potential role of nitric oxide in chronic inflammatory bowel disorders. Aliment Pharmacol Ther, 13(2):135-44, Feb 1999.

[126] F Pizzagalli, Z Varga, RD Huber, G Folkers, PJ Meier, and MV St-Pierre. Identification of steroid sulfate transport processes in the human mammary gland. J Clin Endocrinol Metab, 88(8):3902-12, Aug 2003.

[127] DK Podolsky, R Lobb, N King, CD Benjamin, B Pepinsky, P Sehgal, and M deBeaumont. Attenuation of colitis in the cotton-top tamarin by anti-alpha 4 integrin monoclonal antibody. J Clin Invest, 92(1):372-80, Jul 1993.

[128] Denise C Polacek, Anthony G Passerini, Congzhu Shi, Nadeene M Francesco, Elisabetta Manduchi, Gregory R Grant, Steven Powell, Helen Bischof, Hans Winkler, Christian J Stoeckert, and Peter F Davies. Fidelity and enhanced sensitivity of differential transcription profiles following linear amplification of nanogram amounts of endothelial mRNA. Physiol Genomics, 13(2):147-56, Apr 2003.

[129] AR Pries, TW Secomb, and P Gaetgens. The endothelial surface layer. Pflugers Arch, 440:653-666, 2000.

[130] D Rachmilewitz, F Karmeli, and R Eliakim. Platelet-activating factor-a possible mediator in the pathogenesis of ulcerative colitis. Scand J Gastroenterol Suppl, 172:19-21, 1990. 
[131] Parvaneh Rafiee, Jan Heidemann, Hitoshi Ogawa, Nathan Johnson, Pamela Fisher, Mona Li, Mary Otterson, Christopher Johnson, and David Binion. Cyclosporin A differentially inhibits multiple steps in VEGF induced angiogenesis in human microvascular endothelial cells through altered intracellular signaling. Cell Commun Signal, 2(1):3, Jun 2004.

[132] A Raghunathan, R Sivakamasundari, J Wolenski, R Poddar, and SM Weissman. Functional analysis of B144/LST1: a gene in the tumor necrosis factor cluster that induces formation of long filopodia in eukaryotic cells. Exp Cell Res, 268(2):230-44, Aug 2001.

[133] R Raqib, AA Lindberg, L Björk, PK Bardhan, B Wretlind, U Andersson, and J Andersson. Down-regulation of gamma interferon, tumor necrosis factor type I, interleukin 1 (IL-1) type I, IL-3, IL-4, and transforming growth factor beta type I receptors at the local site during the acute phase of Shigella infection. Infect Immun, 63(8):3079-87, Aug 1995.

[134] JF Reckelhoff. Gender differences in the regulation of blood pressure. Hypertension, 37(5):1199-208, May 2001.

[135] M Rehli, SW Krause, L Schwarzfischer, M Kreutz, and R Andreesen. Molecular cloning of a novel macrophage maturation-associated transcript encoding a protein with several potential transmembrane domains. Biochem Biophys Res Commun, 217(2):661-7, Dec 1995.

[136] D Ribatti, B Nico, A Vacca, L Roncali, and F Dammacco. Endothelial cell heterogenity and organ specifity. J Hematotherapy Stem Cell Res, 11:81-90, 2002.

[137] W Risau. Differentiation of endothelium. FASEB J, 9:926-933, 1995.

[138] A Rivard, JE Fabre, M Silver, D Chen, T Murohara, M Kearney, M Magner, T Asahara, and JM Isner. Age-dependent impairment of angiogenesis. Circulation, 99(1):111-20, 1999.

[139] I Rollinger-Holzinger, B Eibl, M Pauly, U Griesser, F Hentges, B Auer, G Pall, P Schratzberger, D Niederwieser, EH Weiss, and H Zwierzina. LST1: a gene with extensive alternative splicing and immunomodulatory function. J Immunol, 164(6):3169-76, Mar 2000. 
[140] P Romagnani, F Annunziato, MC Baccari, and P Parronchi. T cells and cytokines in Crohn's disease. Curr Opin Immunol, 9(6):793-9, Dec 1997.

[141] O Rosen, C Suarez, VL Schuster, and LP Brion. Expression of carbonic anhydrase IV in mouse placenta. Am J Physiol Regul Integr Comp Physiol, 280(2):R365-75, Feb 2001.

[142] SD Rosen, ST Hwang, PA Giblin, and MS Singer. High-endothelial-venule ligands for L-selectin: identification and functions. Biochem Soc Trans, 25(2):428-33, May 1997.

[143] RD Rosenberg and WC Aird. Vascular-bed-specific hemostasis and hypercoagulable states. N Engl J Med, 340(20):1555-64, May 1999.

[144] Alexander Rosendahl, Evangelia Pardali, Matthaios Speletas, Peter Ten Dijke, CarlHenrik Heldin, and Paschalis Sideras. Activation of bone morphogenetic protein/Smad signaling in bronchial epithelial cells during airway inflammation. Am J Respir Cell Mol Biol, 27(2):160-9, Aug 2002.

[145] ZM Ruggeri and J Ware. von Willebrand factor. FASEB J, 7(2):308-16, Feb 1993.

[146] J Ruh, E Schmidt, F Vogel, and E Klar. Indomethacin-induced disturbances in villous microcirculation in the rat ileum. Microvasc Res, 58(2):137-43, Sep 1999.

[147] E Ruoslahti and D Rajotte. An address system in the vasculature of normal tissues and tumors. Annu Rev Immunol, 18:813-27, 2000.

[148] RK Saiki, S Scharf, F Faloona, KB Mullis, GT Horn, HA Erlich, and N Arnheim. Enzymatic amplification of beta-globin genomic sequences and restriction site analysis for diagnosis of sickle cell anemia. Science, 230(4732):1350-4, Dec 1985.

[149] Masakiyo Sakaguchi, Masahiro Miyazaki, Mikiro Takaishi, Yoshihiko Sakaguchi, Eiichi Makino, Noriyuki Kataoka, Hidenori Yamada, Masayoshi Namba, and Nam ho Huh. S100C/A11 is a key mediator of $\mathrm{Ca}(2+)$-induced growth inhibition of human epidermal keratinocytes. J Cell Biol, 163(4):825-35, Nov 2003.

[150] M Salmi, K Granfors, R MacDermott, and S Jalkanen. Aberrant binding of lamina propria lymphocytes to vascular endothelium in inflammatory bowel diseases. Gastroenterology, 106(3):596-605, Mar 1994. 
[151] J Sambrook, EF Fritsch, and T Maniatis. Molecular Cloning, A Laboratory Manual, volume 2. Cold Spring Harbor Laboratory Press, New York, 1989.

[152] Guy R Sander and Barry C Powell. Expression of notch receptors and ligands in the adult gut. J Histochem Cytochem, 52(4):509-16, Apr 2004.

[153] H Sano, K Tomita, and Y Hitsuda. Expression of vascular cell adhesion molecule-1 on human pulmonary artery endothelial cells an human umbilical vein endothelial cells stimulated by tumor necrosis factor alpha, interleukin-1 beta and lipopolysaccharide. Yonago Acta Med, 1997.

[154] Makoto Sasaki, D Ostanin, JW Elrod, T Oshima, P Jordan, M Itoh, T Joh, A Minagar, and JS Alexander. TNF-alpha -induced endothelial cell adhesion molecule expression is cytochrome P-450 monooxygenase dependent. Am J Physiol Cell Physiol, 284(2):C422-8, Feb 2003.

[155] Yasushi Sasaki, Setsuko Ishida, Ichiro Morimoto, Toshiharu Yamashita, Takashi Kojima, Chikashi Kihara, Toshihiro Tanaka, Kohzoh Imai, Yusuke Nakamura, and Takashi Tokino. The p53 family member genes are involved in the Notch signal pathway. J Biol Chem, 277(1):719-24, Jan 2002.

[156] C Jourdan-Le Saux, H Tronecker, L Bogic, GD Bryant-Greenwood, CD Boyd, and K Csiszar. The LOXL2 gene encodes a new lysyl oxidase-like protein and is expressed at high levels in reproductive tissues. J Biol Chem, 274(18):12939-44, Apr 1999.

[157] EE Schadt, C Li, C Su, and WH Wong. Analyzing high-density oligonucleotide gene expression array data. J Cell Biochem, 80(2):192-202, Oct 2000.

[158] S Schreiber, S Nikolaus, and J Hampe. Activation of nuclear factor kappa B inflammatory bowel disease. Gut, 42(4):477-84, Apr 1998.

[159] S Schreiber, S Nikolaus, J Hampe, J Hämling, I Koop, B Groessner, H Lochs, and A Raedler. Tumour necrosis factor alpha and interleukin 1beta in relapse of Crohn's disease. Lancet, 353(9151):459-61, Feb 1999.

[160] PA Scott and R Bicknell. The isolation and culture of microvascular endothelium. J Cell Sci, 105 ( Pt 2):269-73, Jun 1993.

[161] M Serrano and MA Blasco. Putting the stress on senescence. Curr Opin Cell Biol, 13(6):748-53, Dec 2001. 
[162] Ming Shen, Eri Yoshida, Weiqun Yan, Takeshi Kawamoto, Ketut Suardita, Yasuhiko Koyano, Katsumi Fujimoto, Mitsuhide Noshiro, and Yukio Kato. Basic helix-loophelix protein DEC1 promotes chondrocyte differentiation at the early and terminal stages. J Biol Chem, 277(51):50112-20, Dec 2002.

[163] M Simionescu. Endothelial cell response to normal and abnormal stimuli. Modulation, disfunction, injury; adaptation, repair, death. In M Simionescu and N Simionescu, editors, Endothelial cell dysfunctions, pages 3-9. Plenum Press, New York, 1992.

[164] M Simionescu, N Simionescu, and GE Palade. Segmental differentiations of cell junctions in the vascular endothelium. Arteries and veins. J Cell Biol, 68(3):70523, Mar 1976.

[165] M Simionescu, N Simionescu, F Santoro, and GE Palade. Differentiated microdomains of the luminal plasmalemma of murine muscle capillaries: segmental variations in young and old animals. J Cell Biol, 100(5):1396-407, May 1985.

[166] Alexander M Simon and Andrea R McWhorter. Vascular abnormalities in mice lacking the endothelial gap junction proteins connexin37 and connexin40. Dev Biol, 251(2):206-20, Nov 2002.

[167] JM Smith, JH Meinkoth, T Hochstatter, and KM Meyers. Differential distribution of von Willebrand factor in canine vascular endothelium. Am J Vet Res, 57(5):750-5, May 1996.

[168] Masahiro Sonoshita, Kazuaki Takaku, Masanobu Oshima, Ken ichi Sugihara, and Makoto M Taketo. Cyclooxygenase-2 expression in fibroblasts and endothelial cells of intestinal polyps. Cancer Res, 62(23):6846-9, Dec 2002.

[169] WA Stack, SD Mann, AJ Roy, P Heath, M Sopwith, J Freeman, G Holmes, R Long, A Forbes, and MA Kamm. Randomised controlled trial of CDP571 antibody to tumour necrosis factor-alpha in Crohn's disease. Lancet, 349(9051):521-4, Feb 1997.

[170] TR Stevens, JP James, NJ Simmonds, DA McCarthy, IF Laurenson, PJ Maddison, and DS Rampton. Circulating von Willebrand factor in inflammatory bowel disease. Gut, 33(4):502-6, Apr 1992. 
[171] PR Streeter, BT Rouse, and EC Butcher. Immunohistologic and functional characterization of a vascular addressin involved in lymphocyte homing into peripheral lymph nodes. J Cell Biol, 107(5):1853-62, Nov 1988.

[172] RW Talbot, J Heppell, RR Dozois, and RW Beart. Vascular complications of inflammatory bowel disease. Mayo Clin Proc, 61(2):140-5, Feb 1986.

[173] SR Targan, SB Hanauer, SJ van Deventer, L Mayer, DH Present, T Braakman, KL DeWoody, TF Schaible, and PJ Rutgeerts. A short-term study of chimeric monoclonal antibody cA2 to tumor necrosis factor alpha for Crohn's disease. Crohn's Disease cA2 Study Group. N Engl J Med, 337(15):1029-35, Oct 1997.

[174] CM Terry, JA Clikeman, JR Hoidal, and KS Callahan. TNF-alpha and IL-1alpha induce heme oxygenase- 1 via protein kinase $\mathrm{C}, \mathrm{Ca} 2+$, and phospholipase A2 in endothelial cells. Am J Physiol, 276(5 Pt 2):H1493-501, May 1999.

[175] NP Thompson, AJ Wakefield, and RE Pounder. Inherited disorders of coagulation appear to protect against inflammatory bowel disease. Gastroenterology, 108(4):1011-5, Apr 1995.

[176] Michelle Thornton and Michael J Solomon. Crohn's disease: in defense of a microvascular aetiology. Int J Colorectal Dis, 17(5):287-97, Sep 2002.

[177] H Towbin, T Staehelin, and J Gordon. Electrophoretic transfer of proteins from polyacrylamide gels to nitrocellulose sheets: procedure and some applications. Proc Natl Acad Sci U S A, 76(9):4350-4, 1979.

[178] WJ Tremaine. Refractory IBD: medical management. Neth J Med, 50(2):S12-4, Feb 1997.

[179] K Tsuchida, KY Arai, Y Kuramoto, N Yamakawa, Y Hasegawa, and H Sugino. Identification and characterization of a novel follistatin-like protein as a binding protein for the TGF-beta family. J Biol Chem, 275(52):40788-96, Dec 2000.

[180] Yizeng Tu, Shan Wu, Xiaohua Shi, Ka Chen, and Chuanyue Wu. Migfilin and Mig-2 link focal adhesions to filamin and the actin cytoskeleton and function in cell shape modulation. Cell, 113(1):37-47, Apr 2003. 
[181] Holger Ulbrich, Einar E Eriksson, and Lennart Lindbom. Leukocyte and endothelial cell adhesion molecules as targets for therapeutic interventions in inflammatory disease. Trends Pharmacol Sci, 24(12):640-7, Dec 2003.

[182] Vallance, Dijkstra, Qiu, Van Der Waaij, Van Goor, Jansen, Mashimo, and Collins. Relative contributions of nitric oxide synthase (NOS) isoforms during experimental colitis: endothelial derived NOS maintains mucosal integrity. Am J Physiol Gastrointest Liver Physiol, Jun 2004.

[183] Desiree van der Kleij, Eicke Latz, Jos F H M Brouwers, Yvonne C M Kruize, Marion Schmitz, Evelyn A Kurt-Jones, Terje Espevik, Esther C de Jong, Martien L Kapsenberg, Douglas T Golenbock, Aloysius G M Tielens, and Maria Yazdanbakhsh. A novel host-parasite lipid cross-talk. Schistosomal lyso-phosphatidylserine activates toll-like receptor 2 and affects immune polarization. J Biol Chem, 277(50):48122-9, Dec 2002.

[184] Dorothee Viemann, Matthias Goebeler, Sybille Schmid, Kerstin Klimmek, Clemens Sorg, Stephan Ludwig, and Johannes Roth. Transcriptional profiling of IKK2/NFkappa B- and p38 MAP kinase-dependent gene expression in TNF-alpha-stimulated primary human endothelial cells. Blood, 103(9):3365-73, May 2004.

[185] Theresa Vincent, Ralf F Pettersson, Ronald G Crystal, and Philip L Leopold. Cytokine-mediated downregulation of coxsackievirus-adenovirus receptor in endothelial cells. J Virol, 78(15):8047-58, Aug 2004.

[186] AJ Wakefield, EA Sankey, AP Dhillon, AM Sawyerr, L More, R Sim, RM Pittilo, PM Rowles, M Hudson, and AA Lewis. Granulomatous vasculitis in Crohn's disease. Gastroenterology, 100(5 Pt 1):1279-87, May 1991.

[187] CA Watson, L Camera-Benson, R Palmer-Crocker, and JS Pober. Variability among human umbilical vein endothelial cultures. Science, 268(5209):447-8, Apr 1995.

[188] H Weiler-Guettler, PD Christie, DL Beeler, AM Healy, WW Hancock, H Rayburn, JM Edelberg, and RD Rosenberg. A targeted point mutation in thrombomodulin generates viable mice with a prethrombotic state. J Clin Invest, 101(9):1983-91, May 1998. 
[189] JW Weinsaft and JM Edelberg. Aging-associated changes in vascular activity: a potential link to geriatric cardiovascular disease. Am J Geriatr Cardiol, 10(6):34854, 2001.

[190] Sabine Westphal and Holger Kalthoff. Apoptosis: targets in pancreatic cancer. Mol Cancer, 2(1):6, Jan 2003.

[191] AR Wettstein and AP Meagher. Thalidomide in Crohn's disease. Lancet, 350(9089):1445-6, Nov 1997.

[192] Val Wilson and Frank L Conlon. The T-box family. Genome Biol, 3(6):REVIEWS3008, 2002.

[193] Bianca M Wittig, Andreas Stallmach, Martin Zeitz, and Ursula Günthert. Functional involvement of CD44 variant 7 in gut immune response. Pathobiology, 70(3):184$9,2002$.

[194] Y Wu, D Dowbenko, and LA Lasky. PSTPIP 2, a second tyrosine phosphorylated, cytoskeletal-associated protein that binds a PEST-type protein-tyrosine phosphatase. J Biol Chem, 273(46):30487-96, Nov 1998.

[195] Y Xu, RA Swerlick, N Sepp, D Bosse, EW Ades, and TJ Lawley. Characterization of expression and modulation of cell adhesion molecules on an immortalized human dermal microvascular endothelial cell line (HMEC-1). J Invest Dermatol, 102(6):833-7, Jun 1994.

[196] BR Yacyshyn, MB Bowen-Yacyshyn, L Jewell, JA Tami, CF Bennett, DL Kisner, and WR Shanahan. A placebo-controlled trial of ICAM-1 antisense oligonucleotide in the treatment of Crohn's disease. Gastroenterology, 114(6):1133-42, Jun 1998.

[197] K Yamamoto and DJ Loskutoff. Fibrin deposition in tissues from endotoxin-treated mice correlates with decreases in the expression of urokinase-type but not tissuetype plasminogen activator. J Clin Invest, 97(11):2440-51, Jun 1996.

[198] M Young, H Chen, MD Lalioti, and SE Antonarakis. The human lanosterol synthase gene maps to chromosome 21q22.3. Hum Genet, 97(5):620-4, May 1996.

[199] Tetiana A Zaichuk, Emelyn H Shroff, Rebekah Emmanuel, Stephanie Filleur, Thomas Nelius, and Olga V Volpert. Nuclear factor of activated T cells balances angiogenesis activation and inhibition. J Exp Med, 199(11):1513-22, Jun 2004. 
[200] Baiteng Zhao, Salomon A Stavchansky, Robert A Bowden, and Phillip D Bowman. Effect of interleukin-1beta and tumor necrosis factor-alpha on gene expression in human endothelial cells. Am J Physiol Cell Physiol, 284(6):C1577-83, Jun 2003.

[201] GP Zhizhina, VG Korobko, and AV Alesenko. [Correlation of DNA degradation, induced by tumor necrosis factor-alpha, with accumulation of sphingosine in the nucleus and peroxides in DNA]. Biokhimiia, 59(11):1756-65, Nov 1994. 